\title{
Shine a Light: \\ Surveying Locality, Independence, and Digitization in Ottawa's Independent Rock Scene
}

by

\section{Michael Robert Audette-Longo}

A thesis submitted to the Faculty of Graduate and Postdoctoral Affairs in partial fulfillment of the requirements for the degree of

Doctor of Philosophy

in

Cultural Mediations

Carleton University

Ottawa, Ontario

(C) 2016

Michael Audette-Longo 


\begin{abstract}
This dissertation examines the articulation and reconfiguration of locality in Ottawa's independent (indie) rock scene. It argues that styles of producing and relating to indie music that have been traditionally embedded in local scenic activity and practices of "do it yourself" (DIY) have been translated into more ubiquitous, quotidian, and valuable metadata and labour that organizes and powers the operations of disparate digital media sites, including digital music services like Bandcamp, CBC Radio 3, and Wyrd Distro. This argument is developed through closer analyses of the following case studies: the entrepreneurial strategies and musical focuses of Ottawa-based independent record labels Kelp and Bruised Tongue Records; scene-bound media like zines, blogs, music video and campus/community radio; the re-articulation of local regions as metadata that organize the search and retrieval functionalities of the digital music streaming services CBC Radio 3 and Bandcamp (a particular iteration of local regions I dub the "indexi-local"); and the concurrent incorporation of DIY labour and reconfiguration of the business of independent music evident in the digital music retailers Bandcamp and Wyrd Distro.

This project contends that in the midst of digitization, the media sites, entrepreneurial strategies, and subcultural practices traditionally folded into the production of independence in local indie music scenes persist. This not only nuances narratives of upheaval advanced about digital media technologies, but also challenges narratives of decline and compromise recurrently articulated to the field of independent music. Contra academic and popular discourse that valorizes independent music for its ability to circulate outside of the "mainstream" musical, media, and cultural industries, this dissertation contends that independent music is entangled within these industries.
\end{abstract}


Moreover, the persistence of local music scenes across the sites examined in this dissertation signals the continued value, power, and allure of independent music's activities, subcultural commodities, and grassroots media sites to both scene participants and digital music services alike. 


\section{Acknowledgements}

I want to thank my advisor Paul Théberge, who has read this dissertation a countless number of times and always provided me with the time and support to explore the subject of indie music and digitization. To my committee members, I also want to thank you for your patience, time, and suggestions. Both William Echard and Ira Wagman pushed me to clarify what and how I was arguing. In particular, Ira has been a strong presence throughout my time as a student, beginning with my very first year of undergraduate studies. The innumerable times he has mentored me over the years, whether in terms of writing or career advice, means a great deal to me. I also want to thank previous teachers that facilitated and inspired me to get to this point, including: Paul Attallah, Dina Salha, and Boulou Ebanda de B'béri. To other students and candidates in ICSLAC I want to thank you for the great discussions had over the years, whether in the pub or seminar room. There are too many to thank in one acknowledgements, but I particularly want to thank Tom Everett and Stacy Ernst.

I want to thank my sister Trish Audette-Longo who very closely and patiently read through a final draft of this dissertation. I cannot actually quantify how much you helped me. I want to thank my two children, Wesley and Emily, for the fun distractions provided as I wrote and researched this dissertation over the past few years. And last, but definitely not least, I want to thank Sarah Harvey. She has given me everything I could possibly ask for and more. 


\section{Table of Contents}

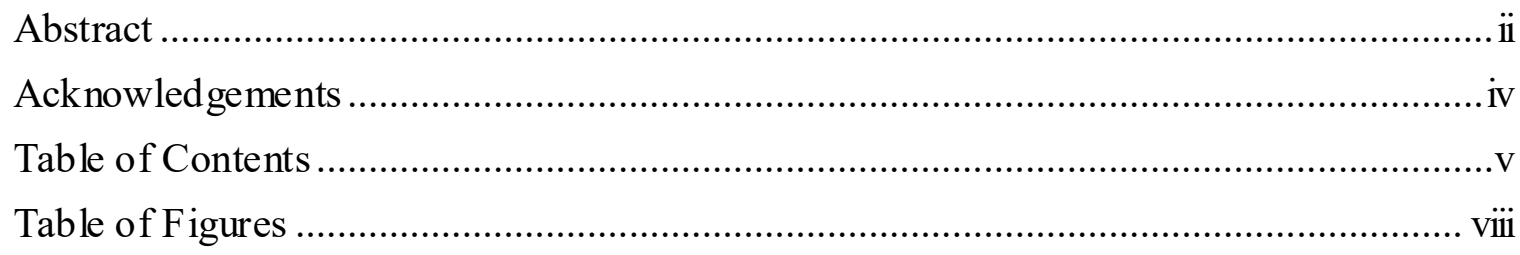

CHAPTER 1. LOCATING INDIE MUSIC: LOCAL SCENES AND DIGITAL MUSIC

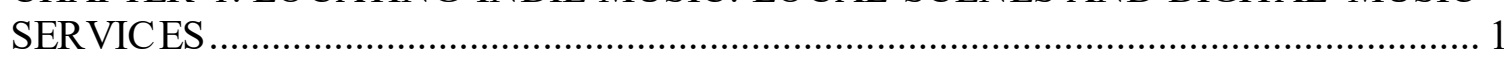

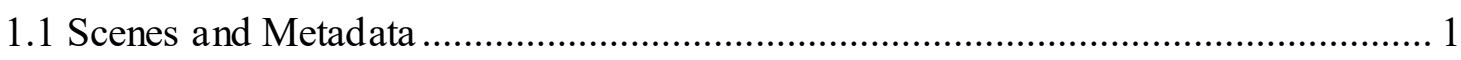

1.2 Research Questions, Thesis, and Case Study ....................................................... 3

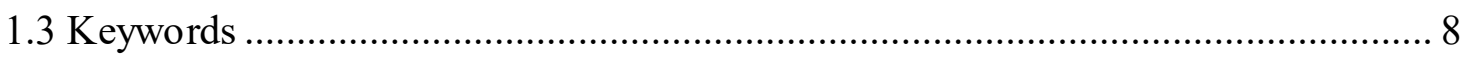

1.4 Theoretical Context and Research Objectives ................................................. 15

1.5 Methods and Chapter Outlines ................................................................... 19

1.6 Chapter Outlines, Stakes, and Research Contributions .................................... 25

CHAPTER 2. REVIEWING INDIE MUSIC: THE PLACE OF SCENIC

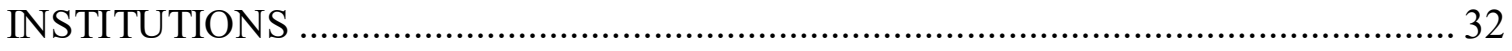

2.1 Indie Record Labels: Cultural Articulations ...................................................... 33

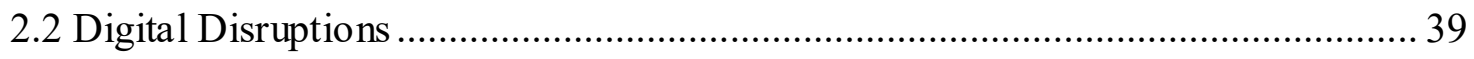

Dis tribution: Label Control, Challenged and Intens ified .................................... 40

Consumption: Empowerment and Co-Creation .............................................. 43

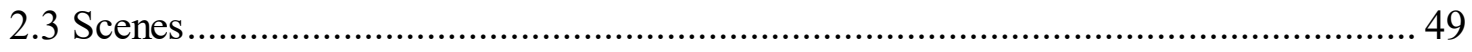

Urban Scenes: Defining Infrastructure, Locating Music and People ...................... 49

V irtual Scenes: Producing Proximity Online....................................................... 57

2.4 Ottawa's Indie Music Scene: Institutional Logics and the "Finely-grained" Case

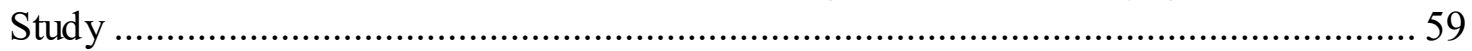

CHAPTER 3. RE-EXAMINING THE INDEPENDENT LABEL ............................... 61

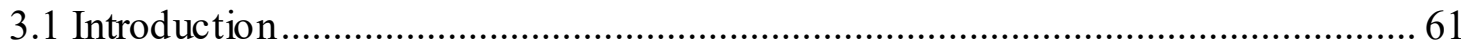

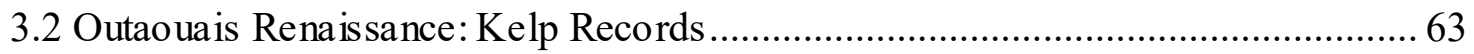

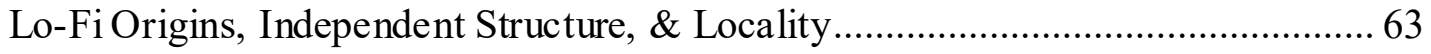

From Kelp Records to Kelp Management: Digital Stabilizations .......................... 70

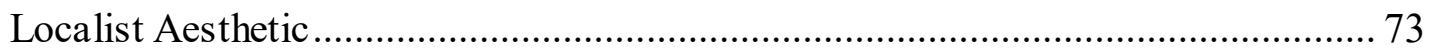

3.3 'Feel the No ise:” Bruised Tongue's Subcultural Modes of Production ................ 76

Punk Artisans: Tactility, Locality, and Control .................................................. 76

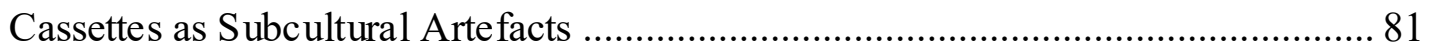




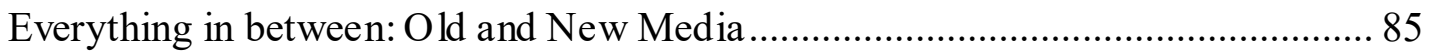

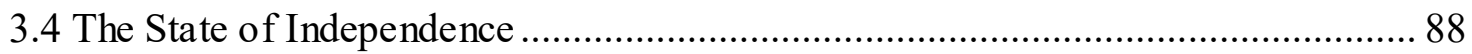

CHAPTER 4. SHINE A LIGHT: LOCATING AND NAVIGATING INDEPENDENT

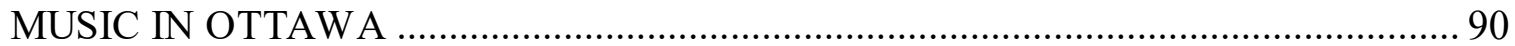

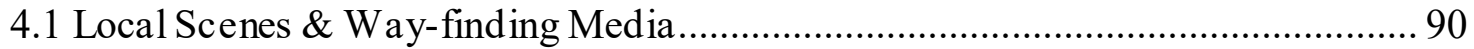

4.2 At Least there's Commotion: Ottawa's Music Venues ............................................ 92

Figure 1. Ottawa Venues - Small Talk …………………...................................... 93

4.3 Zines: Producing Narrative and Formal Proximity ……………………………....... 96

4.4 Blogs: Resource/Document/Critique ..................................................................... 106

4.5 Music Video: Representing the City ………………............................................. 112

Figure 2. Video Still from Bondar's "Night Dangers" ............................................ 115

4.6 “Talking Bullshit with Cool People:" City Slang Radio ........................................ 119

Figure 3. City Slang Zine (Photography by D. A. Reid) ........................................ 124

4.7 Locating Scenes, Scene Locations .................................................................. 127

CHAPTER 5. OUR MUSIC SERVICE COULD BE YOUR SCENE: SURVEYING THE

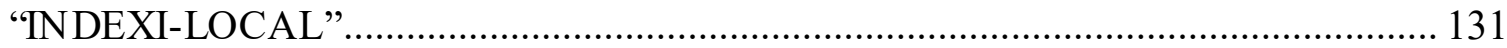

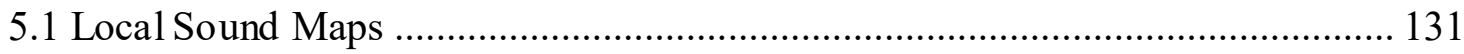

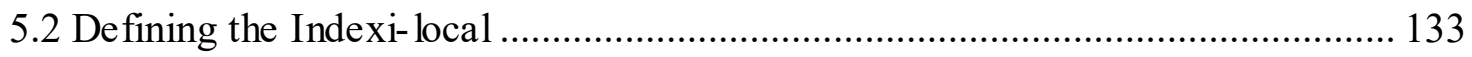

5.3 “The Home of Independent Canadian Music:” Introducing CBC Radio 3 .......... 134

Local Feel: Locating Canadian Indie Music in CBC Radio 3 ............................... 137

Your Scene Could Be our Metadata: Local Regions and/as Metadata .................... 141

5.4 Bandcamp: Our Service Could Be Your Scene ................................................ 145

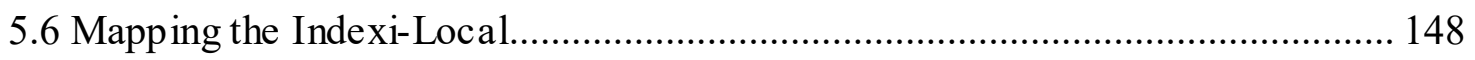

Our Music Service Could Be Your Scene ........................................................ 152

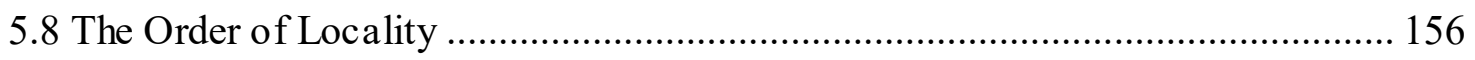

CHAPTER 6. A NEW WAVE: CULTIVATING INDEPENDENCE ONLINE ............ 159

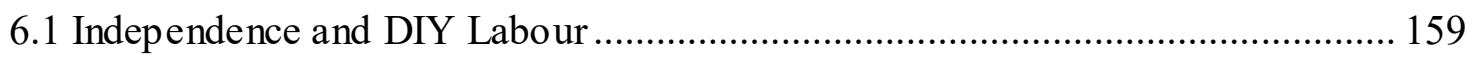

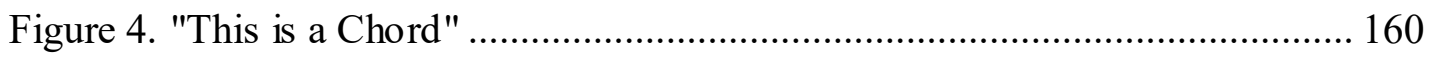

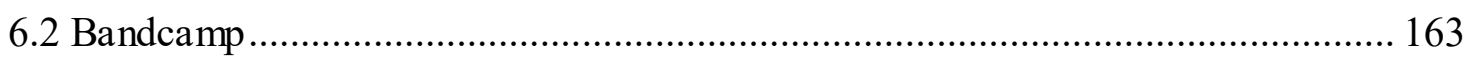

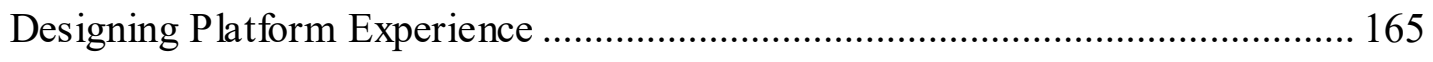

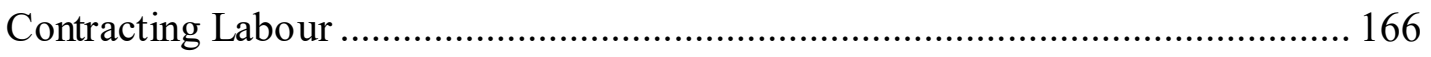

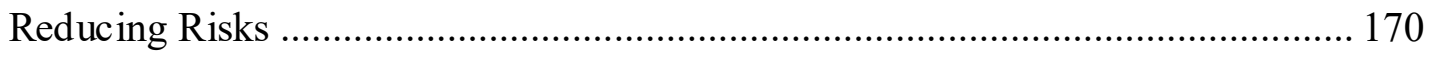

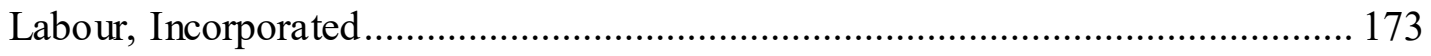

6.3 Wyrd Distro ........................................................................................... 178 
Circulation; or the Things Space can Show ....................................................... 183

Figure 5. Tropical Dripps' (2014) Cool Dude ....................................................... 185

Google Capital and Amazon Cloud Hosting; or the Networking of DIY ............... 192

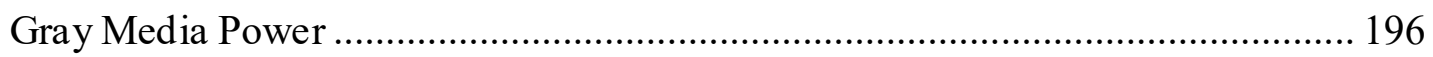

6.4 Digital DIY; or, Do It Yourself, With Our Service ........................................... 199

CHAPTER 7. LOCALITY, INDEPENDENCE, AND DIGITIZATION ..................... 202

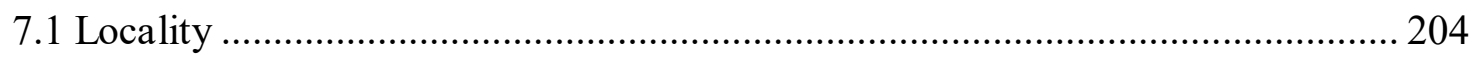

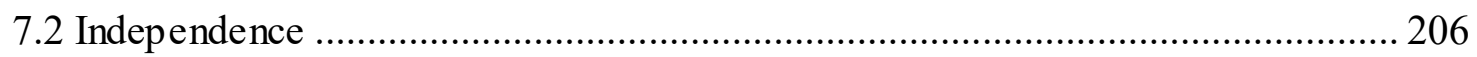

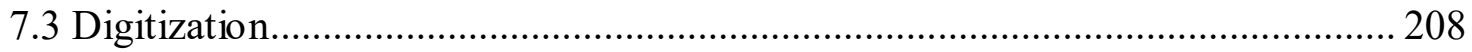

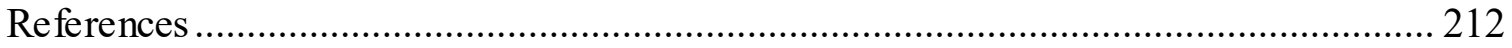




\section{Table of Figures}

Figure 1. Ottawa Venues - Small Talk ....................................................................... 93

Figure 2. Video Still from Bondar's "Night Dangers" .............................................. 115

Figure 3. City Slang Zine (Photography by D.A. Reid)............................................. 124

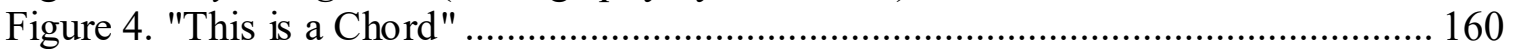

Figure 5. Tropical Dripps' (2014) Cool Dude ............................................................. 185 


\section{CHAPTER 1. LOCATING INDIE MUSIC: LOCAL SCENES AND DIGITAL MUSIC SERVICES}

\subsection{Scenes and Metadata}

The Acorn is an independent (indie) rock group based in the city of Ottawa, Ontario Canada. Since 2004, they have produced and released one Long-playing (LP) album (The Pink Ghosts) and a couple Extended-play (EP) recordings on the Ottawabased independent record label Kelp Records. They write songs about Ottawa and the broader Outaouais region and regularly play and organize shows in and around the city. They also continue to keep their earlier albums with Kelp, even after moving to the larger, Toronto-based independent record label Paper Bag Records in 2007. The band's affiliation with the city is not only clear when focusing on their career, but it has been emphasised in their biography, which opens with the following description of the city:

Ottawa used to be a lumber town . . . beneath the federal veneer, its rural origins linger, drenched in woodsmoke, bar-brawls and glinting saw blades. Two hours down river from Montreal, the woods get a little thicker and the air a little cleaner. It's a place where the city lights merge with constellations, and where The Acorn was born. (The Acorn, n.d., para. 1, emphasis in original)

This biographical excerpt produces a romantic reimagining of Ottawa. On the one hand, it invokes the city's lumber town origins as a rugged essence now glossed by a coat of “federal veneer," for Ottawa is Canada's capital city and public service jobs comprise one of the city's core fields of employment. On the other, it draws out a closer connection between The Acorn and Ottawa by locating the band's emergence within the city.

This biography's foregrounding of Ottawa gestures to the significance of local music scenes in indie rock music. Holly Kruse (2003) argues that specific indie rock institutions housed in local music scenes work to locate indie music; or as she explains: 
The institutions of independent pop/rock music [scenes] - record stores, clubs, record companies, college radio stations - all helped to locate music scene participants within particular physical spaces, within a structure of social and economic relations, and within received and personal narratives of the local and national histories of indie music. (p. 113, my emphasis)

Local music scenes provide, from this vantage, a lens through which to view the circulation and formation of indie music. ${ }^{1}$ The biography's invocation of Ottawa to describe The Acorn provides another instance of this sort of locative function, working to locate the band in this city. The biography's description of birth also presents the city as a creative incubator of sorts, thus alluding in an indirect way to the more infrastructural role that the city has played in the development of their career. These intersecting features gesture to one the key aim of this dissertation: to survey the ways in which indie music participants locate themselves and the genre of indie music within a local music scene. It focuses in particular on the ways in which a city is reimagined and aestheticized by indie music participants working and creating within such traditional indie rock institutions as zines (Pavitt, 2015), independent record labels (Lee, 1995; Hesmondhalgh, 1997, 1999), and campus/community radio (Barclay, Jack, and Schneider, 2001/2011, pp. 24-52; Kruse, 2003, pp. 70-85).

When we turn to digital music services CBC Music (www.cbcmusic.ca) and Bandcamp (www.bandcamp.com), which both stream The Acorn`s music, another iteration of the local music scene's potential to locate independent music becomes evident. Both music services deploy local regions, like Ottawa, as metadata and tags that

\footnotetext{
${ }^{1}$ Examples of taking this sort of "scenic view" (Woo, Rennie, and Poyntz, 2014, p. 5) towards indie music could involve: considering the late 1970s emergence of the group Joy Division (and other similarly aligned post-punk groups) within Manchester(Reynolds, 2005); the early 1990s emergence and formation of Riot Grrrl in-between Olympia, WA and Washington, DC (Marcus, 2010); and the ascent of grunge rock (born from the confluence of punk and heavy metal) in Seattle, WA (Waksman, 2009, pp. 241-253; Yarm, 2012).
} 
organize the circulation and retrieval of music sold and streamed within these services. Metadata is the "data about data" that "describes the attributes of information resources for the purposes of identification, discovery, selection, use, access, and management" (Taylor and Joudrey, 2009, p. 89). In the realm of music's digital circulation, popular instances of metadata include album title, song title, musical artist, etc. (Morris, 2012, pp. 851-853). Meanwhile, tags are a type of user-generated metadata, formulated in a music service like Bandcamp by musicians and listeners alike as a means to catalogue and organize the music they, respectively, upload to and stream through the service. I examine this style of information management in relation to local music scenes in Chapter 5, arguing that local scenes are reconfigured as metadata and tags in digital music services. This works to reify the local in these services, producing the digital semblance of locality I label the "indexi-local." This is a portmanteau that coordinates the words index and local. With this concatenation, I am interested in the operational capacity of an index as it works in a book, whereby the content of a book is broken down and made manoeuvrable through the culling of the book into specific names, subject listings, and page numbers. The deployment of local scenes as metadata and tags works in these concurrently organizational and locative capacities within the digital music services examined in this dissertation.

\subsection{Research Questions, Thesis, and Case Study}

This dissertation focuses on the articulation of locality in a cross-section of independent scenic institutions, paying particular attention to the re-configuration of locality in digital music services that specialize in streaming and selling independent music. It asks: what place do local music scenes have in the distribution, promotion, and 
consumption of contemporary Canadian indie rock music? I argue that styles of producing and relating to indie music that have been traditionally embedded in local music scenes have been incorporated by a cross-section of digital music services specializing in streaming and selling independent music. Moreover, the value and place of local scenic activity in indie music has been reconfigured through this incorporation. Largely emerging in the early 1980s from the punk, hardcore, and post-punk scenes in England and the United States as a reaction against the music, operations, and structures of the "mainstream" music recording industry (cf. Arnold, 1993; Azerrad, 2001; Hesmondhalgh, 1997; Reynolds, 2005), the local music scene and independent record label became two of the pivotal (and often dovetailing) sites of struggle against the mainstream music industry's musical and institutional practices. Specifically, indie music's pursuit of difference from the "mainstream" recording industry's major label system has been traditionally located in the smaller-scaled and largely "do it yourself" (DIY) operations of independent labels located in different, regionally specific music scenes (Azerrad, 2001, p. 456; Moore, 2007, p. 439; Straw, 1991, p. 378). ${ }^{2}$ In Canada, the seeming differences between specific musicmaking regions and the centres of the music industry works in a slightly different manner, due to the fact that Canada's recording industry is largely comprised, in the major label sector, of the Canadian subsidiaries of the multinational label system undergirding the music industry. Moreover, these labels primarily focus on manufacturing and importing international music into the Canadian

\footnotetext{
${ }^{2}$ Writing in 1981 in a more polemical register, future co-owner of Sub Pop Records Bruce Pavitt (2015) advances the following characterization of the importance of local and independent music, contra the music industry's major label system, with recourse to metaphors of homogenizing centres and diverse peripheries. As he wrote "... the mass homogenization of our culture is due to the claustrophobic centralization of our culture. We need diverse, regionalized, localized approaches to all forms of art, music, and politics" (p. 15).
} 
marketplace (Sutherland, 2015, p. 298). Thus, Canadian independent record labels provide the means to produce, distribute, and promote Canadian music specific to, and emerging from, the country's disparate musicmaking regions. ${ }^{3}$

In his study of indie culture, Michael Z. Newman (2009) highlights two tendencies that problematize indie culture's actual independence from the mainstream: its overlap with the very mainstream cultural industries it seemingly (and arguably) opposes and the tendency for indie culture to work as a taste culture that cultivates social distinctions and hierarchies amongst participants (pp. 19-24). Yet, Newman also suggests that while the convergence of independent and mainstream cultural industries problematizes the ease with which one can write of a purely "independent" realm of culture, such blurriness demands that one examine how indie culture's production of subcultural difference is articulated in practice and discourse (p. 17). Newman nuances the articulation of independence by foregrounding its entanglement with larger mainstream industries. Independent rock not only hinges on the creative and institutional infrastructure connected to local scenes, but is also entangled with the mainstream music industry it aims to differentiate from. Local scenes do not merely provide the institutional and social infrastructure conducive to providing an "authentic autonomous alternative" to the recording industry's major label system (Newman, 2009). Instead, they also circulate as ubiquitous and valuable metadata and labour that organizes and powers the operations of disparate online media sites, including digital music services.

\footnotetext{
${ }^{3}$ Ryan Edwardson's (2009) study of "Canrock" details a longer history of Canadian rock music's industrial emergence and circulation, oscillating between regional scenes and nationalist (and nationalizing) discourse and cultural policy.
} 
While the reconfiguration of local scenes as metadata and tags within digital music services has been described above, this project also examines the DIY activities circulating through local scenes, identifying their incorporation as labour that powers digital music services and social media networks. Zine scholar Stephen Duncombe (1997/2008) argues that DIY contains the following imperative: "make your own culture and stop consuming that which is made for you" (p. 7). DIY has been located as emerging in "alternative" sites of media and cultural production, which share the motivation to demarcate a space of media production, representation, and circulation located outside of the cultural industries. DIY has been recognized as both ethos and practice, evident in zines (Dunn and Farnsworth, 2012), record labels (O'Connor, 2008), and scenic activity (Moore, 2007). Questioning locality's re-configuration from the vantage of DIY pinpoints the ways in which the DIY activities of independent labels, media creators, and musicians provide social media networks and digital music services with valuable user-generated content (UGC). I argue that the surplus value accrued through this translation of DIY into UGC signals that DIY operates as more than mere subcultural ethic, as it is often presented (cf. Duncombe, 1997/2008; Moore, 2007). Rather, DIY works as a style of labour that is incorporated within digital services and restaged as a more flexible and subscription-oriented form of service labour that is concurrently creative, manual, and informational. A focus on DIY labour teases out another way in which localized music production, distribution, and promotion is not only re-placed, but actually valorized within digital music services as important sites of offsite labour and warehousing. What concerns me most is how ideals of democratization and empowerment through production contra consumption - which has been articulated to 
DIY (e.g. Duncombe, 1997/2008) - are translated into content and labour that make a wider range of digital music and media services work. This transforms the very productive relationship undergirding DIY from "doing it yourself" in your local music scene, to "doing it yourself," with our music service. My concern with the place of local music scenes in the circulation of indie rock music is, therefore, also an interest in how DIY works within these sorts of platforms as a type of service both promised and provided to musicians, labels, and listeners alike. ${ }^{4}$

As a means to situate this interest in the re-articulation of locality in digital music services, I focus on Ottawa's independent rock scene. Ottawa is a useful case study because it has an active local music culture, as captured by local music critic Lynn Saxberg (2003), who writes: "[Ottawa's] music scene is a diverse collection of thriving subcultures. You don't have to look far to find punk, folk, hip hop, electronica, blues and indie rock" (p. G2). Even though the city has not garnered the sort of national and even international attention that Toronto's and Montreal's indie scenes attained during the 2000s, Ottawa has produced a number of popular performers who have transcended that scene (such as Bruce Cockburn and Kathleen Edwards), while also producing a number of indie music acts that are highly acclaimed within the city's limits (such as New Swears, Steve Adamyk Band, The Yips, and Bondar). The city is situated in between Toronto and Montreal in the touring circuits of Canadian independent musicians, whilst also being largely elided by larger, often national and international independent touring acts due to the lack of mid-sized concert venues (Saxberg, 2015; Vincent and Swain,

\footnotetext{
${ }^{4}$ This branches off of Paul Théberge's (1997) work, which highlights how the digitization of pianos throughout the 1970s and 1980s produced new relations of consumption in practices of music production. His balancing of media, industry, and technology influences this project (pp. 1-7).
} 
2015 , p. 9). Even though the city lacks larger venues to attract mid-level indie musicians, it nonetheless possesses the sorts of "institutions" identified by Kruse (2003) above, including not only her list of "record stores, [music] clubs, record companies, [and] college radio stations" (p. 113), but also zines, music blogs, music video directors, music promoters, and local music organizations. Finally, a larger number of the Ottawa-based indie musicians, record labels, and media producers examined in this dissertation use the digital music services examined in this dissertation, including Bandcamp, CBC Radio 3, and Wyrd Distro. Thus, Ottawa's music scene is not only a part of the broader field of Canadian indie music that has gained national and international attention over the past decade, but also circulates through digital music services. This enables me to not only establish the conventions of locality within indie rock, but also to map out the aforementioned reconfiguration of indie music from a "different" set of subcultural practices and institutions, to metadata and labour within a specific geographical and musical context. The city has also largely gone unrecognized in both academic scholarship on indie rock music, as well as the burgeoning popular literature emerging about Canadian popular music. Thus, this research foregrounds a site of scenic activity that is missing within still emerging popular and academic studies of popular Canadian music (e.g. Barclay, Jack, and Schneider, 2001/2011; Edwardson, 2009).

\subsection{Keywords}

Before outlining the theoretical contexts and methods that both situate and guide this analysis, there are three key terms that will recur throughout this dissertation that demand further definition and explanation: locality; digital music services; and indie/independent. 
Following Andy Bennett (2000), I treat locality as involving both the discursive production of local regions, as well as styles of imagining and relating to a local region (p. 63). Looking to the articulation of locality in indie music then asks about the discourses and relations to the local connected to indie music. Holly Kruse (2003) has noted the importance of scene participants in socially producing the local through personal and shared histories, narratives, and social relations (pp. 1-3). To this work I would also add the substantive role that indie record labels and locally situated independent media - which I later examine in Chapter 4 and treat as "scene-bound media" - have to play in articulating discourses about and representations of the local music scene. Foregrounding the re-articulation of local music scenes in digital music services vis-à-vis a study of locality pinpoints the discourses and styles of relating to local music scenes that emerges in these services, which are shown to relate to existent articulations of the local in local indie music scenes.

Meanwhile, this dissertation's examination of independent digital music services speaks to such digital music sites as Bandcamp, Soundcloud, CBC Radio 3, and Wyrd Distro, which provide a cross-section of indie musicians, record labels, and listeners a means to distribute, sell, promote, stream, and purchase music. The "digital" in digital music services grasps at the platforms and devices through which music is accessed online (such as computers, mobile devices) and the Internet protocols and networks that facilitate access to information. Following Alexander R. Galloway's (2014) recent efforts to identify a digital logic that circulates outside of computational settings (which he deems "digitality"), I also treat the digital as an operationalizing logic that entails "the making-discrete of the hitherto fluid, the hitherto whole, the hitherto integral" (p. 52). 
The digital is thus treated as a logic embedded in particular devices that change the form of analogue phenomena, producing discrete elements from formerly integrated wholes. ${ }^{5}$ At the same time, though, to speak of the digital also demands asking after connectivity. From Henry Jenkins' (2006) examination of the increasing levels of "convergence" evident in the practices and composition of consumer practices, industries, and media technologies alike (pp. 2-3), to Jay David Bolter and Richard Grusin's (1999) contention that newer digital media aim to produce increasing levels of immediacy and cross-media connection for consumers (pp. 5,60-61), digital media's potential to foster connections also demands consideration. This project is concerned with the potentials for digital media to both "make-discrete" and foster connections, in relation to the incorporation and reconfiguration of the local online.

Moreover, this project favours the term service over the increasingly popular term platform, due to the ways in which service highlights the work involved in digital music's online circulation. Indeed, service entails both the work that is performed by a particular organization on behalf of others (e.g. the services provided by different government organizations), as well as the work that individuals perform for others (as, for instance, with the services that waiters, bartenders, and others provide customers in the service industries). I prefer to deploy the term service rather than platform because of the ways in which such a focus foregrounds the type of work done both by and for the digital music sites examined in this project.

\footnotetext{
${ }^{5}$ For example, in a compact disc the whole album has already been rendered into discrete bits, through digitization. This "making-discrete" enables the ease of skipping around album tracks and through songs. Lev Manovich (2001) captures these sorts of actions in his "principles of new media," including numerical representation, variability, and the modularity of digital media (pp. 27-48).
} 
Finally, independence (as well as its cognate diminutive indie) will be mobilized and defined as the industrial and musical production and circulation of music outside of the recording industry's major label system. This follows both popular (Azerrad, 2001, p. 5) and scholarly (Kruse, 2003, p. 1, Lee, 1995, p. 13) accountings of indie rock music. As of this writing, an independent record label is one that operates and circulates outside of the "big three" record labels that currently constitute the mainstream music industry: Warner Music Group; Universal Music; and Sony (Greenberg, 2015). Digitization has disrupted numerous elements of the music industry's key areas of operation; the music industry has, in turn, attained higher degrees of concentration, with the majority of activities (including not only recording and sales, but also publishing, lobbying, and distribution) being controlled and monetized by a handful of major labels. ${ }^{6}$ The independent music sector occupies a more marginal position of the music marketplace, particularly when we look to matters of market share and album sales.

For instance, according to statistics generated and reported by Billboard in coordination with Nielsen, in the first half of 2015 the major labels controlled approximately (and cumulatively) 63.7\% of the market share for music sold and streamed, in contrast to the independent music sector which held $35.4 \%$ of the market share. Meaning that over $60 \%$ of music charting in terms of sales and streams were owned by the majors. In terms of market share over distribution, these numbers get bigger, with these three labels, taken together, controlling $86 \%$ of the market share for

\footnotetext{
${ }^{6}$ A particularly significant means through which the music industry's major label sectorhas secured control and profits is via its lobbying adjunct, The Recording Industry Association of America (RIAA). This organization's lobbying efforts have changed contract law in the state of California to secure contracting arrangements between labels and musicians that are more beneficial to (Stahl, 2013, pp. 105142) and produced prohibitive copyright and intellectual property laws (Burkart, 2005, 2014).
} 
distribution (Ingham, 2015). Meaning that $86 \%$ of the music distributed in the first half of 2015 was controlled by three major record labels, and their myriad of subsidiary companies. A cursory review of Billboard's Top 10 album sales chart for 2015 further reveals higher degrees of control and concentration, evident in the fact that 2 of the top 10 albums sold that year came from independent music sector (these were, respectively, Taylor Swift's 1989 and Fetty Wap's eponymous album). Even these two releases, however, received distribution and promotion from the majors (Christman, 2016).

These numbers look similar when we turn to Canada. Research conducted by Nordicity on behalf of the Canadian Independent Music Association (CIMA) of the independent and major label music sectors for the year 2012 reveals some suggestive resonances between the American and Canadian music market. In terms of Canadian music released in Canada, French and English independent labels accounted for $60 \%$ of album sales (though with $23.5 \%$ of that number entailing distribution from a major). In terms of overall sales, including accounting for imports through Canadian subsidiaries, the total for sales drops to $14.1 \%$ of the Canadian music market, while $76.5 \%$ of album sales in Canada came from international artists distributed through Canadian subsidiaries of the major label network (CIMA, n.d.).

Album and singles sales are not the only facets of the independent music sector; instead, in another research report prepared on behalf of the Canadian Independent Music Association by Nordicity (2013) finds that the Canadian independent music sector is a complexly organized "ecosystem" that is also comprised of generating revenues from such areas that include (but are not limited to): publishing, management, live music performance, music creation, education, and publicity/public relations (p. 13). Thus in 
Canada, the music industry, in both its independent and major configurations, involves the production, distribution, publishing, and performance of music. In independent music, this entails, moreover, that music is neither produced nor distributed through the Canadian subsidiaries of these "big three" labels, with multinational extensions (Sutherland, 2015). This is particularly important since the Canadian subsidiaries of the major labels are primarily involved with importing international music into the Canadian marketplace (Sutherland, 2015, p. 298). ${ }^{7}$

In examining the activities of independent labels situated in Ottawa, I look more precisely to matters of album sales, publishing, and artist management, as they connect to issues of distribution and consumption outlined in Chapter 2.2. Though the music industry is shifting away from the sales of recordings, the sale and streaming of music recordings continues to be an area that generates revenues for both independent and major sectors of the music industry (Green, 2015, The Music Industry). This is particularly so when we look to the indie music service Bandcamp, which specializes in selling albums (both physical and digital) and has been recording revenue growth steadily since 2014. It has registered substantial sales in a seemingly post-commodity digital milieu; as co-founder Ethan Diamond (2016) writes in a blog post:

Bandcamp grew by $35 \%$ last year [2015]. Fans pay artists $\$ 4.3$ million dollars every month using the site, and they buy about 25,000 records a day, which works out to about one every 4 seconds ... Nearly 6 million fans have bought music through Bandcamp (half of whom are younger than 30), and hundreds of

\footnotetext{
${ }^{7}$ Ryan Edwardson (2009) unpacks the composition of Canada's major label system as subsidiaries of the recording industry's multinational major label system. He further clarifies the role of Canadian labels as branch plant extensions of the multinational system, detailing the tendency for Canadian bands (e.g. Our Lady Peace, 54-40, and Rush) to sign to the American branch of the major label and bypassing the Canadian branch altogether (pp. 205-209). Such moves were necessary due to the relative autonomy of these geographically distributed elements of the multinational system; or as he explains: "although the subsidiaries were part of the same multinational label, they operated relatively autonomously, [with Canadian labels] often struggling to get the American offices to pick up a single or an album" (p. 208).
} 
thousands of artists have sold music on Bandcamp. Digital album sales on Bandcamp grew 14\% in 2015 while dropping 3\% industry-wide, track sales grew $11 \%$ while dropping $13 \%$ industry-wide, vinyl was up $40 \%$, cassettes $49 \% \ldots$ even CD sales grew 10\% (down 11\% industry-wide). Most importantly of all, Bandcamp has been profitable (in the now-quaint revenues-exceed-expenses sense) since 2012. (Diamond, 2016, para. 2)

Thus, I look to album sales, management, and efforts to foster relationships for synclicensing in my examination of the entrepreneurial activities of specific, Ottawa-based independent labels.

Indie, meanwhile, is a genre category used to describe more folk and punkoriented styles of music that historically featured more low-fidelity (lo-fi) and DIY means of recording, producing, and mastering (Azerrad, 2001; Bannister, 2006a, pp. 57-90; Fonarow, 2006, p. 39-50). It has also begun to enfold an increasingly wide range of genres and production styles into its sound. Thus, while the city's jazz, improvisation, country, electronic, and hip hop scenes press for further consideration, they exceed this dissertation's closer focus on independent rock. I focus more on rock music, and in particular, folk- and punk-leaning styles of music produced and distributed on independent record labels situated in the city of Ottawa, Ontario. Alan O'Connor (2008) has shown that DIY punk has distinctive institutional organizations and entrepreneurial logics guiding its efforts to produce autonomy. Yet, Barclay, Jack, and Schneider (2001/2011) have shown the porousness of punk and folk in the emergence of Canadian rock music (pp. 6-10). Ryan Moore (2007) too suggests that punk and "alternative" rock music have much to demonstrate, when coordinated together, about the practices of media creation enfolded in DIY-oriented independent music production (p. 439). I draw both indie folk and rock music together with DIY punk in this dissertation as a means to tease out the overlapping articulations of locality evident in these intersecting genres, as 
they circulate within Ottawa's independent rock scene. To keep things succinct, I use the term independent rock to describe the overlapping of folk, rock, country, and punk as it circulates in and through the city.

\subsection{Theoretical Context and Research Objectives}

Examining the reconfiguration of local music scenes in contemporary indie rock's digital circulation asks after the interaction between "old" and "new" media formats and cultural forms. In examining processes of reconfiguration, it not only considers the impacts of digitization on local indie music scenes provisionally highlighted above, but also asks after the "residual" place of locality in digital music services. In the introduction to his edited collection Residual Media, Charles R. Acland (2007a) describes the analysis of residual media as entailing "exploration" of ". . reconfigured, renewed, recycled, neglected, abandoned, and trashed media technologies and practices," with the broader aim of "asserting that the introduction of new cultural phenomena and materials rests on an encounter with existing forms and practices" (Acland, 2007, p. xx, my emphasis). This agenda departs from Raymond Williams' (1980) influential accounting of the emergence and sedimentation of dominant cultural forms, norms, and ideologies, with counter-veiling forms of "residual" and "emergent" culture. The residual pertains to the recent historical past; the emergent with new forms of culture (pp. 40-41). Though he frames both the residual and emergent as "forms of oppositional and alternative culture" (p. 40), Williams is also careful to account for processes by which alternative cultural forms are incorporated by, and work to structure, dominant cultural and ideological forms. This provides a particularly suggestive foregrounding of the temporality of 
ideological formations, looking to the ways in which dominant forms are shaped by both emergent practices and contain residues of previous cultural forms and ideologies.

There is a greater degree of conceptual power in the residual, due to the ways in which Acland (2007a) and the writers contained in his edited collection (Acland, 2007b) shift older and at times marginal - or indeed, "alternative" - media practices and technologies into different, often incongruous moments of contemporary digital culture. These writers are careful not to merely contend that residual media oppose the “dominance" of digital media, instead accounting for Williams' (1980) important insight that "a residual culture is usually at some distance from the effective dominant culture, but one has to recognize that, in real cultural activities, it may get incorporated into it" (p. 41). Adding residual to media sets out a more pronounced place for histories of discarded, abandoned, and forgotten media technologies, which are argued to influence current media tendencies. It also enables study of continued uses and valorizations of "obsolescent" media technologies (such as hand-written letters, VHS, and vinyl records) by different subcultural enclaves. In other words, it asks after the residual media and practices embedded within the digital imaginary, whether as sites of influence or contemporary avenues to engineer subcultural differences.

For this project, the residual helps grasp at and conceptualize the persistence of indie music's "unwired" scenic activity - which was largely developed in the 1980s and early 1990s, before the commercial ascent of both alternative rock and the commercial Internet (Kruse, 2010, pp. 626-629) - in both contemporary indie music scenes and digital sites. Framing the sorts of DIY musical and media activities embedded in local scenes as a residual style of relating to and producing the local both foregrounds and 
historicizes the persistence of certain entrepreneurial, musical, and media activities developed in local music scenes. These residues of indie music scenic activity not only persist in contemporary indie music scenes, but are also incorporated within the design and operations of the digital music services examined throughout the subsequent chapters.

Phrasing locality as the product of articulation aims to denaturalize the seeming coherence of locality, through a study of the ways in which it is produced through discourse in various sites, including independent record labels, "scene-bound media," and digital music services. This follows Stuart Hall's framing, in which he explains, “... a theory of articulation is both a way of understanding how ideological elements come, under certain conditions, to cohere together within a discourse, and a way of asking how they do or do not become articulated, at specific conjunctures, to certain political subjects" (Grossberg, 1986, p. 53). Articulation has been woven into media studies, being deployed as a means to unpack the social, scientific, and commercial construction of particular ideas about how media work. For instance, Jonathan Sterne (2003) examines the pursuit of sound reproduction through a range of early auditory technologies in his book The Audible Past. Criss-crossing between ear doctors, telegraphy, and early efforts to reproduce sound vis-à-vis record players, sound reproduction and cognate notions of fidelity and preservation are shown to emerge not so much as intrinsic features of sound media. Rather, they have also been extrinsic social, commercial, and scientific pursuits. Thus, Sterne surmises that "our most cherished pieties about sound-reproduction technologies ... were not and are not innocent empirical descriptions of the technologies' impact. They were wishes that people grafted onto sound-reproduction technologies - 
wishes that became programs for innovations and use" (p. 8, my emphasis). It is my aim to illustrate in this dissertation how locality is a "wish" developed in a cross-section of scenic institutions that converge in local and digital settings. The "wishes" of locality have been articulated and communicated in range of media sites, cultural artefacts, and digital music services oriented to indie music. Particular wishes identified in this project include stabilizing the instabilities of the digital music marketplace, facilitating social and musical proximity, and forming community.

By working with the term scene as a means to engage indie music in this dissertation, I aim to align my project with scholarship that is both methodologically creative and empirically rich. Following Will Straw (2001), I treat scenes as both expressions of and indexes to cultural creation and participation that attends to capturing and describing, in particular, the spatial distribution of specific pockets of cultural activity in a city centre. As he explains: "scenes extend the spatialization of city cultures through the grafting of tastes or affinities to physical locations. Within scenes, tastes or affinities become organized as itineraries across series of spaces" (p. 254). This dissertation focuses on the organization and location of independently produced rock music in the city of Ottawa. Scene studies are theoretically dexterous, moving from studies of the rock scenes in Liverpool (Cohen, 1991) and Austin (Shank, 1994) that parse out the lived experience of rock music in its finest "micro-sociological details" (Cohen, 1991, p. 6), to studies of the institutional and cultural logics embedded in particular institutions and cultural commodities that impact how particular musical styles circulate through scenes (Straw, 1991, 2001). I am particularly interested in research concerned with scenic institutions (e.g. Kruse, 2003; O'Connor, 2002; Straw, 1991, 2001, 
2004) as they work to locate, organize, and express both participant experiences and broader commercial logics. Foregrounding the study of institutions via scenes further focuses the articulation of locality within three particular scenic institutions: independent record labels; scene-bound media; and digital music services. These are considered scenic institutions due to the ways in which they are located in, articulate representations of, and generate meanings about, Ottawa's independent rock scene.

\subsection{Methods and Chapter Outlines}

The analysis performed in this dissertation is situated in a blend of archival research, formulations of articulation as method of discourse analysis, and political economy.

The archive I am working with in this dissertation is largely self-created, generated over the span of roughly three years (2013-2015). During this time, I sought out Ottawa-based records, cassettes, and zines. I perused and bookmarked a number of indie music blogs and websites, including those based primarily in and focusing on Ottawa's indie music scene. I "liked" and "followed" a number of different social media accounts from a wider range of Ottawa-based indie musicians, record labels owners, music organizations, and media producers, and I listened to a number of campus/community radio shows in both their podcast and terrestrial broadcast formats. I also set up accounts with the digital music services written about (that is, Bandcamp, CBC Music, and Wyrd Distro), though largely used them to stream music and create playlists, rather than purchasing music from these sites. I also did not upload music to these websites. The objects in this archive have textual significance, generating a great deal of representations and discourses about the scene. They also have artefactual 
significance, meaning that they also sediment particular cultural expressions and exert particular commercial and cultural logics through their location and distribution in particular social and private spaces (Straw, 1999-2000, pp. 156-158).

I also conducted interviews with three individuals: Jon Bartlett, a local musician and owner of Kelp Records, an Ottawa-based indie label; Lesley Marshall, a local musician, music video director, and editor of the zine Small Talk; and Emmanuel Sayer, a local musician, campus/community radio station CHUO Program Director, Ottawa Explosion co-promoter, and co-host of the campus/community radio program City Slang. In these interviews, I tended to ask more open-ended questions, with a lesser degree of refocus and redirection, as a means to try and capture their experiences in Ottawa's indie music scene and motivations for creating scenic activity. While these interviews were useful at the beginning of the project, I found as I further pursued research that interviews abound across the scene-bound media with which I consulted. I soon began to favour these sites as a means to grasp at the articulation of locality and indie music, for these are the very indie media sites with which I am concerned. This provides more direct access to my interest in how locality is articulated in those abovementioned scenic institutions. This process of creating my own archive fits with both Théberge's (1997) and Morris' (2015a) research concerning music's digitization, and was necessary due to the largely fragmented dispersal of these texts and artefacts in a range of local and digital sites.

Meanwhile, this study of articulation focuses on discerning the "wishes" advanced about local scenes and indie music by examining both an assortment of primary texts (including: zines, blogs, and interviews), as well as cultural artefacts. Lawrence Grossberg (1992) argues that "articulation is the production of identity on top of 
difference, or unities out of fragments, of structures across practices. Articulation links this practice to that effect, this text to that meaning, this meaning to that reality, this experience to those politics" (p. 54). Following this definition, I too examine a number of texts, generated by the institutions with which I am concerned, and seek to unpack and explain the linkages produced between a number of scene-bound texts and what they have to "say" about the local scene. An important resource for this analysis was Charles R. Acland's (2012) deployment of articulation to identify the "subliminal thesis" in media history. Specifically, he identifies how media came to be seen as powerful sites with the ability to manipulate and influence people. He denaturalizes this concatenation of manipulation and media by looking to the myriad texts and media sites that generate both vernacular and expert depictions of media's forceful work; as he further explains:

... one finds evidence of [articulation in] context-specific life in newspaper and magazine editorials, feature articles, thrillers, satirical movies, speculative science fiction, situation comedies, legislative hearings, scholarly surveys, patent applications, business records, nonfiction bestsellers, retrospective characterizations of an era, talk-show experiences, interviews, lawsuits, websites, and computer games. (p. 28)

Similarly, I look to a range of sites, including: record label rosters, advertisements, blog posts, biographies, artist pages, zine issues, music videos, and campus/community radio shows as a means to highlight the ways in which these media texts and representations generate articulations of locality. I am concerned with the discourse of locality produced in these sites, attempting to re-organize them as a means to identify recurrent characterizations and "wishes." 8

\footnotetext{
8 This follows the research focus set out by Michel Foucault (1969/1972) in his study of discourse analys is in archaeologies of knowledge:

What one must characterize and individualize is the coexistence of these dispersed and heterogeneous statements; the system that governs their division, the degree to which they depend
} 
While political economy is a complex project entailing multiple theoretical interests, Dwayne Winseck (2011) identifies one overall continuity in thought with which political economies of media can grapple: "all approaches to the political economy of media take it as axiomatic that the media industries - the structure of the markets they operate in, their patterns of ownership, the strategies of key players, trajectory of development, and so on - are important objects of analysis" (p. 11). This insight guides my own interest in indie music's formation and circulation through both local labels and digital music services. Specifically, from the vantage of political economy, I unpack the patterns of ownership undergirding Ottawa-based independent record labels, digital music services, and the broader sectors of the networked media industries with which these indie labels come into contact. I also examine the methods of monetization and commoditization enacted by both indie labels and digital music services (treated herein as "strategies of key players"), and how DIY activities are incorporated as labour and usergenerated content by these services.

These interests converge in each chapter. Chapter 3 studies two Ottawa-based independent record labels: Kelp Records and Bruised Tongue Records. I tease out entrepreneurial strategies enacted by both labels by examining how they produce and distribute music within Ottawa's local scene. This is achieved through a blend of referencing interviews from these owners and examining how they distribute or manufacture music by pinpointing their placement in local retail stores and digital music

upon one another, the way in which they interlock or exclude one another, the transformation they undergo, and the play of their location, arrangement, and replacement. (p. 34)

I am less concerned with the broader systems of power that "govern" what is included and excluded, and more concerned with degrees of how articulations of locality generally "interlock" across the institutions examined in this dissertation, through closer consideration of their "location" and "arrangement." 
services. I infer, from existent studies of both the indie and popular music industries, how these label owners both commoditize and manage their labels. I also attend to the "identity" that these labels produce by examining the styles of music, artist rosters, and commodity formats they release, following both Hesmondhalgh (1999) and O'Connor's (2008) studies of indie and punk entrepreneurship.

Chapter 4 focuses on a narrower cross-section of scene-bound media: zines (and in particular, Small Talk, The House of Targ Zine, and City Slang), blogs (Ottawa Showbox and Standard Criteria), music videos of Ottawa-based indie musicians, and campus/community radio (with a closer study of City Slang, an indie punk-oriented show broadcast on the station CHUO-FM). Following Kruse (2003), I treat these sites as important to the "dissemination" of indie music; yet, I also foreground the work they do to "locate" the city's scenic activity, coordinating Stephen Duncombe's (1997/2008) research on zine cartography and Straw's (2004) findings that local media are "wayfinding aids" (p. 413) media. I consult these media sites as texts, identifying the discourse and representations of the city's music scene generated in zine pages, blog posts, music video imagery, and broadcasts. I also consider these media in a more artefactual manner (Straw, 1991, 1999-2000; Sterne, 2006), meaning I consider them as possessing particular material attributes that, in and through their place and distribution in the city's scene and digital media sites, communicate subtler "logics" (Straw, 1991) of locality contingent to scarcity, abundance, localness, and vitality.

Chapter 5 examines two music streaming services (CBC Radio 3 and Bandcamp) through an analysis of interface design. Following Jeremy Wade Morris (2015a), I treat an interface as one of the key aspects of digital music service that "shape how users see, 
hear, feel, and experience the functions of any given piece of software and the cultural content that passes through it" (p. 18). A service's interface is, moreover, the primary way in which everyday listeners interact and experience a service, including clicking through songs, creating playlists, and logging in to one's account. ${ }^{9}$ While studies of interface in digital music have foregrounded the construction of a listening experience, whether through playlist and playback functionalities, this sort of work hones in on the platform as a seemingly self-contained space. I turn to the design of these two music services, examining playback and playlist functionalities, embedded texts, and styles of interaction enabled through design. Particular attention is paid to the circulation of local scenes as metadata and tags that draw local scenes into the design of playback and interaction, which I trace out in these service's search and tag functions to draw out the ways in which these services produce the "feel" of locality (Berland, 1990). I also analyze texts generated by these services as a means to glean how they promote and represent the service. For CBC Radio 3, this entails considering reports generated by the broader Canadian Broadcasting Corporation, as well as blog posts written by DJs. With Bandcamp, I primarily engage blog posts written by the service's co-founder Ethan Diamond.

Chapter 6 examines two digital music services: Bandcamp and Wyrd Distro. I revisit interface design, albeit attempting to discern what meanings and values about locality are evident in the music's presentation and design in both services. I draw from Will Straw's (1998a, 2007) suggestive work on the impacts that big box stores and video

\footnotetext{
${ }^{9}$ Following Morris and Powers (2015), I define an interface as “. . all that greets a userwhen she/he starts up a service, including design, features, content organization, navigational options, etc., as well as the affective pull this combined assemblage has on users" (p. 110).
} 
stores had on the cultures of music and film (respectively), as a means to read and understand the sorts of meanings these e-retailers generate about their services from the layout and distribution of commodities in these two digital music services' interfaces. I also draw from journalistic discourse and indie press coverage of these two services as a means to discern motivations and practices of the owners and operators of these respective services. Finally, there are two key differences in my two case studies: my examination of Bandcamp's incorporation of DIY as labour draws from Matt Stahl's (2013) work on contracting as means to control for music creativity, and I pursue a closer reading of Bandcamp's terms of subscription in light of his research. This is also coordinated with research on immaterial labour and incorporation (e.g. Lazzarato, 1996; Terranova, 2000). For Wyrd Distro, I am concerned with the ways in which this FACTOR-funded, not-for-profit indie music retailer is drawn into the broader circuits of the networked media industries through the realm of "gray media" (Fuller and Goffey, 2012). Google's place in this company is highlighted through the service's use of its Documents app for administrative purposes. Meanwhile, their use of Amazon's "cloudhosting" services is identified from their FACTOR grant application that explains core operations. Thus, I examine interviews given by Wyrd Distro's co-owners and operators, which have been procured from indie music blogs and popular press coverage, alongside its publicly available FACTOR grant application. ${ }^{10}$

\subsection{Chapter Outlines, Stakes, and Research Contributions}

Chapter 2 sets out the scholarly foundation on which this dissertation rests, pinpointing the utility of examining scenic institutions to glean the articulation of locality

\footnotetext{
${ }^{10}$ Publicly available as a Google Document. (Levin, 2013)
} 
and independence within local and digital settings. It coordinates three sets of scholarship to arrive at this argument, beginning with work that examines the ways in which independence is produced in independent record labels through both scenic activity and negotiation of the recording industry's business practices. Then, I identify an inclination to present digitization in the music industry as either securing increasing degrees of corporate power, or empowering listeners. I argue that these two literatures complement one another, raising the problematic of how to gauge the ways in which independent record labels navigate the digital music marketplace. I pinpoint my own interest in adopting the "scenic view" as a means to gauge the articulation and reconfiguration of locality in both local scenes and digital music services. After further working through an evident tension between institutional and sociological studies of scenes, I argue that this dissertation charts out a more reconciliatory approach to scenes that attends to the articulation of locality in three institutions: record labels; scene-bound media; and digital music services.

Chapter 3 unpacks and examines the entrepreneurial strategies shaping the musical activities and commodification practices of two Ottawa-based independent record labels: Kelp Records and Bruised Tongue Records. Kelp Records is currently navigating the choppy waters of digitization by: performing artist management duties; working with local musicians to secure international networking and distribution opportunities; and providing support services for local musicians trying to secure synclicensing deals. Bruised Tongue Records, meanwhile, operates at a smaller scale, largely creating an independent record label that releases and promotes music through such "subcultural artefacts" (Harrison, 2006) as zines, cassettes, and vinyl. At the same time, 
Bruised Tongue Records relies (primarily) on a number of social media platforms (and in particular, Facebook, Twitter, and Instagram) for networking and promotional purposes. Both labels demonstrate how independence is produced through the locally embedded DIY activities of indie entrepreneurs that focus on, and orient their business practices towards, the local music scene. Moreover, both labels creatively appropriate and reject entrepreneurial strategies developed both in the music recording industry, as well as past practices of independent music production. This suggests the residues of indie's commodity and entrepreneurial histories in contemporary indie music.

Chapter 4 hones in on the local independent media sites that specialize in covering the city's independent music activity. After introducing the layout of the city's live music venues and arguing that it signals the lack of any sort of musical centre in the city, it focuses on the locative functions of four scene-bound media sites: zines; blogs; music videos; and campus/community radio. I highlight how these media filter the circulation of independent music culture in the city and incorporate a number of digital media services. These services work to extend and reorganize the reach of these (predominantly) grassroots and/or independent media. I also show how these media sites open up access points to the city's music scene, and how they emerge from the activities of scene participants. I then conclude by highlighting particular cultural logics evident in these media, including: the navigational and locative role that independent media play in this largely insular and fragmented music scene; higher rates of turnover in such media as blogs, social media, and zines, which intensify the seeming buzz and exclusive/scarcity of the scene; the locally bound circulation of many of these media; and the archiving 
functions of websites and podcasts, which work to endow the city's scene with scenic memory.

Chapter 5 is organized around a closer reading of two digital music services that not only focus on independent musicians, but also integrate local regions into the design of their interfaces. First, I examine $\mathrm{CBC}$ Radio 3, which is a digital radio station and music blog that is part and parcel of the broader $\mathrm{CBC}$ Music streaming service. Both Radio 3 and CBC Music produce the "feel" of locality (Berland, 1990) through its narrative emphasis on the local regions and scenes from which independent Canadian emerges, which threads through its broadcasts, artist profile pages, and blog stories. I argue that the service's emphasis on local regions fulfills the CBC's programming mandate to produce media services and cultural programming that both reflect, and speak to, Canada's diverse regions. Bandcamp, meanwhile, is a digital sales platform that targets independent musicians and record labels. Bandcamp integrates local regions as user-generated tags that, while aiming to produce "community" within the service (Diamond, 2010), also produces order in the search and retrieval of music. Both case studies suggest that local scenes are reconfigured as a form of metadata that I label the indexi-local.

Chapter 6 moves to the study of two digital music services as a means to map out both the incorporation of locally embedded DIY labour, as well as the institutional and economic production of independence from the recording industry online. I start the chapter with another engagement of Bandcamp, this time focusing on its embrace of indie music distribution as a means to maximize profits and lower risks (or rather, offset the risks and costs of production onto service subscribers). This is further traced out through 
discursive analysis of the service's contracting terms that highlights how independent labels and musicians are incorporated on indeterminate terms of subscription. A closer reading of Wyrd Distro, a FACTOR-funded and non-profit digital retailer that positions itself as a curator and tastemaker, comprises the chapter's second half. My examination of Wyrd Distro shows how it performs the sort of DIY labour incorporated by Bandcamp on behalf of the musicians and labels that it incorporates in its digital retail space. The service primarily sells physical (not digital) music commodities. I then highlight the subtler place of corporate power in its operations by turning to Wyrd Distro's use of Google's Docs app to organize its informational services, and its use of Amazon's cloudhosting services. These instances of "gray media" (Fuller and Goffey, 2012) demonstrate the incorporation and valorization of DIY by this particular pocket of the networked media industries. Both case studies signal the translation of DIY from subcultural ethic effected in sites of alternative media and cultural production, to a part of the digital media's service industries.

Chapter 7 pieces together the argumentative threads of this project, further clarifying and explaining what this critical reconsideration of the place of local music scenes in contemporary indie music and digital music services contributes to understanding the place of locality and independent music in the digital music and media industries.

The impacts of digitization on local music scenes that work to locate indie music have pressing implications threading through this dissertation. I show that the two labels that fit within the broader circuits of Canada's independent music industry are adapting to the disruptions introduced by digitization through two measures: first, embracing and 
incorporating a cross-section of indie-oriented digital distributors and retailers into their operations, and second, producing a closer focus on releasing albums and supporting the careers of musicians from that local music scene. Thus, there is a more pronounced focus on the local in local music scenes. The greater abundance of indie music activity in local scenes provides a range of scene-bound media - including campus/community radio, zines, blogs, and music video - the opportunity to both re-organize and locate this abundance of musical activity within the local music scene. A cross-section of indieoriented digital music services also orient their services to the very local scenic activity, whether by distributing, selling, uploading content generated by those scenes, or translating scenes into metadata. These services draw on and support local activity, thus centralizing the widely dispersed and locally oriented regions from which independently produced music. Both local scene-bound media and digital music services promise access and centralization.

As a contribution to cultural studies, I aim to clarify and operationalize the term scene, which has been critiqued for its abstraction and imprecision (Hesmondhalgh, 2005). I do this by demonstrating its utility for producing a more institutions-oriented treatment of indie music's re-articulation and location in both urban and digital media settings. The term's usefulness to pinpoint broader industry upheavals within local settings suggests its value to producing a conjunctural style of analysis that can blend matters of political economy and cultural studies. To digital media studies, I aim to build on the burgeoning cross-section of scholarship concerned with the styles of labour performed within the digital media industries. I identify a flexible and precarious form of service labour connected to the incorporation of DIY, which threads together creative, 
informational, and manual labours that have been in the foreground of digital labour studies. ${ }^{11}$ To studies of popular music - and in particular, Canadian popular music - this dissertation contributes a detailed reading of, on the one hand, the place of indie music in Canada's capital city, and on the other, the place of this city in the wider and contemporary independent rock milieu.

11 This scholarship includes: apprenticeship labour for creative industries (Shepherd, 2013); free labour performed by fans for musicians (Baym and Burnett, 2009; Morris, 2014); manufacturing and waste labour (e.g. Dyer-Witheford, 2015; Gabrys, 2011); and creative labour (Dyer-Witheford and Sharman, 2005; Stahl, 2013) 


\section{CHAPTER 2. REVIEWING INDIE MUSIC: THE PLACE OF SCENIC INSTITUTIONS}

This chapter reviews the scholarship foundational to this dissertation's questioning of the place of local scenes in contemporary Canadian indie rock music. It argues that independent record labels, digital music services, and scene-bound media are important sites to measure and examine the reconfiguration of locality in indie music. First, I examine a cross-section of scholarship that treats independent record labels as “cultural articulations" (Lee, 1995, p. 14), shaped through entrepreneurial navigation of the commercial music marketplace, particular musical-aesthetic interests, and local scenic activity. This research guides subsequent chapters' examinations of indie record labels (Chapter 3) and digital music services (Chapter 6), foregrounding in particular the DIY activities and entrepreneurial strategies guiding these institutions. Second, I highlight studies of digitization that emphasize the myriad disruptions affecting means of musical distribution and consumption. This focus on disruption orients my studies of indieoriented digital music services. Specifically, these services' reliance on DIY as usergenerated content is shown to both minimize risks associated with content production, in favour of monetizing distribution, as well as re-intermediate facets of the traditional record company (including promotion and market analytics) (Chapter 6). Finally, I work through studies of scenes, arguing that they provide a useful method, attuned to the social and institutional production of music in local settings, with which to ascertain the composition and commercial logics undergirding indie music's urban and digital circulation. A "finely-grained" study of Ottawa's indie music scene guides the following chapters in this dissertation (Gitelman, 2006, p. 11). The study of institutional logics is of 
particular use to Chapter 4's examination of scene-bound media, which not only provide access-points to the city's scenic activity, but also produce a sense of 'buzz," urgency, and stability.

\subsection{Indie Record Labels: Cultural Articulations}

Indie rock music tends to be presented in scholarly literature as a field of musical activity that is different from the "mainstream" music industry, whether in terms of music genre (Bannister, 2006a, pp. 57-90; Fonarow, 2006, pp. 39-50; Hibbet, 2005, pp. 60-69), or the potentially democratizing social and musical relations enabled by independent modes of musical production and distribution (Hesmondhalgh, 1997; Moore, 2007).

This project of engineering difference is central to the field of indie music because:

... without dominant, mainstream musics [sic] against which to react, independent music cannot be independent. Its existence depends upon dominant music structures and practices against which to define itself. Indie music has therefore been continually engaged in an economic and ideological struggle in which its 'outsider' status is re-examined, re-defined, and re-articulated to sets of musical practices. (Kruse, 2003, p. 149)

The scholarship examined in this chapter further follows the grain of this argument, partaking in the discursive negotiation of this ideological and economic struggle for an "outside" from "dominant music structures and practices" through studies of the entrepreneurial and scenic activities of independent record labels. These works argue that independent record labels provide an important site through which to understand not only contemporary practices of DIY in local music scenes, but also ways in which the broader music marketplace - and indeed, "mainstream" music industry operates. 
Stephen Lee's (1995) study of independent record label Wax Trax! Records (based out of Chicago, IL) focuses on the label's incorporation into the recording industry's major label system through a production and distribution arrangement with Interscope Records (p. 15). Lee argues that the acceptance of this P\&D deal was more complex than the label merely selling out; rather, he examines how the commercial dynamics of the music marketplace were unfavourable to this indie label which, after facing increasing levels of global popularity for select artists, faced distribution hurdles and levels of growth that were difficult to sustain (pp. 16-20). The label accepted the P\&D deal to sustain its further operations. This sets out independence as an entrepreneurial project that navigates through the commercial terrain only by attaching itself to the larger recording industry (pp. 29-30). He supports this argument by juxtaposing data procured through interviews with label employees, ethnographic observation of the record label's entrepreneurial decisions and place in Chicago's indie scene, and postmodern theorizations of late capitalism (pp. 22-23). ${ }^{1}$

Though Lee provides a nuanced reading of indie as produced through the navigation of the broader recording industry's commercial logics, the juxtaposition of observation and theorization effectively repositions the record label's business activities as expressions of the broader forces of late capitalism. Chapter 3's examination of Kelp Records' move towards artist management, re-releases of catalogue "hits" on vinyl, and provision of professionalizing support services to local musicians is framed as the label's

\footnotetext{
${ }^{1}$ More precisely, in Jean-Francois Lyotard, Lee finds an always already expanding form of late capitalist power that incorporates all differences. In Fredric Jameson, he finds an accounting of capitalism's alienating effects, and its tendency to falsely parse off culture, capital, and aes thetics from one another. This artificial division inflects, in turn, ideas about indie's oppositional potential (pp. 22-23).
} 
attempt to situate itself within the logics and practices of the commercial music marketplace. I am less inclined to dismiss these efforts as indicating the label's ideological compromise of a "truly" independent position, and more concerned with Kelp's re-articulation of independence as a means of supporting local musicians.

David Hesmondhalgh (1999) argues for a more complex interconnection between commerce and aesthetics to understand independent music's difference. For Hesmondhalgh, aesthetic qualities do not merely reflect the economic and commercial structures of independent record labels; instead, he suggests that aesthetic interests actually drive the economic and entrepreneurial decisions made by independent record labels (pp. 36, 55). He illustrates this through a closer reading of two independent British record labels: One Little Indian and Creation Records. In One Little Indian, Hesmondhalgh identifies a desire to support the musical acts signed to the label through efforts to expand market growth through internationalization; this effort was, in turn, enabled by financing from a major record label (pp. 42-45). Meanwhile, Creation Records' investment in the aesthetics and styles of rock history produced a record label aesthetic that not only "sounded" mainstream, but also was amenable to networking with major record labels (pp. 45-49). From these buy-ins, Hesmondhalgh argues that the political potential of indie record labels to democratize access to musical production has been compromised, due to the broader propensity for "conformism and conservatism" he traces out in contemporary indie music (p. 55). Though Hesmondhalgh usefully reframes the study of indie to consider the influence that aesthetics have on both entrepreneurial styles and label identity, my project counters his dismissal of indie as a compromised and attenuated site of cultural and entrepreneurial activity. I consider the continued place, 
value, and struggle of both indie labels and digital music services to articulate independence (Chapters 3 and 6). Moreover, by identifying a "localist" aesthetic threading through both Kelp Records and Bruised Tongue Records (Chapter 3), as well as Wyrd Distro (Chapter 6), this project considers the ways in which economics and aesthetics dovetail in the articulation of locality within independent music praxis.

Barry Shank (1994) argues that there is a greater degree of creativity evident in the appropriations and remixing of major record label activity by independent punk record labels, surmising that "just as the first punk fans had recombined already existing elements of the culture into a collage signifying freedom, these punk entrepreneurs could recombine elements of the culture industries into a new distribution system" (p. 94). For Shank, the ways in which punk labels adopted and adapted elements of the recording industry's operational practices signals the further development of punk resistance as a mode of stylistic bricolage (p. 94), which Dick Hebdige (1979) found central to punk styles of subcultural resistance (pp. 102-105). Yet, in such a richly detailed book that focuses on scenic activity, Shank does not actually focus on any punk record labels located in the city; instead, he infers this sort of creative entrepreneurship through syllogistic reasoning: that is, because it is a punk-oriented record label and bricolage is a significant style in punk, punk entrepreneurship works as style of bricolage. My own study of Bruised Tongue Records asks after the fit between punk aesthetics and entrepreneurial styles, but is focused through a study of the label's locally embedded DIY activities, and in particular, its specific focus on locally manufacturing, distributing, and promoting its music through such "subcultural artefacts" (Harrison, 2006) as cassettes, vinyl, and zines. 
Holly Kruse's (2003) Sites and Sound explores major and indie label interactions, albeit through a closer focus on two particular ways in which major labels incorporate indie label activities: first, major record labels sign away successful indie musicians, thus relegating the indies to a sort of "farm league" for the major record labels; and second, major record labels tend to create "boutique" indie record labels that look and sound, but are not structured like, an independent record label (pp. 44-50). Kruse argues that these sorts of incorporative tendencies, along with the distribution services that majors offer to indie labels, signal the difficulty of producing and distributing music that is truly independent of the recording industry. This sets up her subsequent argument that indie is irreducible to label composition, but rather created through the social construction and composition of independent music in local music scenes (pp. 68-69).

Wendy Fonarow's (2006) study of British indie music's "aesthetics and rituals" follows a similar path of argumentation, relegating labels to a section of her introductory chapter that identifies the different ways in which indie can be defined. These definitions include: as mode of aesthetic judgement; "pathetic" styles and stereotypes of participation, which involve such emotions as depression, isolation, obsessive collecting (pp. 53-57); ethos; and industry (pp. 25-78). Her study of industry is brief and largely circles around, again, to questions of ownership structures and distribution methods, with a closer focus on a handful of indie labels and distribution networks (pp. 33-38). Like Kruse, Fonarow surmises that label composition is merely one part of the value of indie music (p. 38); her work is more interested in mapping out the sorts of "rituals" performed by musicians and fans alike in the milieu of the live performance. 
Both Kruse and Fonarow unpack and highlight the complexity of indie as a category that operates in generic, social, industrial, and aesthetic registers. Yet they largely mobilize indie labels as a bridge to their broader concerns with scene participants and rituals. The key aim of this dissertation is to foreground the importance of local scenes in contemporary independent rock music, in terms of record labels, scene-bound media, and digital music services. In terms of label activity, my research considers how local music scene anchor entrepreneurial activities that, in turn, are navigating disruptions correlated to digitization. This particular role of scenes has been largely unconsidered and provides another example of the value and place of local music scenes in contemporary indie rock, to both digital music services and local labels.

This subtler reading of labels and scenes is advanced in Alan O'Connor's (2008) political economy of independent punk record labels. O'Connor demarcates the aesthetics, styles of entrepreneurship, and social affiliations that circumscribe the independent record labels undergirding punk music's broader struggle for autonomy. Through interviews with label owners and proprietors; examination of the funding, production, manufacturing, and distribution conditions of punk labels; and discussion of the ways in which both youth and adults affiliate with punk, O'Connor's broader argument is that punk is neither subcultural style nor musical genre. Rather, he argues, punk is a "cultural field" contingent to the activities of punk musicians and entrepreneurs navigating both major and independent record labels (pp. 1-9). I want to adopt his insightful reframing and reconceptualization of punk autonomy, but highlight the ways in which locality is produced and negotiated in indie label activity and re-articulated in both local and digital settings. 
Overall, these authors share a core concern with the ways in which independence is developed, negotiated, and struggled for, through the entrepreneurial, aesthetic, and scene-bound activities of independent record labels. Moreover, these writers deploy interviews, consult various pockets of indie music press (including fanzines), consider the circulation of indie music in local scenes, pursue closer readings of entrepreneurial strategies, and examine the aesthetic and musical styles emerging from independent record labels as a means to glean the articulation of independence. This research influences my own focus on the ways in which independence is produced in the aesthetic and musical activities of both indie record labels and digital music services, through navigating, supporting, and incorporating both local scenic activity, as well as the entrepreneurial and commercial practices of the recording industry. Yet, the question of how to both frame and study digitization in relation to questions of music's distribution and consumption requires further consideration and development.

\subsection{Digital Dis ruptions}

A number of media theorists have argued that digital media inaugurate either new and empowering aesthetic, affective, and creative forms and experiences (cf. Lévy, 1996; Benkler, 2006; Jenkins, 2006), or new figurations of power and control (cf. Deleuze, 1990/1995; Hardt \& Negri, 2000; Galloway, 2004). In this section I establish how this narrative of digitization's disruptiveness is re-articulated by music scholars examining digitization's impacts on the distribution and consumption of music. This research identifies new opportunities afforded to listeners and the reinforcement of existent music monopolies, through studies of platforms and political economy. I argue that indie 
music's digital circulation and reconfiguration provides an important vantage through which to map out these impacts of digitization on the value and circulation of music.

\section{Distribution: Label Control, Challenged and Intensified}

Steve Jones (2002) provides a robust examination of how digitization has not only challenged and reinforced the controls that the recording industry has over the means and networks through which music is distributed, but also re-configured the spaces and places in which listeners create community. His essay threads together the narrative of digital control and empowerment introduced above, often in the same case study. Thus, he finds that new modes of sharing and downloading music online has introduced processes of "re-intermediation" in the recording industry, in which areas of distribution that were formerly controlled have been taken up by other media sites not controlled by the recording industry. This has prompted the recording industry to react by creating new licensing arrangements and percentages, experimenting with digital retail, and developing new valorizations of, and legal activities pertaining to, copyright (pp. 219-222).

Meanwhile, he argues that digital media have potentially dis-placed the spaces and places in which music was traditionally heard, enabling forms of listening that are "bound" more by desire than geographic location (p. 230). Though this conclusion could be read as contributing to broader digital myths celebrating the "end of geography" (Mosco, 2004, pp. 85-98), Jones' essay also emphasises the place and value of examining the very digital music sites in which music is consumed. Jones' focus on re-intermediation and the very digital spaces that "bind" digital modes of distribution and consumption are central to this dissertation. Re-intermediation influences Chapter 6's examination of Bandcamp and Wyrd Distro, and in particular, how they work to "re-intermediate" the distributive 
capacities of indie record labels. His call to study the digital settings in which fans listen and consume influences my decision to deal with a cross-section of indie-oriented digital music services. However, Jones' discounting of geographic location in the consumption of digital music is problematized in both Chapters 5 and 6, which highlight the ways in which local scenic activity is incorporated as labour and metadata by digital music services.

Patrick Burkart (2005) also examines the impacts that digital media have had on existent practices of distribution in the recording industry's commercial practices by focusing on the "Celestial Jukebox," a model of music distribution and retail developed by the recording industry throughout the 2000 s. He underlines the importance of distribution for the recording industry, but demarcates efforts to maintain and intensify controls over distribution through two efforts: first, licensing songs to a limited number of digital retailers (pp.494-495); and second, then-nascent means of data rights management, which produced a variety of limits on the actual ways in which music could be owned online (p. 495). Like Jones, Burkart identifies the ways in which further degrees of control and monopolization in the recording industry are achieved in reaction to destabilizations in the marketplace spurred by digitization. Returning to this problematic nearly a decade later, Burkart (2014) describes overarching continuities between the "Celestial Jukebox" and current streaming-based models of digital music distribution. While he surveys new advances made by the music industry in its control over digital means of distribution (pp. 397-402), he also demarcates the place of "pirate parties" in circumventing and outright resisting digital controls enacted by the recording industry. Burkart corrects a narrative of control, by introducing sites of resistance. 
Resistance is produced in a myriad of sites, whether protesting bits of legislation focused on copyright and software that support the "Big Three's" control over digital music or supporting the peer-to-peer download network Pirate Bay (pp. 402-404). My research too follows the everyday and ground-level navigation of the changes described by Burkart, examining how both indie record labels and digital music services navigate the terrain of music distribution being reconfigured by digitization.

Burkart and Jones align in their focus on how digitization is working to both disrupt existent practices and create new means of control within the music industry. Matt Stahl and Leslie Meier (2012) corroborate this accounting of monopolistic powers extended and intensified in the current digital music economy through their critical reading of the increasing centrality of "360 degree" contracts in the recording industry. This form of contracting extends both the terms of contractible musical labour, as well as areas of commoditization, moving into publishing and live musical performance. This contracting shift emerges, moreover, as a means of control for the myriad of risks now characterizing a music marketplace only partially defined by the (increasingly diminishing) sales of musical recordings, and in particular, CDs (p. 444). The crux of this argument is that the digital music marketplace demands an increasing degree of flexibility to meet consumer demands and new media disruptions. Controlling the labour of musicians through extended contracting means and terms vis-à-vis "360 degree contracts" provides such a means of creating stability (p. 445). Chapter 3 examines Kelp Records' experimentation with 360 degree contracts and how this means of contracting fits within the label's broader aims to support and cultivate local music careers. Chapter 6 examines the means by which Bandcamp contracts musicians and record labels through 
its terms of use, highlighting a more precarious and indeterminate contract that hinges on subscription, revenue-sharing, and album sales. Even more subtly, the local music scene is emerging as a site in which labels and digital services alike are attempting to stabilize the tumultuousness of the digital marketplace.

These writers all pursue a political economy of the recording industry, enacting a more "macro" and "top-down" approach to matters of corporate concentration and the increasing controls set in place to stabilize the musical marketplace disrupted by digitization. I want to engage the commercial terrain on which the indie music services and labels I examined operate, albeit by shifting from this broader and all-encompassing vantage that prioritizes the "major players." Instead, my work surveys these industry dynamics at the smaller scale of the local indie music scene. Such an orientation "flips" studies of the music industry towards a "bottom-up vantage." This sort of approach is evident in scholarship that examines the end-points of that distribution network: that is, studies of consumption through these newer platforms of digital music streaming and retail.

\section{Consumption: Empowerment and Co-Creation}

Jeremy Wade Morris has written a number of platform-oriented studies of digital music. His 2015 book, Selling Music, Formatting Culture, examines the upheavals in digital music distribution described above through a closer study of five digital music sites: Winamp, the Compact Disc Database (CDDB) that manages the distribution of digital metadata; Napster; iTunes; and streaming services. Morris draws together examinations of interface design with discursive analysis of both popular journalistic accounts and promotional discourses generated by the companies behind these platforms 
(pp. 22-23). Through these case studies, he identifies two overarching tendencies in digital commoditization. On the one hand, these services attempt to design new listening experiences through interface design, marketing efforts, and branding; on the other hand, new methods of commodifying both audiences and music are evident in these services. This platform-oriented approach enables Morris to hone in on and clarify broader industry dynamics in more local settings. Such an approach can even reverse established narratives, as with his analysis of Napster's emergence in the late 1990s, in which he writes against scholarship that treats it as a site that resists music industry praxis. Instead, he identifies the future interests and focuses of streaming music provisionally set out in this service's interface: that is, a listening audience base that subscribes to, and aligns with, a single service, that not only communicates a branded listening experience, but also repackages and commoditizes that subscriber base as valuable to potential investors (pp. 94-96).

This focus on the newer means of commodifying both audiences and music is further pursued in an essay written by Morris and Devon Powers (2015), which examines the impacts that music streaming services like Spotify, Pandora, and Beats Music (now Apple Music) have had on practices of music consumption. They surmise a broader transition in the music commodity from a consumable good to a utility that (like water) is expected to be ubiquitous and accessible (p. 109). Though this would seem to signal an empowered listening milieu that is able to stream any song, anytime, anywhere, they argue that reliance on internet connectivity and the influx of dynamics and terms of licensing contracts signals a more heavily constrained and controlled digital listening milieu that is most valuable for internet service providers and music companies (p. 118). 
This traces problems in commoditization and licensing from that local region and back to industry dynamics. I also adopt this mode of analysis in Chapters 3 and 6, which examine and pinpoint industry dynamics enacted in this digital music era from, respectively, the vantage-point of two Ottawa-based independent record labels and two indie-oriented digital music services.

Following a similar 'bottom-up” approach, David Arditi (2014) examines Apple's iTunes store and the ways in which it blocks the potentially egalitarian means of music distribution through peer-to-peer download networks online (pp. 413-414). Arditi sets out "illegal downloading" as the crux of this potential of egalitarian distribution, which is regulated, in turn, by the recording industry through copyright, criminalizing illegal downloading, and finally, prioritizing licensing of digital music sales through the iTunes store, which has worked to consolidate the music industry's control over distribution (p. 421). In this respect, he re-frames the iTunes store as a piece within the music industry's bigger puzzle of "domination."

While raising the issue of consumption, the consumers behind these new platforms are elided (or rather, framed in terms of what the service enables them to do). Yet, keeping in mind the interest in music services discussed in the previous chapter, what sort of work do consumers do for and within these sorts of digital music services? Patryk Galuzska (2015) identifies a broader blurring of production and consumption in the "new [digital] economy of fandom," surmising that contemporary music fans now work, particularly in the more experimental fields of independent music, in a wider range of capacities for musicians and labels. His is a narrative of consumer empowerment though, in which he suggests that in this "new digital economy," the "traditional 
recording industry" plays a role of diminishing importance; instead, it is fans that are now more involved in the business of music, working as "sponsors, co-creators of value, stakeholders, investors, and filters" (pp. 31-39). ${ }^{2}$ Each of these instances signal how digital media services have enabled heightened modes of involvement in the music business, which is framed by Galuzska as empowering consumers.

Writing in a more ambivalent register, Morris (2014) examines the ways in which the internet has blurred existent categories of music production and consumption, but examines a more quotidian example: the social media account of musician Imogen Heap. He sees two tendencies: on the one hand, fans are doing more work, and in doing so, performing "free labour" for this musician (pp. 281-283); on the other, that musician too is doing more work, not only working as a musician but also a sort of entrepreneur of self, involved in record promotion and the work of connecting with fans (pp. 283-285). This is demonstrated through discursive analysis of both popular press accounts of her musical and social media activities, as well as "data scrapes" of Imogen Heap's social media accounts (p. 273). Morris is leery of reducing this increased level of involvement by both fans and musicians in social media settings to either empowerment or

\footnotetext{
${ }^{2}$ Sponsorship refers to the ways in which fans can "gift" and/or donate money to musicians through digital music services (p. 32). Co-creating value refers to the incorporation of fans in more "creative" roles, whether designing graphics or providing remixes to musicians who, in turn, embed this material/content in their websites (p. 33). Stakeholders are teased out through a briefer examination of CASH Music, a music coalition for independent musicians that has experimented with incorporating consumers/fans in different ways, whether inviting them to invest in financing a song for which they are then provided a percentage of future sync-licensing profits, or providing fans with sheet music for songs and then uploading music produced and performed by these musicians (p. 34). Investing gestures to the direct financing of musical projects from fans through such platforms as Kickstarter and Indiegogo (pp. 35-36). Finally, he identifies "net-labels" as largely fan-run DIY operations that both aggregate and make available different styles of music for other fans (pp. 37-38).
} 
exploitation, instead suggesting that the current digital music economy demands forms of "co-creative labor" in these sites (p. 287).

The blurring of boundaries detailed by both Galuzska and Morris builds off Paul Théberge's (1997) research, which too demarcated the ways in which digitization blurs the boundaries between production and consumption. However, in contrast to highlighting the ways in which consumers become producers, his research pinpoints the myriad ways in which music producers become highly attuned consumers as a means to keep up with advances and developments in the hardware and software necessary for digital recording and production (p. 5). His research incorporates a range of resources, spanning from the instrument industry's design initiatives, to marketing discourse, to the popular and specialized music press (p. 5). I am more inclined to follow Morris and Théberge's lead, working to re-evaluate and reconsider - rather than valorize and celebrate - the ways in which digital music services have incorporated and re-configured the DIY work contained in indie music scenes. Galuzska's celebratory tenor is situated in a study of exceptional moments of empowerment; conversely, Morris examines more everyday practices of social media's integration in music and Théberge takes in practices of promotion, creation, and mediation. Due to the volume and ubiquity of indie musicians in these digital services, I treat the incorporation of scenic activity as metadata and DIY labour within digital music services as more quotidian than exceptional.

Taken altogether, I am concerned with the re-configuration of distribution and consumption that has been connected to digitization, as it both impacts on and is navigated by indie labels and digital music services alike. While studied for the ways in which it maintains and challenges monopolies, this facet of the digital music industry has 
important implications for the field of independent music, which - as outlined above develops industry practices and entrepreneurial strategies in dialogue with that industry. Digital services have disrupted the means and methods of distributing and consuming indie music, not only providing consumers and record labels with seemingly direct access to one another, but also re-intermediating traditional facets of the indie music industry. Yet, studies of digitization in indie have largely elided these questions of labels, services, and distribution. Instead, they examine matters of consumption, networking, and marketing, including: the integration of social media by touring musicians for purposes of networking and accruing social capital (Sargent, 2009); the integration of social media in scenic activity (Kruse, 2010); the ways in which indie rock's pursuit of difference resonates with the recommendations algorithms in digital retail sites like Amazon (Hibbett, 2005); and the adoption of DIY as marketing hook for "indie" musicians aligned with major record labels to frame their uses of new media for means of promotion and distribution (Strachan, 2007, pp. 259-260). An essay that resonates with this dissertation's interest focuses on the "free labour" performed by fans for indie musicians (Baym and Burnett, 2009), yet this too elides the sort of work that indie labels and musicians also perform for indie digital music services.

The issues in distribution and consumption outlined above affect the very process and practice of DIY, which is not only embedded at the scale of the local music scene, but also incorporated and reconfigured in these digital music services that focus on distribution, streaming, and retail. Yet what sorts of activities and institutions can we designate as scenic? 


\subsection{Scenes}

While the study of scenes have been articulated in different theoretical contexts and towards different argumentative ends (Hesmondhalgh, 2005, pp. 27-30), I argue that scenes afford a more detailed and materially attuned consideration of the media sites and institutions that articulate particular "wishes" and characterizations of indie music locality in urban and digital settings. Yet, because this project identifies the incorporation of local scenic activity as metadata and labour, it is pressing to ask and answer: what counts as a part of a music scene? Distilling the major concerns, approaches, and methods threading through the existent scholarship on scenes clarifies and sets up my own use of the term to study the musical, medial, and technological articulation of locality in the following sites: record labels, media, and digital music services. These are drawn together in my study of Ottawa's indie music scene and treated as important sites that articulate particular wishes about locality through their shared emphasis on indie music.

\section{Urban Scenes: Defining Infrastructure, Locating Music and People}

Sara Cohen's (1991) Rock Culture in Liverpool provides a richly detailed accounting of the production and performance of rock music in Liverpool's music scene. Through a method that blends together ethnographies (e.g. interviews and participant observation), semiotic analysis (analysis of lyrics and music styles), and cultural geography (with a more pronounced emphasis on Liverpool's cultural and economic history), Cohen illuminates how rock music is not only framed and experienced in everyday musical practices of local musicians, but also how a city centre's social environment both impacts on, and is reshaped through, local music-making activities (p. 7). This is revealed through studies of scenes, which provide a corrective to focuses on 
rock music that treat it as a form of youth culture, glean its ideological components, and situate it within the operations of the recording industry. For Cohen, such approaches work to articulate rock as mass cultural phenomenon (p. 6). In contrast to such a "mass" approach, she pursues a study honing in on the "micro-sociological" details of musicmaking in the city (p. 6), thus providing a rich accounting of the places, sounds, words, and performers that make rock music happen in the city. However, her closer emphasis on musicians and larger disregard of both media sites (e.g. local radio, music press, music video), as well as cultural artefacts (recordings, album artwork) produces a more myopic consideration of scenes as commensurate with the experiences of local musicians. Her closer focus on institutions and textual analysis will be useful to study the ways in which locality circulates through particular institutions used by local scene participants.

In an essay published this same year, Will Straw (1991) departs from these sorts of sociological details privileged by Cohen, instead pursuing a study of scenes as a means to glean how particular institutions and practices contained in a city work to embed, sediment, and stylize globally circulating music cultures (p. 375). This is an approach that is both dense and prismatic, gleaning a number of seemingly musical and experiential qualities from the ways in which particular institutions operate. Thus, for instance, he pinpoints the conservative and largely similar sounds of "alternative rock" across a wider range of local music scenes as emerging from two particular institutionally-contingent practices. The first, he writes, are forms "of connoisseurship" cultivated in alternative rock scenes that slow down rates of cultural turnover. These are influenced, in turn, by such institutions as independent record stores, the music press, and campus radio (pp. 
376-377). The second set of practices, Straw writes, focus on careers cultivated through recording and live performance by alternative rock musicians (p. 377). In this, we can see a focus on the ways in which operative "logics" undergirding both the cultural artefacts and institutions circulating in a scene impact on the stylization and experience of music.

Straw articulates a radical vantage point for scene studies that influences this dissertation. Specifically, I am also concerned with the ways in which institutional logics impact on forms of music. I am concerned, primarily, with the utility of this approach to glean the logics evident in scene-bound media (Chapter 4) and digital music services (Chapters 5 and 6), treating them as significant sites that work to both produce and reflect particular wishes and characteristics about locality articulated in Ottawa's indie music scene. In particular, Chapter 4's study of scene-bound media considers logics exerted through format that influence characterizations of the scene. For instance, the futuresoriented and (at least) daily rhythms of blogs and social media produce a sense of urgency and vitality in the city's music scene. Zines, podcasts, and websites, in turn, are generating ad hoc and decentralized archives of the city's scenic activity, endowing the city's scene with more pronounced subcultural memory. This perspective produces difference, shifting from celebration of the city's scenic activity to diagnosis of the forces and media that frame and inform the city's activities. Yet, I also want to provide a more precise and detailed consideration of the ways in which these scene-bound media generate narratives about, and work to locate, the city's overabundance of scenic activity. This consideration helps to foreground the ways in which these media's logics also reflect and express extrinsic social and subcultural interests and values. 
Barry Shank's (1994) research on Austin Texas' "rock n roll scene" in the 1980s suggestively draws together Cohen's ethnographies of musicmaking and Straw's (1991) study of institutions. His study of punk music's emergence in the city's limits identifies a number of factors, including: a narrower cluster of music venues supporting local punk musicians; American record distribution companies beginning to import punk records that were, in turn, received at local record shops; and fanzine and music press coverage of both international and local punk rock music (pp. 91-117). This sort of focus on the constellation of institutions, musicians, and scene participants that made rock $\mathrm{n}$ roll happen in this city threads through his book, whether discussing the emergence of "progressive country" in the city (pp. 38-65), or highlighting efforts enacted by musicians and local organizations to professionalize the city's music scene (pp. 191-237). Shank situates the wealth of details accumulated about how people in the city experience and invest (whether professionally or emotionally) in rock $\mathrm{n}$ roll in the city of Austin within Lacanian theories of transgressive identify formation (pp. 118-161). This enables him to argue for both the potentially empowering ways in which people participate in a scene, as well as the ways in which such semiotic and affective "overabundance" is captured and commoditized in subsequent efforts to reorganize and professionalize the scene. I am similarly motivated - albeit without recourse to Lacanian psychoanalysis - to map out the place and circulation of indie music through a cross-section of institutions in which Ottawa-based scene participants are located. The depth of detail running through Shank's examination of Austin inspires my own closer reading of indie rock's circulation and place in Ottawa. 
Throughout this scholarship about scenes in the 1990s, we can see the term deployed as a means to survey the sorts of practices and logics shaping the formation and circulation of particular music genres in particular locales, whether through sociological, psychoanalytic, or materialist means. This focus persisted as the term further developed and circulated in the 2000s. In this subsequent restaging, it continued to hone in on local music activities, even as it began to enfold (and react against) an even more disparate body of scholarship.

Alan O'Connor (2002) deploys the term scene as a means to account for the ways in which punk musicians and fans across a number of different city centres actively produce the infrastructure - such as record labels, venues, promotional companies, and media - that make punk happen. He does this as a means to pinpoint the very urban conditions shaping punk music's regional and global circulation. What is striking about O'Connor's use is that he is using the term scene to resist "de-materialized" studies of culture that emphasize hybridity and global flows, which have seemingly eradicated considerations of "real" lived situations (p. 225). O'Connor uses the term scene in the "punk sense:" that is, as the creation of infrastructure, which helps him grasp, in turn, the social and musical "organization" of punk music vis-à-vis a more pronounced examination of its regional formation and circulation (p. 226). I too am attuned to questions of the media and institutions that create musical infrastructure, which works to align this essay with the more radical facets of Straw's essay.

Flipping this approach, Matt Stahl (2003) politicizes and problematizes popular notions of indie music creating and facilitating more egalitarian and accessible musical experiences for scene participants by highlighting the social and creative hierarchies that 
persist in San Francisco's indie scene (p. 141). He does this largely through participant observation and interviews, embedding himself in this scene, reporting on various extramusical social gatherings (such as dinner parties and talent shows), and then highlighting the hierarchies that persist in these settings. Adopting the "scenic view" enables Stahl to highlight the smaller scaled performance and reiteration of liberalism's veneration of individuality vis-à-vis local scene celebrities. He argues they enact a range of social activities that, though seeming to efface hierarchical differences, actually work to excuse and reinforce these very differences (pp. 156-159). The performance, reinforcement, and excusing of scenic hierarchies vis-à-vis celebrity is less central to this dissertation. Instead, Stahl's re-framing of indie rock's valorization of community, creative autonomy, and egalitarianism as "scripts" (p. 144) handed down in rock music provides a suggestive way to consider the persistence and re-articulation of locality in digital music services.

Though O'Connor and Matt Stahl, and Cohen and Straw, seem to suggest branching projects (one for materials, one for experiences), Geoff Stahl (2003) draws together these approaches in his examination of local music-making practices in Montreal, Quebec's Anglophone rock scene. He uses "scene" as one of a pair of terms the other being bohemia - with which he grasps at and illustrates the discursive production, musical practices, and experiences of Anglophone rock musicians in the city. His is a distinctly robust methodology, blending ethnographic and qualitative data (including diaries, interviews, and participant observation) with discursive analysis of local media sites and political economic analyses of the city's musical institutions (pp. 264-266). Yet, Stahl's examination is largely concerned with the relationship between cities and musicmaking (p. $\mathrm{x}$ ), thus asking after the ways in which a city shapes 
musicmaking. I am less concerned with musicmaking, however, than with the ways that labels, scene-bound media, and digital music services re-place the city in their disparate activities.

Holly Kruse (2003) argues that the value and meaning of indie music is actively produced by scene participants in local scenes. She ascertains this through analysis of the ways in which scene participants shape both personal biographies and indie music's history through their own investment and involvement in their local music scene (pp. 1213). Kruse adheres to Cohen's (1991) "micro-sociological" details (p. 6) in her study of scenes, largely privileging interviews with a wider range of scene participants (including musicians, media producers, label owners, promoters, and fans). Kruse's clarification of how local music scenes produce the value and meaning of indie rock influences my own approach, though her closer focus on participant experience is less useful to my own study of how media matter within, and work to shape and influence, the perceived and produced experiences of local scenic activity. Phrased another way, I am concerned with gauging the articulation of locality through a closer reading of scene-bound media and digital music services, rather than through participant experience.

In two essays published since 2000, Will Straw $(2001,2004)$ returns to scene studies, both expanding and clarifying what it is that the term can do for studies of music and culture. In Straw's (2001) earlier essay, he highlights a more pronounced place for both cultural institutions and media sites in scene studies. He continues attending to the sorts of logics that can be induced from the varieties of practices and activities contained in a local scene, suggesting that it is a useful term with which to glean the scale, rhythms, and movement of cultural activity (p. 249). It is once again a more prismatic approach 
that highlights such tendencies as: music venues not only embedding tastes in a city, but also ritualizing and rendering normal seemingly "vanguard" musical and cultural activities (pp. 253-254); the slower rates of cultural turnover in city's scene (p. 254); and a myriad of social protocols and norms that are both performed by, and demanded of, scene participants (pp. 255-256). In the later essay, Straw (2004) continues to expound on what one can study with scenes, noting that urban policies and regulations such as alcohol licensing, the size and circulation of undergraduate student populations, the "effervescence" of cities (or indeed, the ways in which cities are both experienced and discursively produced as entertaining), and the architecture of venues impact the form and experience of music in city centres (pp. 414-420). Both essays follow through his previous focus on logics embedded in institutions, but in these later essays, scene is becoming an inter-local term. That is, it moves across cities, inducing broader theoretical and argumentative tactics from the wealth of observations and characterizations gleaned across a number of different scenes, ranging across a range of locations and periods.

The concept of scenes has guided a number of studies of music's circulation in different urban centres. Though differences abound in this scholarship - whether over theoretical foundations, argumentative norms to react against, or a more basic branching of scholarship towards either sociological or material-oriented studies of local music this work nonetheless provides a rich field of scholarship with which to grasp at the institutions shaping music's circulation. This place-based orientation is even more pronounced when considering the brief "virtual" turn in scene studies in the early 2000 s encapsulated by Andy Bennett $(2002,2004)$. 


\section{Virtual Scenes: Producing Proximity Online}

In his study of virtual scenes, Andy Bennett $(2002,2004)$ highlights the ways in which music fans share their passion for particular musicians and scenes in different online spaces. In cyberspace, participation largely emerges through practices of sharing information because, as he further explains: “. . . virtual scenes, by virtue of their nonface to face quality, depend upon other displays of competence, notably articulation and musical knowledge and information" (2004, p. 230). The sites examined by Bennett are primarily web 1.0 websites (for this work primarily emerged in the early $2000 \mathrm{~s}$ ), including discussion forums, chat rooms, listservs, and fan websites generated for particular musical acts. Fan proximity in these services hinges, more precisely, on sharing and participating in a shared online space.

What is striking about studies of virtual scenes is that they tend to focus on either distinctive music figures - such as John Prine and Kate Bush (Bennett, 2004, pp. 231232) - or more marginal realms of musical activity. Such marginal realms might include the Canterbury Sound scene of the late 1960s/early 1970s, which has been celebrated and documented in websites and mix CDs, and the Postcard 2 listserv that was devoted to altcountry (Bennett, 2004, pp. 231-232). The focus on expressions of fandom and musical investment in marginal genres has suggestive applications for studies of indie music, though Bennett's narrower focus on distinctively digital and online places elides the more complex blurring between digital and local scenes, with which this dissertation is concerned.

Holly Kruse (2010) studies the circulation of local music scenes online, turning to Bennett's work. Through a critical reconsideration of the previous research she conducted 
on scenes, she finds that the ways in which indie rock musicians incorporate social media and music e-retailing services signals that local scenes provide the infrastructure on which virtual music scenes rest (pp. 630-631). Thus, the local music scene provides a foundation of sorts, while its virtual iteration augments and extends scenic activity. Yet, there are still more difficult questions to ask concerning how local and online scenic activity imbricate: that is, the ways in which local and virtual iterations of scenic activity overlap, in perhaps uneven ways. What sorts of power relations transpire in the incorporation of scenic activity within digital music and media services? Does extension of scenic activity from offline to online spaces have particular stylistic and design attributes? Subsequent chapters show that digital music services, scene-bound media, and a host of social and digital media services do more than extend local scenes: they also reorganize scenic activity.

These writers mobilize the virtual as a heuristic with which to tease out the ways in which musical fandoms are both shared and produced online. These studies resonate with a broader turn towards the virtual in media studies that focuses on the ways in which social, cultural, and aesthetic experiences emerge through embodied interactions with new and digital media sites (cf. Lèvy, 1998; Hansen, 2004). Yet, a number of writers have challenged the concatenation of the virtual with digital, instead pursuing studies of the virtual as a means to prise open the experiential potentialities of culture, with particular attention paid to politics and aesthetics (Grossberg, 2010; Massumi, 2002, 2011). This interest in the virtual as experiential potential is further developed in Chapter 5's examination of the "indexi-local," which examines the imbrication of digital music services with local scenes through the deployment of local regions as tags and metadata 
that organize the playback and listening experience designed in the digital music services CBC Radio 3 and Bandcamp. My discussion will build on the deployment of virtual scenes as both primarily online spaces developed by fan interactions, as well as virtuality as experiential potentiality provisionally teased out in this section by examining the ways in which local regions are mobilized to organize the listening experiences produced within digital music platforms.

\subsection{Ottawa's Indie Music Scene: Institutional Logics and the "Finely- grained" Case Study}

The studies of indie record labels, digitization in distribution and consumption, and music scenes examined in this chapter offer a wider range of methods and approaches, weaving through ethnographic observation, qualitative interviews, political economies of industry praxis, semiotic analyses of platform design, consumer uses, press discourse (whether popular or alternative), musical/aesthetic interests, marketing and branding efforts, and specific institutional logics. My own interest with this range of scholarship is to survey the "wishes" about locality that have been articulated through a cross-section of scenic institutions invested in indie music. In subsequent chapters, I largely step aside from the ethnographies of musicians and fans that have been privileged in scene studies, instead attempting to produce a deeper reading of scenic media and institutions. Indeed, Kruse (2003) has already identified the social production of locality by scene participants, and her insights are central to my own interest in the articulation of locality. My interest is in producing a more pronounced place for studies of scenic institutions - and in particular, record labels, media, and digital music services - that work to articulate discourses about, and stylizations of, the value, meaning, and place of 
the local in indie music. Such an approach will help to produce a "finely-grained" study of the "wishes" about locality generated in contemporary indie music institutions (Gitelman, 2006, p. 11). More precisely, Lisa Gitelman (2006) outlined the methodological and analytical utility of the "finely-grained" case study in Always Already New, surmising that they generate more "exacting" accounts of the interplay between cultural practices and media technologies, particularly in light of the emergence and impacts of new media on existent practices (p. 11). Or as she explains:

... the detail and specificity of each case permits an account that is exacting, and at the same time broadly suggestive of ways that new media emerge into and engage their cultural and economic contexts as well as the ways that new media are shaped by and help to shape the semiotic, perceptual, and epistemic conditions that attend and prevail. (p. 11)

Following Gitelman, the scenic institutions guiding this analysis of locality's place in contemporary indie music "are both shaped by and help to shape" the very problematic that I am concerned with: the place of local scenes in indie music. By attending to scenic institutions, I too want to provide an accounting of the reconfiguration of locality in digital music services, as connected to the field of indie music, that is both exacting in detail and suggestive of the broader place of locality in indie music's digital circulation. These branching interests guide subsequent chapters, oriented towards a "finely-grained" study of Ottawa's indie music scene. 


\section{CHAPTER 3. RE-EXAMINING THE INDEPENDENT LABEL}

\subsection{Local Activities}

In his study of punk record labels, Alan O'Connor (2008) advocates for a more nuanced focus on punk as economic and institutional process rather than end-product, writing that "it is a mistake to regard punk as a thing and then to argue about its true spirit or meaning. Punk is an activity or a series of activities that take place in time" (p. 1, emphasis in original). This is an important critique that insists on paying closer attention to the current circulation and production of punk music. Following O'Connor, this chapter examines indie music as a process of articulating locality by focusing on two Ottawa-based record labels: Kelp Records and Bruised Tongue Records. Through closer readings of these two labels' entrepreneurial strategies and shared focus on Ottawa's indie music scene, I argue that both labels pursue a locally focused and primarily DIY project. Kelp has moved into the realms of supporting local musicians through artist management, arranging sync-licensing, and facilitating local musicians' opportunities to network with national and international sectors of the music industry. Meanwhile, Bruised Tongue is a DIY punk label that focuses on local musicians, distributing and promoting their releases through older media formats (in particular, cassette tapes, lathecut vinyl records, and zines). These activities reveal indie as process, connected to both labels' DIY labour and activities that are, in turn, articulated to and through select pockets of the city's indie music scene.

These labels are part of a broader field of independent music activity in the city, including (but not limited to): Spins and Needles, which is a label that focuses on releasing locally based electronic dance music (EDM); Label Records/Record Centre 
Records, which releases music from local country, rock, blues, and indie musicians; and Marlow Records, which specializes in jazz music. Kelp and Bruised Tongue have been chosen both for their affiliations and points of contrast. Both labels have made a sizable impact on the city's musical culture, attain coverage in the city's local media, have rosters of musicians that are both popular and critically valorized, participate in cultural and musical events in the city (both large and small), and produce music that circulates outside of the major label sector of the music industry. They have even collaborated together, with Kelp pressing into services the production and design work of Bruised Tongue's co-founder Pierre Richardson in a round of vinyl re-releases to mark the label's twentieth anniversary. Yet, the two labels have different generic specializations, with the former specializing in the genres of folk, rock, and singer-songwriter and the latter releasing noisier experimental and post-hardcore punk rock. They also contrast in the ways in which they valorize and distribute musical commodities (in both their physical and digital formats). Kelp is an older label than Bruised Tongue that is building on existent practices of artist development connected to the recording and performing careers of local musicians and moving towards practices of management, professionalization development, and arranging sync-licensing agreements between musicians and advertising companies. Bruised Tongue, meanwhile, emerged in 2009 and specializes in releasing music through lathe-cut vinyl records and cassette tape formats that it both self-distributes and manufactures. I have chosen these two labels for their distinctive investments into independence vis-à-vis their overlapping focus on the city's music scene. Yet independent rock in its folk, singer-songwriter, and DIY punk iterations is merely one pocket of activity in this city's wider range of music activities. 


\subsection{Outaouais Renaissance: Kelp Records}

\section{Lo-Fi Origins, Independent Structure, \& Locality}

Jon Bartlett started Kelp Records in 1994 while he was living in Fredericton, NB. At that time, the label largely specialized in releasing cassette tapes of the music Bartlett was recording and playing with his friends. Bartlett recalls the label branched off of his then-burgeoning interest in lo-fi and DIY music-making. As he explains:

I was obsessed with Guided by Voices, who were my favourite band. Red Red Meat, which is now Califone, The Grifters, and the Flaming Lips even at that point - all those bands were doing self-recorded, home recorded things and just listening to those records was inspiring. We could just write songs and sit in the basement, press record, and do everything ourselves. That was really what was behind the aesthetic of the label at that time - just kind of doing everything ourselves and putting the cassettes together and mailing them out. (Personal Communication, November 26, 2014)

Bartlett moved to Ottawa in 1999, and once he got to the city he began shifting the label's focus from these more insular lo-fi home recordings and towards the musicians he was starting to associate with in the city's music scene. One such musician was singersongwriter Andrew Vincent, with whom Bartlett aligned, to perform on and release the cassette tape To Thine. Bartlett explains the shift: "there was interesting stuff going on and I was getting to know all these bands and that's when Kelp was starting to look outwards” (Personal Communication, November 26, 2014).

In 2016, Kelp Records is a midsized independent label that largely specializes in releasing albums through digital, Compact Disc (CD), and vinyl formats. ${ }^{1}$ Since 1994, it

\footnotetext{
${ }^{1}$ Kruse (2003) breaks down indie labels as small, medium, or large: small tend to specialize in a particular playback format (like seven-inch singles) and forego distribution in favour of mail-order systems; medium tend to have diverse release formats and use distribution companies, but have smaller rosters; and large are defined as bigger-name record labels that have larger distributive reach, such as the internationally extending indie labels Rough Trade or Sub Pop (pp. 50-51).
} 
has released nearly seventy albums, largely focusing on lo-fi rock, folk, and country rock genres (Simpson, 2014, p. D5). In terms of ownership structure, the label is independent: it is neither aligned with a major record label in terms of its ownership and financing, nor in terms of distribution. Instead, Kelp works with two distribution companies: Outside Music for Canadian distribution and Carrot Top Distribution (CTD, Ltd) for American releases (Kelp Records, n.d.a). Both companies distribute albums from a number of different independent labels. Outside Music distributes albums in Canada from independent labels that are located both inside and outside of Canada, from the popular Olympia, WA-based indie label K Records to the Calgary-based label Flemish Eye (Outside, n.d.). Carrot Top, meanwhile, brings an assortment of albums from Canadian indie labels into the United States (CTD, n.d.). Albums from artists signed to Kelp Records make their way into both a wide range of physical stores, as well as to a number of digital retailers and streaming services, including MapleMusic, Zunior, Amazon, the Apple iTunes store, Spotify, and Apple Music. The reliance on independent distribution companies allows the label to distribute albums to a wide variety of retail locations in both Canada and the US without relying on either the distributive or promotional services of the major label sector of the music industry.

While the label operates in an independent manner, this does not mean that it is privately financed; instead, it assembles additional funding through a cross-section of private and public funding bodies, including: MuchFact (http://muchfact.ca), a product of MuchMusic and the Bell Media subsidiary M3 that invests in music video production; Factor, a private-public funding body that provides grants to artists and record labels; and the Ontario Media Development Corporation (OMDC). This range of financing - as well 
as the provision of grant writing support through Kelp's sister company Megaphono suggests the label's ability to navigate the choppy waters of arts and culture funding bureaucracy, which is prone to unstable budgeting, dense application processes, and at times oblique criteria for evaluation (Spalding, 2008, pp. 153-155).

Kelp's production and distribution of music outside of the recording industry connects it to a longer historical trajectory of independence, defined in economic and institutional terms. This historical connection is also evident both in its early focus on lofi recordings, as well as its overt specialization in folk-leaning rock music. ${ }^{2}$ There are a number of musicians signed to the label that release music within these genres, including: Ottawa's Winchester Warm; Toronto's New Country Rehab; and the Ottawa-based singer-songwriters Andrew Vincent and Jim Bryson. For Bartlett, making decisions about who to sign to the label is as much a matter of personal musical tastes as it is a matter of who is in his social network; as he explains: "[Kelp Records has] been this family of mostly dudes in Ottawa ... I grew up with soprano Measha Brueggergosman in Fredericton and (we) sang in a church choir together" (Simpson, 2014, D5). On the one hand, the signing of musicians from one's local social and musical networks is a common strategy mobilized by a number of independent labels, both past and present (Azerrad, 2001; O'Connor, 2008). On the other, the label's focus on working with a smaller group

\footnotetext{
${ }^{2}$ Folk music provides a rich historical precedent to indie rock's authenticity debates, with similar debates and tensions over commercial (over-)exposure, celebrity, and "selling out" taking place in this particular musical field. Simon Frith (1981) examines folk's place in the wider discursive articulation of rock's symbolic, social, and emotional value, while Michael Azerrad (2001) explicitly situates indie as an extension of 1960s folk music, even suggesting independent bands signing to major record labels is an affront to existent fandoms that is similar to Bob Dylan "plugging in" and going electric in 1965 (p. 8).
} 
of musicians over a longer period of time can be seen as extending a strategy popularized by the recording industry in the 1960s and 1970s: that of artist development.

Artist development aims to produce a pool of recordings by a single artist. With each new release by that artist, there is the intertwined hope that not only will the new recording be a hit, but that that hit will also spur interest in the artist's previous recordings (Frith, 1981; Straw, 1990; Stahl, 2013). Artist development demands the longer-term investment of the record company into a musician, which Matt Stahl (2013) highlights as emerging through the signing of musicians to longer-term contracts that hinge on number of albums released, rather than a number of years. ${ }^{3}$ A pillar of artist development is both investment into, and support of, the recording artist, with the hope that one of their releases would connect with popular audiences and become successful. Such success would then spur the sales of previous albums: a return on previous investments that also cultivates a recording career. At Kelp, the emphasis on artist development is evident in the closer and lengthier ties that Bartlett has made with a selection of musicians signed to the label, even when they record and release at an infrequent pace. For instance, Andrew Vincent has recorded and released three albums with Kelp - two solo, and one with his backing band The Pirates - over a ten year period, spanning 1999 to 2009.

\footnotetext{
${ }^{3}$ For instance, upon signing to Arista Records in the mid-1970s, Patti Smith signed a contract for seven albums (Waterman, 2011, p. 106). Though initially releasing albums at a clip of one every year, or every other year, the tempo of releases slowed by the 1980s. Smith's seven-album contract entailed producing albums for a single record label for the better part of twenty years.
} 
Artist development was a core strategy for the recording industry until 1979, when the overall sales of vinyl records swiftly plummeted. ${ }^{4}$ Over the next few years, as the recording industry charted out a plan of recovery to stabilize its sales, the model of artist development was supplemented with two new strategies: a focus on blockbuster artists and catalogue re-releases. The blockbuster model involved higher levels of investment in a smaller pool of musicians. When these artists "hit," then the losses accrued in other areas of the business were recovered (Negus, 1992; Stahl, 2013). Musicians that benefited from the blockbuster approach included those in the midst of careers already well-developed through existent strategies of artist development (such as Bruce Springsteen and Michael Jackson), as well as a larger pool of "one hit wonders" (Marcus, 1989; Stahl, 2013), whose successes were also bolstered by the advent of MTV, which focused on airing singles rather than the then-dominant practices of Albumoriented Rock (AOR) defining radio airplay (Straw, 1993). The blockbuster approach has not been a key part of Kelp's business practices. This said, the company has produced one-off releases by larger musicians - such as a 2010 album released on Kelp that found Jim Bryson leading the popular Winnipeg-based indie group The Weakerthans, or the release of an album of rock songs by the popular soprano singer Measha Brueggergosman - which can be understood as smaller-scaled and locally-focused attempts to create such a "hit."

\footnotetext{
${ }^{4}$ The causes of this decline are contested. Knopper(2009) reinforces a more commonplace assumption that this decline resulted from the over-investment of finances into disco music, which abruptly became unfashionable. Straw (1990), meanwhile, argues that this decline was rooted in a more widespread lack of innovation in the recording industry.
} 
Another medium-specific strategy developed by the record companies was catalogue re-releases, connected to the advent of the compact disc (CD) format in the 1980s (Knopper, 2009; Witt, 2015). Before the CD format, record labels were likely to let records go out of print. With the advent of the CD, the "major six" labels in the 1980s were able to re-release - in updated and re-mastered editions - albums that resided in their respective back catalogues, thus capitalizing on their existing pool of developed artists. If one of the major characteristics of the recording industry is market indeterminacy - i.e., an inability to predict what will sell (Frith, 1981; Hesmondhalgh, 2013) - catalogue re-releases are oriented to providing a bit of stability to this risky cultural industry. Re-releases capitalize on what has already been successful. In the digital milieu, the re-release and re-mastering of albums in digital formats can still spur excitement, as for instance, the release of The Beatles' whole discography on Apple's iTunes store in the late 2000s and on streaming services like Spotify in 2014.

Interestingly, there is also an evident reversal of trends now, whereby it is digital music primarily released on $\mathrm{CD}$ that is being re-released on analogue formats like vinyl records and cassette tape. These catalogue re-releases have been important for music companies both large and small, major and independent because they capitalize on money already invested, as it is cheaper to repackage what has already been produced then to develop and produce new product. They also spur new activities, including potential reunion shows, new rounds of critical coverage, moving older albums out of discount bins and back into stores, and potentially stoking further sales of other recordings by those re-released artists for the label. 
In celebration of its twentieth anniversary in 2014, Kelp Records re-released a number of earlier recordings from the label on vinyl for the first time. In 2014, The Acorn's first and only Kelp releases (the full-length The Pink Ghosts and extended-play Blankets) were re-released in limited edition pressings, with newly coloured vinyl records. These records were re-released alongside Andrew Vincent and the Pirates' 2003 release, I Love the Modern Way, and Andy Swan's 2005 album, Andy Swan's Ottawa, which were limited to pressings of approximately 100 copies. Limited edition rereleases like Kelp's, which feature hand-numbered pressing editions and re-designed album artwork, appeal to (and stoke the interests of) record collectors, a notable sub-section of indie rock participants (Straw, 1991, 1998b; Bannister, 2006b; Davis, 2007).

Alan O'Connor (2008) argues that the back catalogue and roster of musicians are central and distinctive features of an independent record label's identity (p. 85). Tracing backwards from artists signed and records released to label identity, in Kelp we can see a primarily Ottawa-centric label that focuses on a variety of lo-fi, folk, and country-leaning rock music. ${ }^{5}$ But keeping in mind Stephen Lee's (1995) identification of the power possessed by major record labels to define the commercial and entrepreneurial terrain on which indie labels work, Kelp's adoption of artist development and catalogue re-releases can also be seen as reiterations of the business strategies developed in the recording industry. By extension, the label's very institutional and economic identity as an "independent" label is produced by incorporating and negotiating these strategies within

\footnotetext{
${ }^{5}$ Or, as Bartlett explains the label's generic inclinations: "There has been mostly rock and singersongwriter, folk oriented artists and releases, for the most part, though we have dabbled in otherthings. We were never going for a particular sound, just music that seemed interesting and exciting" (Personal Communication, November 26, 2014).
} 
its practices. I now turn to experimentation with management services and professionalization strategies as a means to further this narrative, and indeed, further tease out how the label's indie business strategies work to articulate locality.

\section{From Kelp Records to Kelp Management: Digital Stabilizations}

In a contemporary musical marketplace characterized by declining record sales and a smaller cross-section of "blockbuster" artists, the major record companies have come to increasingly rely on strategies that include: Licensing songs to other media and entertainment companies; cultivating international record sales and audiences; and creating 360-degree contracts (Stahl and Meier, 2012; Sutherland, 2015). This section will examine Kelp's negotiation and incorporation of these contemporary strategies, which have been enacted through Bartlett's expansion of Kelp Records into two sister organizations: Kelp Management and Megaphono. It will demonstrate the ways in which these particular strategies both fit with and extend the existent local and musical focuses of the label demarcated above.

During the 2010s, Bartlett has paid more attention to both managing artists and attaining sync-licensing deals, pursued respectively through Kelp Management and Megaphono. The band New Country Rehab, which signed to Kelp in 2012, spurred his interest in this line of activity; as he explains:

New Country Rehab played 160 to 180 shows a year, they had a bookkeeper and everything established, they had books, the singer and leader was very organized on that side, and we came on as label and management and since then management has grown to become our main focus for the company, so we have drifted from Kelp Records and into Kelp Music and management is the main thing. (Personal Communication, November 26, 2014) 
Since signing New Country Rehab, Kelp Management have begun working with musicians that are not signed to the label, including: U.S. Girls, Andy Shauf, and Michael Rault. In this capacity, Kelp Management assists in various areas of artistic and professional development and promotion, including: Arranging press and media coverage; assisting in the booking of domestic and international tours; advising on various matters of career development; and supporting artists with grant and funding applications. The label's shift towards management services signals its effort to open up other revenue streams in addition to album sales. This sort of expansion into different revenue streams and areas of musical activity is commensurate with the increasing use of 360 degree contracts in the recording industry. Such contracts are applied to both new and blockbuster artists, and monetize a wider assortment of musical practices, including: merchandise sales, live shows, and music publishing and licensing (Stahl \& Meier, 2012; Stahl, 2013). These contracts are different from previous iterations of contracting, which primarily focused on (and contracted for) recorded outputs. Kelp's turn to management not only extends this sort of commodification of extra-recorded musical activity, but also sets up Kelp as a professional intermediary that supports and guides the development of musicians' careers.

Megaphono, meanwhile, provides professional assistance to a wider assortment of Ottawa-based musicians that not signed to Kelp. Megaphono targets musicians that are interested in not only licensing their recordings for use in films and commercials, but also garnering contacts with international connections. This was initially developed when Megaphono provided interested musicians with a website and Bandcamp account that was open and available to potentially interested parties. Starting in 2015, Megaphono 
began to articulate more active networking opportunities through its winter concert series/showcase events, entitled Megaphono Festival. With the Megaphono Festival, a number of international contacts and connections - ranging from press to record labels to music publishers - are flown into the city to watch a week-long concert comprised primarily of Ottawa-based musicians. This facilitates connections between Ottawa's music scene and the international music marketplace. It demonstrates another aspect of the broader internationalization of Canadian independent music identified by Sutherland (2015) as being central to contemporary independent music production in Canada. However, rather than internationalization emerging through the areas of activity Sutherland described (either Canadian musicians signing with international independent labels, or local music scenes garnering international attention), in the Megaphono Festival there is evident effort to bring forth professional contacts and international connectivity by connecting Ottawa's music scene to this wider milieu. These services are being offered as a means to help facilitate the ease of, and level the barriers to, connecting Ottawa artists to international "players." They also bring local musicians into contact with music publishers and companies in charge of licensing songs to the broader swaths of the cultural industries, including movies, gaming, and advertisements. In this respect, Megaphono is positioning itself, again, as a professional intermediary that can help Ottawa-based independent musicians enter into and profit from a realm of international attention and commercial licensing that is lucrative, potentially profitable, 
but often takes place outside of the more immediate and intuitive milieus of live musical performance and album production in local music scenes. ${ }^{6}$

Even though Kelp Records is negotiating the realms of artist development, catalogue rereleases, management, and sync-licensing, Bartlett explains these terrains do not conflict with one another because of the creative musician/personality at the centre of these markets:

It's always been about being in the studio and creating and being involved in other people's records. I've gotten interested in management because it's got me back working with artists and being involved in the creative process, making decisions. I guess it is sort of the same reason: being excited about music and getting the word out about artists. (Simpson, 2014, p. D5).

In this we can see an emphasis on the individual career of the recording and performing artist, and moreover, Bartlett's personal passion for these musicians. In a certain respect, this passion for the city's music scene and musicians bridges the divide between a musical milieu defined by record sales and 360 degree contracts. Producing such management and support services also helps to maintain, and in fact, build up the city's musical infrastructure and stabilize local musical networks. Whether cassette tapes or commercial licensing, the focus on local social and musical bonds persists.

\section{Localist Aesthetic}

David Hesmondhalgh's (1999) work on the fit between aesthetics and economics can help explain the correlation between an independent record label's entrepreneurial strategies and the aesthetic interests of the individuals who own and operate a label. His research demonstrates that particular aesthetic practices do not merely emerge from

\footnotetext{
${ }^{6}$ These facets are central to the always already "on" aspects of creative labour in the independent music industries. (Hracs \& Leslie, 2014).
} 
economic decisions (that is, to operate independent of the recording industry); rather, those who own and operate record labels often have particular aesthetic dispositions that inform the economic and organizational decisions made (p. 36). Hesmondhalgh focuses on the independent label Creation - and in particular, Alan McGee, the label's founder as a means to understand the label's eventual decisions to align with the recording industry. Rather than merely emerging as a "sell out" move, Hesmondhalgh argues that the aesthetic interests of McGee actually contributed to the label's eventual mainstream presence and acceptance of major record company investment (p. 36). Specifically, Hesmondhalgh identifies two aesthetic dispositions in his closer reading of Creation Records: classicist and aestheticist. He defines the classicist position as involving a more conservative respect for rock music's history, evident in both the aesthetics of album covers and styles of music performed by the label's roster. His prime example of this tendency is the signing and subsequent ascent of the "lad-rock" group Oasis, who performed a melodic and often anthemic blending of The Beatles and The Rolling Stones in their music, which reached, in turn, wider audiences (pp. 47-48). He also identifies this classicist tendency in the musical output of the group Primal Scream, who released an album written and performed in the style of 1970s-era The Rolling Stones in 1994 (pp. 48-49). Meanwhile, the aestheticist disposition privileges the aesthetic value of the final musical product; such as album packaging, the sound of an album, etc. (p. 56).

Building on this insightful reworking of the relationship between aesthetics and economics, we can see Kelp's investment and involvement in Ottawa's local music scene through investment in the careers of the musicians with which it works as expressing a sort of "localist" aesthetic disposition: one that favours the predominantly localized 
musical and social relations embedded in the scene. The specialized focus on Ottawabased musicians and reliance on a social network has not only fostered a label identity deeply engrained in Ottawa's music scene, but also bolstered a more collaborative milieu within the label, which is evident in the appearance of musicians in key roles in the label. For instance, The Acorn singer and songwriter Rolf Klausener worked for a short time at the label, and Andrew Vincent co-authored the OMDC-funded report on Ottawa's music scene Connecting Ottawa Music. The comradery amongst the musicians affiliated with the label is highlighted by Bartlett, who recalls in an early interview with Exclaim!:

John Higney of the Flaps plays in Greenfield Main with me, and I was blown away by their incredible live shows. Rolf Klausener is also in Greenfield Main, and his other band Recoilers were one of the first Ottawa bands I ever saw, and are still one of the best live acts in town. (quoted in Whibbs, 2006, para. 5)

This localist aesthetic is also evident in one of the label's core (and recurrent) events: The Annual Kelp Birthday Celebrations. Each year, starting around the time of its fourteenth anniversary in 2008, Kelp puts on either a concert or series of concerts in Ottawa celebrating its history. In 2011, it hosted a weekend of shows at the Dom Polski community centre. The weekend was co-sponsored by campus station CHUO and local craft beer company Kichesippi Beer. During the weekend, a number of Kelp Records musicians performed their albums in their entirety: The Acorn played Pink Ghosts and Andrew Vincent reunited with his backing band The Pirates to play his 2003 album $I$ Love the Modern Way, along with a host of B-sides from that period (Kelp Records, 2011). In these events, the network of social affiliations and musical collaborations that undergird the city's music scene and are re-articulated through the label's localist aesthetic become more clearly evident and expressed on the live stage. The Megaphono Festival, too, sees Ottawa-based music pushed into the spotlight, with a week-long 
festival of specifically Ottawa-based music programmed for an audience comprised of local fans, national music critics, and international music industry personnel and music critics.

As it moves into its third decade of operation, Kelp has navigated through two different musical and retail milieus. Its emergence as a cassette-only label, available in either Fredericton or through mail order, preceded the digital music economy that exists today. But, through the adoption and adaptation of different entrepreneurial strategies taking place in dialogue with the broader music recording industries, Kelp's independent status persists. It sets up distribution through larger (albeit, still independently owned and operated) distributors as a means to get albums into stores (both online and offline). It licenses its releases to digital retailers both big (e.g. Amazon and the Apple iTunes store) and small (MapleMusic and Bandcamp). It has begun signing management deals with musicians and is entering into the realm of "brokerage" through its Megaphono extension. Yet as it expands its operational base, it retains a smaller label roster, focusing on the development of its musical acts and back-catalogue, which are both rooted in the same cluster of recording artists working largely within the indie rock genre in Ottawa (and the surrounding area) that has a limited (but not exactly non-existent) commercial reach. Kelp Records' focus on a small cross-section of recording artists situated in Ottawa's local music scene connects it with another independent label situated in the city: Bruised Tongue.

\section{3 "Feel the Noise:" Bruised Tongue's Subcultural Modes of Production}

Punk Artisans: Tactility, Locality, and Control 
Bruised Tongue Records is an independent record label situated in Ottawa that specializes in releasing a selection of post-hardcore punk music through digital and cassette tape formats. It was started in 2009 by musicians Craig Proulx and Pierre Richardson as a means to self-release a seven-inch record from their group Fucked Corpse entitled Apple Meat. However, after finding it difficult to sell these records, and happening onto a cheap stereo tape duplicator, Proulx and Richardson began releasing cassette tapes of bands they knew and liked in the city, whom they met at various live shows (Sayer and Boisvenue, 2013). A record label emerged out of the confluence of this local musical network and older media format. In an interview with The Ottawa Citizen, Proulx and Richardson describe the decision to release music through the cassette tape format as being situated in the intertwining efforts to both minimize the costs of pressing albums, as well as to maintain a more "in house" style of operation and organization (Boisvenue, 2009). Releasing vinyl records can be a more expensive and time-consuming process that involves pressing up master tapes, sending albums off to pressing plants largely located outside of Ottawa, procuring the services of 'brokers' (intermediaries that assist in scheduling and budgeting releases), and pressing up test copies to listen to before finalizing one's orders (Miller, 2014). Furthermore, doing business with record and compact disc pressing facilities often demands placing and pre-paying minimum orders of at least 1000 records (O'Connor, 2008, p. 27), which can raise a label's expenses, running the cost of releasing a small number of vinyl records into the area of a few thousands of dollars (Miller, 2014). Conversely, it is cheaper to dub cassette copies, which they do "in house" at the cost of 60 to 90 cents per album (Boisvenue, 2009). 
Peter Manuel (1993) has examined the democratizing potential of the cassette format, arguing that its cheapness, ease of reproducibility, and accessibility help foster and support the production and distribution of a range of non-commercial music emerging from different regions that circulate outside of the recording industry's network of major cities. His identification of the value that cassette tapes have for disseminating music created in (and circulating through) more geographically disconnected musicmaking regions helps explain Bruised Tongue Records' embrace of the cassette format. Though Ottawa possesses a rich independent music scene that intertwines with larger music-making cities like Toronto and Montreal, it is also city that lacks the sorts of institutional and professional connections to the recording industry typical of larger-sized music cities like Toronto and Vancouver (Saxberg, 2015; Vincent and Swain, 2015). In turn, the cassette format enables this particular label to create a cheaper, more accessible, and largely self-controlled means of producing physical musical commodities.

Thus, the label produces and manufactures its releases, which focus on the city's punk scene, locally and in-house. This more locally embedded form of DIY production also extends to the label's distribution practices, for Bruised Tongue Records does not use the sorts of professional distribution networks outlined above; instead, it largely selfdistributes either through the city, or through digital music services Bandcamp and Wyrd Distro. ${ }^{7}$

In the city, Bruised Tongue Records' albums are available to purchase at either the independent record store Gabba Hey!, or at various live shows put on by bands affiliated with the record label. Gabba Hey! is a smaller independently owned and

\footnotetext{
7 These two digital music services are further examined in Chapter 6.
} 
operated music store that sells vinyl and cassette tapes, mostly from local musicians. It is housed in a rehearsal space named Capital Rehearsal Studios that is situated in a more isolated (but by no means inaccessible) area of the city centre. The store is located in a cluster of warehouses that shares space with other businesses (including design, paper, and a bakery) and its hours of operation run alongside those of the studio: approximately from 5:00 pm to midnight, Monday to Friday, and noon to 9:00 pm on weekends (Feiber, 2014). The label also distributes releases through the network of venues through which its musicians circulate. Holly Kruse (2003) has noted that one of the primary places at which musicians and fans meet is the live music venue, writing, "live musical performance is arguably the most immediate means available for disseminating [indie] music, since it locates performer and audience within the same physical space" (p. 102). The live show is also one of the label's central retail sites, for the label largely sells releases at live shows put on by bands affiliated with the label. Yet, live shows happen at a sporadic pace in the city, so to buy the album from the musician, one must be attuned to concert listings and attend live shows. Again, this is not impossible, but it does render the retail experience for those that live in the city a more involved and proximate one, whereby one will often be exchanging cash for cassettes with the very musician that has created the album. Co-owner Proulx (2014) highlights this more local and insular focus as a mandate of sorts for the label, explaining that Bruised Tongue was "originally intended as an outlet for a close group of friends to release home-recoded material that may have never seen the light of day" (p. 2). The signing of musicians from one's local social and musical networks is a common strategy mobilized by a number of independent labels, both past and present (Azerrad, 2001). 
The city is central to both the production and distribution of music released by the label, producing a greater degree of proximity. Yet, can we read such proximity in the commodity forms? Alison Piepmeier's (2008) work on zines helps set out such an argument. She suggests that the tendency of zine writers to assemble zines by hand aligns reader and writer through the sense of touch, as both the reader and writer of a zine have actually touched that same zine issue (pp. 229-235). This increasing sense of proximity facilitates, in turn, the formation of "embodied community" between reader and writer. Both the cassette and lathe-cut vinyl records produced and distributed by the label facilitate a more immediate and tactile relationship with music production and assembly. Album artwork (whether LP or cassette tape) is cut and assembled by hand; tapes are duplicated by the label owners and stickers are affixed to one cassette side as a means to designate the A side; for limited edition lathe vinyl, edition numbers are enumerated by hand on the record's label; and LP artwork is comprised of a sticker that is folded (sometimes at irregular angles) onto record sleeves (Boisvenue, 2009; Runciman, 2015). This more tactile production and assembly of music provides a more materials-oriented instance of what Wendy Fonarow (2006) has identified as the "do it yourself" ethic in independent music praxis, which she explains in the following way:

For many, indie is the spirit of independence, being free from control, dependence, or interference. Self-reliance, not depending on the authority of others, has been the guiding value of indie music .... Independence in music means actively eschewing a centralized corporate hierarchy where decisions are made by distant executive bodies. (p. 51, emphasis in original)

Producing and assembling the cassettes intensifies this dynamic. It is not merely a matter of "eschewing" the recording industry's major label system, but also the various 
intermediary organizations that are typically involved in the production, assembly, and distribution of albums.

While the label's focus on releasing music through vinyl and cassette formats has been shown to provide a cheap and accessible format for music reproduction that both emerges from and circulates through local musical networks, these very qualities are also readily evident and ubiquitous within a host of digital music platforms. What value, then, do cassettes and vinyl records have in a digital musical milieu?

\section{Cassettes as Subcultural Artefacts}

In his study of the circulation of cassettes in San Francisco's underground hip hop scene, Anthony Kwame Harrison (2006) argues that this particular playback format works as a "subcultural artefact" that "endure[s] within particular subcultural enclaves as a practical and symbolic barrier to cultural industry appropriation" (p. 285 ). Deploying the term "subcultural artefact" enables Harrison to draw attention to how the underground Bay area hip hop scene attempts to articulate and reinforce its subcultural status through the eschewal of both "dominant" musical styles and media formats associated with mainstream hip hop music. Thinking through these qualities in light of Bruised Tongue Records' use of the format, there is also a wider-reaching underground noise-punk and experimental music scene taking place across Canada at this moment in time that circulates through a more insular network of cassette-only record labels (Sayer and Boisvenue, 2013). In this respect, the cassette tape not only distinguishes the label from other indie labels that offer more traditional musical commodities, but also connects it with a dispersed and decentralized scene of noise, punk, and experimental music that is also being released, primarily, through the cassette format. 
While Harrison's focus on cassettes enables him to discern the mobilization of this particular media format to articulate and reinforce subcultural dynamics, the term artefact also reveals the subcultural histories that are imbricated with this particular format. Harrison establishes this by teasing out the historical formation of hip hop vis-àvis the cassette tape. To further this point, he highlights the central role that cassette tapes played in the formation of hip hop in the late 1970s, whether providing deejays a means to document, share, and promote their musical activities, or enabling consumers to produce a more local and mobile means of music playback through the city streets via "boombox" stereo systems (p. 287). The artefactual nature of cassette tapes challenges one to prise open the histories of subcultural sensibilities that have been cultivated vis-àvis particular media formats. In this light, the cassette tape's ease of reproducibility and cheapness also bolstered the dissemination and promotion of indie rock music in the 1980s. For some indie musicians that practiced and garnered notoriety for their home recordings - such as Daniel Johnston, a singer-songwriter based in Austin Texas - the cassette tape format, coupled with four-track home recording technologies, enabled them to record, produce, and distribute albums through their local music scene. This local exposure provided musicians with opportunities to book live shows and even, in the example of Johnston, to sign to larger independent record labels (Shank, 1994, pp. 157160). The localized music distribution practiced by Bruised Tongue Records was highlighted above, but from the vantage of artefacts, these practices can also be seen as extending the sorts of local and DIY sensibilities cultivated in indie rock and punk in the 1980s and 1990s. 
Bruised Tongue also produces smaller numbers of cassette and vinyl, which suggests a strategy of "planned scarcity" that stokes potential consumer/collector interests. The label produces smaller printings of releases, ranging from 40 (for lathe-cut vinyl releases) to 300. Barbara Klinger (2006) describes the commercial logic of planned scarcity in her work on film collecting, writing:

This type of limited special edition, which offers relatively few copies to the consumer, seeks to define itself as outside of the excesses of contemporary mass reproduction and therefore more rare. It thus attempts to carve out an aesthetic place by appealing to the conditions of scarcity, conditions so important to constituting an aura of value for collectibles. (p. 62, emphasis in original)

Producing limited editions of physical copies not only keeps operating budgets down, but also stokes the potential interests and investments (both affective and financial) of collectors circulating through the indie and punk rock subcultures (Bannister, 2006b; Reynolds, 2011; Straw, 1991, 1998). As Thornton (1996) has noted, owning such exclusive and scarce commodities - an inclination also shared in DJ and dance scenes, with the limited manufacturing of 12" singles (Rietveld, 2007; Straw, 1990) - fits within the sorts of subcultural capital accrued and displayed by members of a subculture. The actual possession of a particular cassette tape may or may not actually impress others, depending on whether or not they agree to the implicit rules of subcultural capital accumulation (Hills, 2002, pp. 20-36). However, the potential scarcity of these items translates into real capital for independent record labels that have mobilized this inclination and desire to collect as a strategy to promote releases and secure a (relatively) stable and committed listening audience. For instance, when Sub Pop Records first formed in the mid-1980s in Seattle, to fund operating costs for the upcoming year they started a limited subscription service for seven-inch singles. For an annual fee - paid in 
advance - subscribers would receive a different seven-inch single every few months. These seven-inch singles were pressed in limited numbers, hand-numbered, and printed on different coloured vinyl throughout the year. Subscription numbers were high and these releases sold out (Azerrad, 2001,pp. 426-427).

This privileging of older media forms is also evident in Bruised Tongue Records' early involvement in producing a local zine entitled Small Talk, which emerged as a means to promote the musical activities of musicians signed to the label (including live shows and albums releases). This particular zine will be further examined in chapter 4, but particularly under the editorial guidance of co-founders Proulx and Richardson, the zine provided a means to promote the label, whether through show listings, album reviews, or interviews with musicians signed to the label. The label's embrace of these older media formats can be understood as a more retrospective impulse that connects it with the musical and aesthetic development of both independent and punk rock music (Bannister, 2006b; Reynolds, 2011). Specifically, in his work on indie rock aesthetics, Matthew Bannister (2006b) highlights a tendency towards "archivalism" that circulates through the music-making practices of indie musicians that conserve and re-present particular pockets of musical history in contemporary musical practices (pp. 81-84). This sort of "archivalism" in indie rock music is evident and formulated both in the musical styles developed by musicians, as well as the host of extra-musical cultural activities, including writing in the underground rock press, cultivating distinct tastes within social and/or musical networks of peers, and purchasing albums (perhaps in dialogue with record store owners) in record stores (pp. 81-84). From this, Bannister suggests - with reference to Will Straw's (1998b) research on gender and collecting - that that indie 
rock's collector-oriented practices of "archivalism" does not merely imbue consumer practices, but also translates into particular, "archive-"oriented styles of music-making. Simon Reynolds (2011) further develops this line of argumentation, highlighting the conservative and retrospective facets of early punk rock music, which largely incorporated musical and stylistic references to pre-psychedelic forms of rock $\mathrm{n}$ roll music (pp.240-259). Extrapolating further, Bruised Tongue's focus on releasing music through the "cruder" formats of cassette tape and lathe-cut vinyl, its distribution of releases through local musical and retail networks, and its production of a zine, both reference and re-articulate indie rock's media histories. However, rather than recovering and revitalizing a marginalized canon of artists or genres through consumption or music creation, there is a suggestive effort to recover and revitalize older, more obsolescent media formats.

\section{Everything in between: Old and New Media}

Bruised Tongue Records' use of older media has been shown to not only create a primarily local, tactile, and DIY approach to music production and distribution, but also to reference and re-articulate the residues of subcultural histories connected to this particular format. Branching off of Harrison (2006), it would seem that older media formats work as a mode of resistance to the dominant media forms through which music circulates. Harrison's treatment and examination of the resistant potentials of older media technologies, through his notion of 'subcultural artefact,' closely coordinates older media to particular subcultural practices. Yet, the label does not merely release cassettes and vinyl outside of digital networks; rather, it also incorporates digital music services and social media in its distributive and social media practices. 
Bruised Tongue Records uses two online services to sell its music: Bandcamp (http:/bruisedtongue.bandcamp.com/) and Wyrd Distro (http://distro.weirdcanada.com). These two digital music services will be further examined below, and in fact, are the core subject of Chapter 6. For the purpose of this chapter, I argue that these services work like mail-order once did: to expand the distributive reach of the label outside of the city's limits by listing albums for sale, which are available to order. Moreover, Bruised Tongue produces digital copies of all the albums they release, which are available to download at varying prices through the service. Cassette tapes purchased come with a download code, redeemable at Bandcamp.

Bruised Tongue Records does not merely adopt digital music platforms to sell its music; rather, it also incorporates an array of social and digital media platforms to promote its musical releases and zine. Its website is created through, and hosted on, WordPress, while it also has profile pages on Twitter, Facebook, and Instagram. The WordPress website features an infrequently updated news feed, listing of musicians signed to the label, contact information, and links to the service's different social media accounts. Meanwhile, followers of the label's various social media accounts receive information on a range of topics, including upcoming album releases, album streams, new music videos, tour dates, links to critical write-ups, and new merchandise created by the label's co-owners. While the label's social media footprint spreads across many of the major social networks, its posts are primarily limited to promoting albums and shows. This ranges from the creation of event pages for shows affiliated with the label, to posting pictures and status updates related to such facets of the label's work as assembling artwork for albums and live shows. This promotional approach primarily focuses on the 
musical practices related to the label. The label's social media profiles fit particularly easily into the label's DIY practices and local social networks, being primarily used to promote the merchandise and albums produced by the label. These profiles are often created by the label's co-founder, Pierre Richardson (Sargent, 2009; Kruse, 2010).

In the label's incorporation of social media services and digital music retailers, there is a style of interaction between old and new media that resonates with Carolyn Marvin's (1988) argument that "... the introduction of new media is a special historical occasion when patterns anchored in older media that have provided the stable currency of social exchange are re-examined, challenged, and defended" (p. 4). In Bruised Tongue, the "patterns" of independent music production, distribution, and promotion - which have traditionally been anchored in a DIY ethos and focus on locality - are largely defended rather than challenged by the label's use and blending of old and new media in the circulation, production, and promotion of music. Specifically, both old and new media enable this record label to do business independently, or outside of the institutional structures of the recording industry and with minimal assistance from external intermediaries. These media provide cheap and accessible resources with which to produce, distribute, and promote their releases. The local scene is both a focus of, and infrastructure on which, the label's production, distribution, and promotion of posthardcore punk rock music is built, through residual media formats. To hint at future chapters, the sorts of locally embedded DIY activities evident in Bruised Tongue Records are also valuable for digital music services that rely on subscribers to ship and receive orders, design profile pages, and warehouse orders. 


\subsection{The State of Independence}

This chapter demonstrated how particular entrepreneurial strategies and aesthetic interests enacted by these two independent record labels are not only negotiated in dialogue with indie rock's history and contemporary practices of the recording industry, but also embedded in local scenic activity. ${ }^{8}$ It has shown that Kelp incorporates and experiments with a host of strategies from the mainstream recording industry in the pursuit of creating a locally focused independent record label; meanwhile, Bruised Tongue produces a primarily local label through an assemblage of both old and new media formats and sites that draw on indie music's subcultural histories. Both labels articulate a largely DIY and localist bent to their musical and entrepreneurial practices that focuses on (and builds off of) existent social and musical relations embedded within the city of Ottawa. Thus, both labels' production of independence coordinates with a closer focus on, and valorization of, local music and culture. In Kelp, the localist aesthetic disposition is expressed through different support initiatives developed by the label, as it moves towards providing the services of artist management and professional intermediary. In Bruised Tongue, its recovery and revitalization of older media formats works to articulate a more insular subcultural niche that limits its releases to those that participate in the scenes in which it is entangled, whether Ottawa's music scene or the broader punk and experimental noise cassette scene that reaches across Canada. Independence is articulated both in the present tense as a negotiation of the recording industry's broader organizational and economic logics, as well as an invocation of indie

\footnotetext{
${ }^{8}$ This motivation mirrors Straw's (1991) own concern with gauging how community is produced in a local scene, rather than treating local musical practices as expressions of community (p. 378).
} 
music's entrepreneurial and media histories. Though the traditional means and methods of musical commoditization and circulation have been upset by digitization, the independent record label persists. Moreover, it relies on the local music scene to negotiate these upheavals. Local scenes have been shown to emerge as an aesthetic and entrepreneurial focus of these labels. Locality circulates as residues in this digital moment: traces of a longer negotiation of the music industry that both reimagines and supports local music-making. 


\section{CHAPTER 4. SHINE A LIGHT: LOCATING AND NAVIGATING INDEPENDENT MUSIC IN OTTAWA \\ 4.1 Local Scenes \& Way-finding Media}

The Arboretum Music Festival is an "immersive, independent music festival" that has the following agenda: "curate acclaimed national and local artists, partner with national and international presenters, [and] present music industry events, cultural talks and regional food, for the benefit of Ottawa's cultural footprint" (Arboretum, 2016). In the 2014 edition, this goal was achieved through a cross-section of locally-focused organization, presentation, and promotion efforts: Ottawa-based independent rock musicians were programmed for both headlining and supporting slots; a variety of food and drinks were created and provided by local chefs and craft brewers; and a number of local music promoters (e.g. Fryquency and Spectra Sonic), music venues (e.g. House of Targ, Mugshots!, and Gabba Hey!), local media (e.g. CBC's Ottawa branch, zine Small Talk, and campus/community radio station $\mathrm{CKCU}$ ), and local business sponsor (e.g. the Downtown Rideau Business Association and craft brewer Beaus) were incorporated in the festival's structure. Arboretum's artistic director Rolf Klausener explained that, with the festival, "essentially, we want festivalgoers to come here and get a real taste for our city, like an outdoor house party representing our entire community of music, food and art” (Simpson, 2012).

A promotion created by the festival that aimed to provide "a real taste for our city" was Arboretum's City Guide, which was posted to both Arboretum's website (Arboretum, 2014) and CBC Music's Radio 3 blog (Stuart, 2014). The Guide worked as an itinerary of sorts that listed and described a selection of music venues, pubs, 
restaurants, and retail sites in the city, with the aim of providing readers with a more direct and in-the-know introduction to the city; as the opening paragraph promises:

Once you connect with a local, or scratch below the city's federal veneer, we've also got a solid selection of all the things that makes a modern city enjoyable: a nationally renowned culinary scene, breweries, a vast amount of local retail, and naturally, an exhausting weekly schedule of parties and cultural events. The following is an incomplete list of some of the things that make it easy to call this former lumber town, home. (Arboretum, 2014)

Both the City Guide website and music festival are positioned as tools to help with this process of "scratching below the city's federal veneer" by providing attendees with a list of some of the sites through which music, art, culture, and people circulate in the city.

I begin with the example of Arboretum 's City Guide because it gestures both to the place of Ottawa in the city's independent rock scene, as well as the ways in which media produced by the city's participants have the potential to both reimagine the city and reveal its scenic activity. Both characteristics speak to this chapter's broader goal: to demarcate the primarily local and independent media sites - and in particular, zines, blogs, music video, and campus/community radio - which generate representations of the city's indie music scene. While studies of media in independent music have tended to either focus on the ways in which they work to "disseminate" independent music (Kruse, 2003), or treat them as expressive tools that both enable and empower subcultural resistance (Moore, 2007), I am interested in highlighting the ways in which these media both emanate from the city's scene participants, and provide points of access to this scenic activity. It is for these reasons I deem them "scene-bound" media, from which I trace out a broader inclination to locate the city's scenic activity and participants. One reason for locating the city's music scene has to do with its fragmented quality, which I now map through a quick overview of the city's venue distribution. 


\subsection{At Least there's Commotion: Ottawa's Music Venues}

One of the primary places to participate in indie music is the music venue (Kruse, 2003, p. 102; Shank, 1994, pp. 118-161). Scholars of indie music have studied the live music venue as a means to glean the various affective, musical, and professional bonds cultivated and performed within a scene (Cohen, 1991; Shank, 1994). Yet there is a suggestive body of scholarship that has redirected focus from participants to the live music venue itself. Wendy Fonarow (2006) examines the music venue through its architecture and grouping of audiences as a means to discern particular musical and social qualities. Specifically, she identifies the qualities of intimacy and immediacy readily identified in the experience of performance within the very layout of the smallersized music venues in which indie music is typically performed. She also examines different groupings of fans in different parts of the venue as a means to discern their degree of investment within the scene. ${ }^{1}$ Will Straw (2001), meanwhile, suggests that music venues are one of a number of institutions that reveal the ways in which the tastes of music fans and musicians are both embedded and distributed within a city (p. 249). Both writers discern particular social, aesthetic, and musical qualities from the architecture and layout of this particular music institution, suggesting the emergence of particular musical qualities from the architecture and distribution of the live music venue. Using data procured from every issue of Small Talk published between 2013 and spring 2015 (a zine that emerges from the Bruised Tongue label) and using the freely available

\footnotetext{
${ }^{1}$ Fonarow's "zones of identification" break down along three groupings: the first zone is at the front of the stage and is typically comprised of more eager fans; the second zone is typically towards the middle of the venue, comprised of more neutral and/or social groupings; the third is typically towards the bar and/or back or sides of the venue, where musicians typically tend to aggregate (pp. 79-153).
} 
online mapping application MapCustomizer (which enables one to draw maps through Google Maps), I map out the distribution of venues in the city as a means to highlight the city's fragmented indie music scene.

\section{Figure 1. Ottawa Venues - Small Talk}

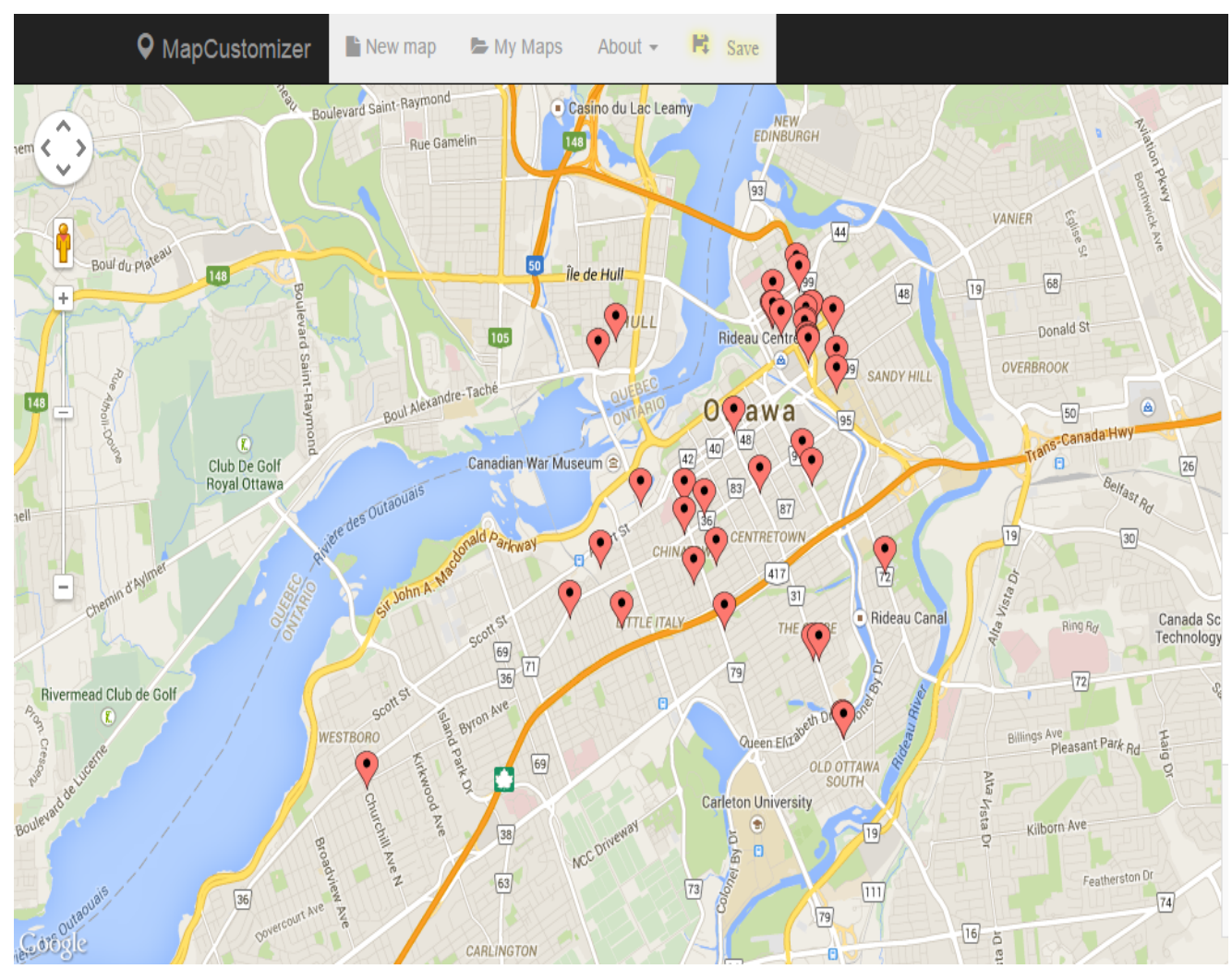

In Figure 1, there is a tighter clustering of venues towards the middle of the page, with a decrease in the number of venues located towards either the right (and in particular, past the Rideau River) or left (past Little Italy) sides of the map. While there are a smattering of venues located at such western leaning points as Westborough and Carlington (to the lower left side) and eastern leaning neighbourhoods such as Vanier, Industrial Park, and Overbrook (to the right side), there is nonetheless a tighter and denser clustering of music venues in the centre of this map, and in particular, the Centretown and Lowertown neighbourhoods (i.e., the city's downtown core). The 
number and distribution of these venues suggests that the music venues' layout takes the form of a network.

Dealing with networks enables one to ask after the organization and formation of relations in different systems because, as Anna Munster (2013) argues, networks “... give rise to [the] form and deformation of conjunctions - the closures and openings of relations to one another" (p. 3). This particular application of networks to discern relations is a recurrent focus in studies of independent music, which deploy the term as a means to either gesture to the complexity of social relations embedded within a scene (Stahl, 2003; Crossley, 2008; Kruse, 2010), or to describe particular media and institutions (Arnold, 1993; Hesmondhalgh, 1997; Azerrad, 2001). Both applications of the term grasp at the relations shaping the experience and circulation of independent music. Holly Kruse (2010) sets out such a role for the network metaphor in indie music when she writes:

The social and economic connections and structures of indie music could, in the end, be seen as networks in which musical knowledge, genre, geography, and position in the independent music business located subjects within one or more sets of relations. (p. 629)

As the music venue is one of the central sites in which these sorts of social and economic relations are contained and developed, mapping the layout of the venues through which independent music circulates suggests that Ottawa's independent music scene is a sprawling one, with multiple points of entry. There are more than thirty music venues programming independent music in the city, largely clustered in the downtown core. This network of venues is also smaller than the more general number of venues located in the city, which Swain and Vincent (2015) estimate runs in the range of approximately seventy (p. 44). Moreover, these venues are typically smaller in size, program 19+ shows, 
and are multi-purpose (i.e., providing other sorts of entertainment and service options alongside live music). These venues are typically either cafes/pubs that host shows (e.g. Pressed, Raw Sugar, The Manx), or smaller-sized music venues that also offer food and drink service (e.g. Zaphod Beeblebrox, The Dominion Tavern, Babylon, and House of Targ). A selection of house-shows - that is, shows that take place at someone's home are also becoming increasingly popular in the city (Cruikshank, 2012).

Alexander R. Galloway (2004) discerns differences in network forms, arguing that there are three in particular: centralized, decentralized, and distributed. The above clustering of Ottawa venues resonates with what he has described as a "distributed" network, which is a network that lacks any sort of necessary interconnections between the embedded nodes. In contrast to a centralized network, which has one central hub to which all other nodes communicate back, and a decentralized network, which contrary to its name, actually has a number of centres, a distributed network lacks any sort of centre of connectivity. Such a networked form demands rules - or what he labels "protocols" - to make it operate. ${ }^{2}$ An example of a distributed network, posited by Galloway, is a highway (p. 35). One can move from point A to point B through a number of different routes and roads. Roads connect to other roads and connect to highways comprised of multiple exits, laneways, etc. What brings order to the movement are such protocols as speed limits, lane demarcations, and the basic rules of driving (including signalling, lane changes, etc.). I am less interested in unpacking the social protocols and relations that make the city's music scene work, however. Instead, I am concerned with the role that a

\footnotetext{
${ }^{2}$ As he further explains: "distributed networks have no chain of command, only autonomous agents who operated according to certain pre-agreed 'scientific' rules of the system"' (p. 38).
} 
narrower cross-section of media have in locating the city's scenic activity. Specifically, because the city's scene lacks any particular centre, I will now show how a cross-section of scene-bound media work to locate the city's scenic activity.

\subsection{Zines: Producing Narrative and Formal Proximity}

The Small Talk zine was briefly examined in the last chapter and treated as a site that complements Bruised Tongue Records' more specialized integration of older media formats in its entrepreneurial and musical activities. Taken alongside the label's focus on cassette tapes and lathe-cut vinyl, zines were identified as another subcultural artefact connected to indie rock and punk histories that contributed to the label's DIY identity. However, Chris Atton (2010) has critiqued a recurrent inclination to subsume the study of zines to a subcultural approach that hinges on reading subcultural politics from particular aesthetic forms. Atton flips this approach, advocating instead for studies of zines that attend to the critical and discursive work that zine writers do to "construct" disparate music genres (p. 522). This is because "the fanzine has a central position in establishing and developing discourses about listening ... [it is] where arguments about music are assayed, and where fans organize their musical experiences" (Atton, 2010, p. 523, my emphasis). This chapter's examination of zines, which is focused on a closer reading of Small Talk and The House of Targ Zine, departs from Atton, teasing out the ways in which these two zines "construct" and re-organize the city's music scene.

Small Talk first emerged in winter 2013 as a zine created, written, and edited by Bruised Tongue Records co-founders Craig Proulx and Pierre Richardson (L. Marshall, Personal Communication). In its first three issues, the zine focused exclusively on the musical activities of bands and musicians affiliated with the label. It was formatted as a 
"single-sheet" zine (i.e. one single page, unfolded, and printed on both sides) that was printed in smaller numbers and distributed largely through the network of venues in which Bruised Tongue-affiliated bands performed. Its inaugural issue featured on its front page reviews of two albums released by the label - Boyhood's When I'm Hungry and Grime Kings' First View of the New. These reviews were accompanied, on the front page, by a transcription of a conversation between two musicians signed to the label, members of the band Bondar and Boyhood's lead singer and songwriter Caylie Runciman. The back page, meanwhile, featured an assortment of photographs of bands affiliated with the label and a half-page of Show Listings for musicians affiliated with the label (Proulx \& Richardson, 2013a). The zine's second issue followed a similar format, again featuring a front page comprised of reviews of two albums released by the label the New Swears' Funny Isn't Real and The Yips self-titled EP - alongside an interview with the New Swears conducted by the label's co-owners, and a list of upcoming releases. The back page of the zine featured, once again, show listings of bands signed to the label and photographs of different musicians signed to the label (Proulx \& Richardson, 2013b).

Stephen Duncombe (1997/2008) highlights a cartographic tendency in music zines, in which zine writers map out and bind together the disparate spaces and places that comprise a particular scene (pp. 60-65). Small Talk's promotion of forthcoming album releases and live shows, its critical evaluation of live shows and recordings, and its documentation of scenic activity through interviews and photographs of different live shows are evidence of such mapping of scenic activity, albeit through a narrower focus on Bruised Tongue-related bands and venues. This works to re-locate the city's scene 
through this particular cross-section of bands and the venues through which bands signed to this label perform.

Starting with its fourth issue - which saw local musician and video director Lesley Marshall take over the editorial task formerly held by Proulx and Richardson - the zine shifted away from a single-sheet iteration that focused more exclusively on musical activities affiliated with the label, to an edited, submissions-oriented, multi-page zine covering a wider range of the city's scenic activity. In this expanded iteration, Small Talk began to not only feature a cover image of original artwork designed by Ottawa-based artists and designers (L. Marshall, Personal Communication, December 2, 2014), but also began accepting submissions from local writers, artists, illustrators, and graphic designers.

Stephen Duncombe (1997/2008) argues that zines are notable for eschewing the sort of demographic-oriented formatting of content privileged by "mainstream" magazines, in favour of a more idiosyncratic assortment of content (pp. 12-13). This sort of editorial style is also evident in Small Talk, which featured stories of a more political nature - ranging from Mugoli S' (2015) exploration of the vandalism of a \#BlackLivesMatter mural in Ottawa, to Daryl Andrew Reid's (2015) examination and criticism of the white, cis-male privilege evident in Ottawa's punk scene, which works to erect barriers of access to this particular subculture. There is also more idiosyncratic and humorous fare too, including a detailed recounting of lining up and meeting the popular science theorist Neil Degrasse Tyson (Le, 2015), computer-generated epic poetry (Drystek, 2014), and erotic fan fiction about Montreal-based indie rock musician Mac Demarco (Why, 2014a). 
Small Talk privileges providing content written and designed by people from Ottawa; it also features advertisements from local businesses to offset and cover costs of production (Marshall, Personal Communication). The zine also produces depictions of the city's indie music scene, which works to not only present it as a more intimate and proximate scene, but also highlights broader stylistic and generic styles of indie within local musicians. We can see these tendencies when turning to reviews of live shows. For instance, Alanna Why's (2014b) review of the XXXMas show at Pressed (which took place December $21^{\text {st }}, 2013$ ) possesses a more intimate quality, mentioning members of the performing band by first name, listing the venue in the opening sentences, and spending the first two paragraphs of this five paragraph review describing the start of the show - that is, how members of the band made it to the stage to begin the show, including a bass player unwrapping his bass, as if it were a gift. In an episodic manner, the review hones in on details of the show, such as select instances of stage banter, the tossing of beer amongst band members, and song lyrics from songs sung that night. This is a detailed, slice-of-performance review that resonates with J.A. Vance's (2014) review of a show from Strange Attractor, WTCHS, and Scattered Clouds, which took place at Gabba Hey! Vance's review is similarly episodic and even more poetically impressionistic in its attempt to tease out intersecting experiences and sonic elements of the show; as Vance writes:

SCATTERED CLOUDS rattle ribs with bowed, electric double bass. Space-echo call and answer, sheets of noise, and great songs. WTCHS. Centre-stage. Eyes closed. Gales of feedback and ritual drums. Distant melodies. This band will trick you into thinking you took a hit of LAD . . . next level stuff. Take a break, have a beer. STRANGE ATTRACTOR turns the crowd into tornadoes. Garage-punk gunshots, rock and rollers falling everywhere. Hands from all sides grabbing them up again. Good people. We all smile. (p. 2) 
These reviews focus on the more immediate elements of the live show, largely framed through the personal recollections of the reviewer. Connection and proximity are particularly foregrounded by Vance, who writes of the "hands" of "good people" picking up fallen performers. This more subjective and personal approach to reviewing also inflects Alanna Why's (2014c) review of the Ottawa Explosion Weekend, 2014, which takes the form of a nearly two page comic and provides a highly personal take on the weekend. It includes panels that describe when she leaves the festival because she is "burnt out," when a particular show has air conditioning, shows that prompt particular emotional responses, and descriptions of when particular musicians appear in the crowd. Live show reviews tend to foreground intimacy and personal experience; in band and album reviews, musical references are mobilized to situate (and indeed, re-place) that local musician within the indie rock canon. For example, in Lesley Marshall's (2014) write-up of the Ottawa-based band Babereham Lincoln, she begins by describing the band as a blend of "new grunge" and "show gaze" (a seeming twist on the notably antistar shoegaze genre that foregrounds showmanship) before invoking the following references: "J. Mascis will be getting jelly and Dave Grohl better watch his fills, because Baberaham Lincoln's 'severe love of music and Kathleen Hanna' have driven them to record this single and hopefully out to play a show for us soon" (p. 2). Matthew Blenkarn's (2014) review of Bondar's Caustic album describes the album with reference to genres and musicians; as he writes:

Two EPs in, Roberta Bondar have already fused nimble noise-rock with an experiment edge. Their latest, Caustic, grinds alt-rock and shoegaze into a sludgy pulp. "Children" opens with a string section that makes Bernard Hermann sound as serene as Brian Eno and features a repeated, mantra-like chorus. (n.p.) 
Penny Clark's (2015) review of Bonnie Doon's album An Affair to Imagine takes a similar approach, highlighting the band's Ottawa-based lyrical focus and group vocal style, which she describes as "... some kind of insane Monster Mash/Bikini Kill/Frankenstein monster" (n.p.). Meanwhile, Joshua Robinson's (2015) review of the Yips' album Air Loom takes a more impressionistic, almost poetic form, attempting to capture the energy of the band's sound; as he writes of the band:

Sound waves buried with garage spirits that once stood so still now force their way through the parapets that keep their potential energy at bay. Air Loom is a staggering edifice of sound; a source of the waves that emanates from the eye of the storm, intorting [sic] its breath to the point of becoming the heavy dissonance that turns calm to clamour; 'yeah yeah yeahs' that reverberate across the northernly compass. (n.p., emphasis in original)

The review grasps at the heavier sound of the group; the album's higher production value; the group's use of reverb; and sonic resonances with the popular group Yeah Yeah Yeahs, while also highlighting the group's Canadianness (with reference to the "northernly compass"). All these reviews re-place Ottawa's indie music scene via references to established indie rock bands; a common feature of music reviewing that works, in this respect, to re-locate indie music style within the city's limits.

Small Talk both covers and emerges from the city's indie music scene, providing a detailed level of coverage not typically found in other, Ottawa-based media. This is because as Marshall (Personal Communication, December 2, 2014) explains: "We find that our [Ottawa] events are not covered by national media, our events are not publicized in publications like Exclaim!, we're pretty much ignored.” The zine corrects such absence, providing readers with both a list of places to go in the city, as well as critical coverage of the city's indie music scene. This provides zine readers with a means to navigate through the sounds and places that constitute the city's indie music scene. 
Another zine that has closer affiliation with a particular institution is The House of Targ Zine, which is a monthly zine produced by and distributed in the music venue of the same name. House of Targ is a music venue started by local record producer Paul "Yogi" Granger, who has also produced a number of seminal punk albums recorded and released by punk musicians located in Ottawa (including Big Dick, White Wires, and Steve Adamyk Band). While it has become one of the central places for local musicians to play in the city, it is also a mixed-use venue, featuring vintage and refurbished pinball and arcade machines and a menu primarily comprised of pierogis (Vicente, 2014, pp. 3740). The zine, in a manner similar to those earlier issues of Small Talk examined above, contains a number of features that focus specifically on the venue, including: a pierogis menu; a show calendar entitled Perogram featuring musicians that will play the venue (with a short description of the music); a House of Targ monthly pin-up/foldout featuring a photograph of either a musician that has come through the venue in the previous month, or a player that has attained high scores on one of the machines; and different, regular features from staff working at the venue, ranging from the comic Toys $R$ Josh (a photo/comic spread featuring vintage toys collected by a staff member) to the monthly list/feature Ska-Jeff's Top Five. The zine also has advertisements from local businesses and craft brewers. In contrast to highlighting the range of musical activity in the city - as later issues of Small Talk do - it possesses a more insular focus, writing about activities happening within House of Targ and different issues related to vintage arcade and pinball gaming. ${ }^{3}$ Thus, the zine works as a promotional item that lists menu items and upcoming

\footnotetext{
${ }^{3}$ Refer to House of Targ's (N/A) January 2016 and January 2015 is sues to see the recurrent format this zine follows.
} 
shows. It also works as a collectible artefact of the venue, providing visitors with an item they can bring home with them, and as a creative platform for those working at House of Targ to write about gaming and local music cultures.

I have argued both zines generate representations of the city's scene that work in a more navigational matter. Yet, to what degree can we trace out the very localness in the zine's form? Alison Piepmeier (2008) argues that zines create forms of "embodied community" between writers and readers. She traces this out in three ways: first, the very tactile quality of the zine, which she identifies as bonding reader and writer through the sense of touch, in that both the reader and writer of a zine have actually touched a particular zine issue; second, the tendency for zines to be "gifted," rather than sold; and third, the semblance of shared "care" and affection that emerges between reader and writer over their shared interest in the often personal, diary-like narratives advanced in zines (pp. 229-235). These qualities of touch, gifting, and shared concern produce forms of "embodied community" between zine writers and readers.

In terms of the tactile handling of zines, though these zines are largely the product of photocopying - thus eliding some of the more decorative and tactile qualities of hand assembly identified by Piepmeier, such as the use of glue, glitter, and other sorts of adornments - there is nonetheless the handling of zines, as they are fed through photocopier machines and/or printers, hand-distributed to different retail sites, and read by the reader. For instance, Small Talk is printed in editions of 800 to 1000 copies, with the assistance of a risograph photocopier located at Saw Gallery, and is distributed throughout the city in such venues as: coffee shops, music venues, pubs, restaurants, and retail shops (L. Marshall, Personal Communication, December 2, 2014). House of Targ 
Zine is also produced and distributed in the city, though its circulation is largely limited to this particular venue. Both zines can also be considered "gifts," for they are distributed free of charge to readers. To cover costs of production, both zines feature advertisements from different local businesses. The shared concern that binds together reader and writer is that of musical and cultural activity in the city: though this particular inclination does not fit with the more personal and diary-like narratives examined by Piepmeier in her cross-section of feminist zines, both Small Talk and House of Targ Zine demonstrate a more specialized and insular focus on punk and indie aligned cultural activities in the city. Another facet that contributes to the sorts of "embodied community" created between zine reader and writer - not directly engaged by Piepmeier - can be traced out in the ephemerality generated through the monthly turnover of these zine issues. Both Small Talk and House of Targ Zine are released at a monthly tempo, and any issues that have not already been picked up at the end of the month are pulled off of shelves by the zine's network of volunteer distributors. Taken alongside the enumeration of issues, the turnover of zine issues creates a certain degree of scarcity and collectability involving the ability to actually procure an issue before that issue has been picked up.

Piepmeier (2008) articulates her reading of materiality and zines by drawing out differences between zines and digital media culture (and in particular, the use of blogs). She argues that blogs are less personal, and oriented more towards enabling creativity through the provision of formats and templates (p. 221). Though she would seem to set out an antagonistic relationship between blogs and zines, both of the zines examined above have integrated a number of social and digital media into their activities. Small Talk has a website (housed at www.small-talk.ca) that provides potential contributors 
with a number of different avenues to contact and submit content to its editorial and writing team. It accepts contributions through the zine's Gmail account; it also has a version of its Listings that are hosted on (and available for editing through) Google Docs. The website also hosts scanned versions of the zine, though they are embedded in a "flipthrough" and non-downloadable manner. Small Talk also has a Facebook account, which it uses to both promote the release of upcoming issues and procure content submissions.

House of Targ, meanwhile, has a more diverse media profile, using both Facebook and Twitter to post updates about game nights, menus, and shows that either have happened or will be happening. In particular, it possesses a prolific Twitter account, with a higher number of followers and an almost equal number of profiles that it follows. Its posts fully embrace both retweeting tweets from other users that post favourably about the venue, and incorporating (and tagging) other users' handles. House of Targ also possesses a website with pictures of the venue, a list of game machines, another copy of the pierogis menu, and links to PDFs of the zine that are available to download from the website.

Taken together, these zines work to represent and locate the city's scenic activity. These logics resonate with Atton's (2010) arguments concerning the limits of examining "resistance" in zine analysis in his examination of the way zines shape particular genre conventions. The zines examined in this chapter demonstrate how these zines not only promote particular local businesses and music institutions, but also provide readers a resource with which to navigate the pockets of scenic activity featured in these zines. By re-locating the musical, semiotic, and experiential over-abundance of a scene (Shank, 1994; Straw, 2004) within particular networks of venues, musicians, and scenic activity, 
these zines also work to locate particular pockets of musical activity (and indeed, more indie-oriented musical fare) and filter out others (such as the city's jazz, hip hop, and blues scenes). Both zines also work to locate the city's musical activities within the downtown core, emphasizing the smaller cluster of venues primarily located in the Centretown and Lowertown neighbourhoods.

\subsection{Blogs: Resource/Document/Critique}

Blogs provide another means to generate coverage of the city's independent music scene. Ottawa Showbox is devoted to covering independent music based in Ottawa. It was started by local music fan Matías Muñoz in 2012 and now features a slate of five writers. The blog aims to provide a "comprehensive resource for Ottawa's independent music scene ..." (Ottawa Showbox, n.d.) and features a wider range of subjects pertaining to Ottawa-based indie music, including: reviews of albums and live shows (including photography of live shows); listings of upcoming shows; links to newly released music videos and albums; and interviews with different Ottawa-based musicians and musical professionals (including musicians, recording engineers, producers, promoters, etc.).

Ottawa Showbox covers a wide range of musical genres. These range from the blog's "Metal Thursday" feature (which interviews with heavy metal musicians either coming from, or passing through, the city), to its coverage of the city's independent hip hop and country scenes. Thus, the diversity and density of this city's music scene becomes content for the blog; the blog in turn provides a means to navigate through the scene. As a "resource," the blog also provides information about the city's music scene, ranging from a list of the city's "best” music venues (Muñoz, 2014a), to articles that 
aggregate pertinent information for local musicians applying for funding (Muñoz, 2014b).

Don McLeese (2010) has argued that the internet has had ambiguous impacts on music criticism. On the one hand, he identifies the increasing ease with which writers can interact with readers: “. . contemporary music journalists have considerably more tools at their disposal that allow them to link to the music and the performance of it (rather than merely describe and evaluate it) and interact with their readers in an ongoing dialogue" (p. 436). He suggests, furthermore, that it is easier than ever to see one's name in "print" with the abundance of online publishing platforms (p. 436). On the other hand, he argues that it is increasingly difficult to get paid for writing about music, whether one is a blogger or published music journalist, due to the diminishing advertising dollars available to music-oriented publications, both online and off (p. 436). This shows that contemporary music critics are working between two industries (music and journalism) that are both in the midst of massive transformation due to the various upheavals spurred by digital platforms and shifting consumer habits. Though he highlights disruptiveness, he suggests that finding success in this new media economy will demand a certain degree of self-promotional acumen and entrepreneurial zeal for the music critic, whose prestige will emerge from what they write, not where they write (p. 446).

McLeese highlights increasingly blurring boundaries between reader and writer in digital music criticism, as well as the upheavals in existent commercial models for music criticism that demands further degrees of entrepreneurial experimentation on the behalf of critics. Ottawa Showbox demonstrates this tendency towards boundary blurring, with fans becoming bloggers and sharing enthusiasm for their musical passions for the music 
scene. In regards to cultivating the critic's identity, Ottawa Showbox has also begun

moving into show promotion, extending the blog's brand and name from online to offline spaces of the scene. Ottawa Showbox is, thus, not only generating coverage of the city's scene, but also creating and showcasing musical activity within the places and sounds that it covers and critiques.

As a resource, the blog takes a primarily local focus; when national and international musicians are interviewed, coverage is anchored to that musician performing in the city. The blog's local focus also emerges in terms of advertising that is posted to the page, which largely takes the shape of advertisements posted on the banner and sides of the page. These advertisements are largely from local businesses - as with Small Talk and The House of Targ Zine - because, as the blog explains to potential advertisers:

We're on the lookout for building ad partnerships with Ottawa-Gatineau area organizations that our readers would be interested in. Ottawa Showbox has a dedicated reader base that are engaged with our content, one that is growing every month. One of our main goals is to continue growing our readership and get more of the general public involved in Ottawa's music community. A by-product of this is the opportunity to display your ad to a niche, hyper-local audience of people who love music, the arts, concerts, and more. (Ottawa Showbox, n.d.).

This call for advertising reveals much about how the blog understands itself and its audience. It highlights readership growth, a committed readership that is attuned to the blog, and the possibility of heightened degrees of involvement from this "hyper-local audience." Readers typically use music blogs to both learn about new music, as well as discover what sorts of musical acts are currently garnering and generating "buzz" (O'Donnell and McLung, 2008, pp. 80-81). In other words, the pursuit of new and "hip" music can be motivating factors for music blog readers; these sorts of tendencies are also 
evident in Ottawa Showbox, albeit this blog generates "buzz" about musicians and bands circulating through the city of Ottawa.

Standard Criteria (www.standardcriteria.ca) is another blog created by a large cross-section of volunteer writers. Departing from the sort of celebration and coverage of new music evident in Ottawa Showbox, Standard Criteria is spearheaded by Layla Brown, who is also a member of the feminist promotional and advocacy collective Babely Shades. The blog features a number of different writers writing about aboriginal, gender, sexuality, and race issues circulating through Ottawa, which often (but do not always) intersect directly with the field of independent music. For instance, in 2015 the blog published an article in response to the Ottawa-based radio station Hot 89.9's promotion "The New Normal," which is a competition that awards the successful applicant with $\$ 40,000$ that can be used for their gender transition surgery (Reid, 2015). The author critiques this particular campaign for its normalizing, condescending, and medicalizing discursive framing of trans bodies, honing in on the application requirements and protocols that demanded a doctor's note, employment status, the applicant's birth name and gender, and disclosure of any sexually transmitted diseases that may have been contracted. She writes:

See, I had this stupid naive idea that you would have us just write and explain our lives, like, write honestly about why we could use forty G's. But no, you want medical data, diagnosis and our dead names. You want to know if I'm married or have kids, whether a medical professional thinks I'm Trans enough for hormones. You want to know if I've contracted CAMH. You don't care about my life and my struggles, you want to know if I am really trans or one of those fakers who are only in it for the money. (para. 7)

Meanwhile, Amy Volume's (2014) blog post detailing the disparate hurdles and troubles she has encountered using her wheelchair in Ottawa's public spaces (such as trying to 
watch a parade) provides a troublesome recounting of the myriad of hurdles in accessibility to different public places and spaces in Ottawa.

Stories relating to Ottawa's music scene thread through this broader focus on the inequalities and hurdles to accessibility facing those participants in the music scene who are not white, able-bodied, and cis-male. Elsa Mirzaei's (2015) essay on DIY in the city's scene unpacks the disparate factors that hinder the supposed accessibility of Ottawa's "DIY scene," including its visible but denied racism and sexism, which works to exclude trans-, females, and non-white participants. Mirzaei writes:

It reminds me that people of colour and other marginalizations aren't friends with the people who are putting mixtapes together, who are booking bands, who are taking photos and blogging about artists. Not only are marginalized people dealing with no visibility, they're also dealing with being poorer than the average single income late twenties part-time musician and not having the "in" to affordable spaces. They're dealing with not having access to people who will lend you recording equipment. They're dealing with social exclusion that stops them from being able to network for their own visibility.

Meanwhile, Mackenzie Smedmor (2016) writes about the age-ism evident in Ottawa's live music, highlighting the increasing need for there to be a larger number of venues open to programming all-ages shows. The website has also posted a link to a recording of an afternoon panel entitled "One Girl, Five Babes: An Interactive Panel," which took place in summer 2015 at Pressed Café and featured a wider-ranging panel discussion on "gender and racism in local music" (Listen, 2015). This blog works in a more critical manner, exposing and unpacking the power relations and inequalities that are presented as both underpinning and circulating through Ottawa's indie music scene. The fit of this blog within the broader advocacy and promotional work pursued by Babely Shades also signals both the re-location and residues of battling sexism in the field of independent music; a struggle that was also illuminated and problematized in the Riot Grrrl musical 
and media movement during the early 1990s (Marcus, 2010; Dunn and Farnsworth,

2012). It re-places and underlines these broader social issues in the city's music scene. In her work on blogging, Jodi Dean (2010) differentiates between mass and networked forms of mediated communication, arguing:

... if mass media addressed society directly, organizing and speaking to masses as collectives, contemporary networked communications have multiple addressees, addressees known and unknown, friends and strangers. Bloggers may write for others whom they imagine share their interests, a group of the uninformed they might enlighten, or future versions of themselves .... Blogs and social networks do not provide broadly shared symbolic identities from which we see ourselves. Blogs don't address society writ large. They invite singular readers to consider what they have on offer. (pp. 72-73)

What is striking, though, about this "invitational" quality of blogs, oriented to "singular readers," is the persistence of a sort of fragmented networked reading public. The blog format is imbricated with the local and independent media that both emerge from, and produce representations about, the city's scenic activity. These media may not reach too far outside of an insular cluster of participants.

Taken together, both blogs provide a critical platform for a disparate number of writers to post, in a public and largely accessible fashion, writings about Ottawa-based independent music. While the focuses evident in the writings of Ottawa Showbox and Standard Criteria differ, they both open up the layers of Ottawa's music scene. Ottawa Showbox highlights events, provides show reviews, features interviews with different Ottawa-based musicians, and covers different professionalization initiatives that may be of value for aspiring musicians. It also offers musicians a chance to submit music for consideration on the website, thus providing a largely accessible platform for critical coverage. Standard Criteria, meanwhile, provides a platform for writers to speak out against the various -isms and -phobias (transphobia, racism, sexism, age-ism, and 
ableism) that intersect the city's music scene and draw up barriers to the sorts of accessibility both promised and denied within the city's DIY and independent culture. Both blogs work to locate readers, whether in the buzz and business of indie music, or the social inequalities and unequal power relations distributed through the scene.

\subsection{Music Video: Representing the City}

The music video is another scene-bound media site that is both created by scene participants and generates representations of the city's musical activities. The music videos produced for independent Ottawa musicians tend to feature representations of the city. They also share an inclination towards experimental aesthetics that foreground the music video production process, thus providing suggestive visual and aesthetic parallels to the musical practices of DIY and lo-fi, work to promote (and generate revenues for) musicians, and fit within the creative profiles of select scene participants. They not only promote and disseminate indie Ottawa music, but also emerge from and stylize the local music scene.

Though it would be impossible to provide an all-encompassing overview of the aesthetics and themes shared by these videos, two particular recurrences stand out: an emphasis on Ottawa in the mise en scène of these music videos, and the privileging of experimental aesthetics that foreground the formal qualities of the music video. There are a number of music videos produced about indie musicians that emphasize the spaces, places, and people in Ottawa. Big Dick's 2013 video Colours (directed by Lesley Marshall) intersperses footage of the duo performing the song (both outside in the winter, as well as inside a larger and empty performance space) with footage of the Ottawa-based independent wrestling company C4 (Capital City Championship Combat) Wrestling, 
which takes place in the Vanier neighbourhood of Ottawa. Threading these two narratives together is a myriad of quick cuts to (and shots of) various parts of Ottawa's Centretown area, including: public murals, the interiors and exteriors of different businesses; and the city's OC Transpo buses.

The Acorn's 2015 music video Influence - directed by Travis Boisvenue, co-host of the campus/community radio show City Slang - also focuses on Ottawa, albeit providing a more "slice-of-life" depiction of the Ottawa-based artist Marisa Gallemit. As The Acorn frontman Rolf Klausener describes the video to the music blog Line of Best Fit (which received the exclusive premiere of the video):

The camera follows Gallemit through a day in downtown Ottawa in a series of vignettes: working quietly at her craft, intimate moments with her son, quality time with close friends, and a long night of work at Ottawa's infamous arts pub, The Manx. A few locals make appearances including me, housepunk band Silkken Laumann, photographer Remi Theriault, and others. (Bell, 2015, para. 4).

The dance-punk group SILKKEN's 2013 music video House of Common Problems (codirected by SILKKEN and Acorn member Rolf Klausener and artist Rémi Théirault) is set in three Ottawa-based shops (which are listed in the opening credits to the video): the café and performance venue Raw Sugar, the restaurant Oz Café, and the independent clothing retailer Victoire and juxtaposes shots of a dance party erupting in these everyday environs, with footage of the band performing the song. Bondar's 2013 music video Night Dangers is filmed (and set) in the Kichesippi Brewery, a local, Ottawa-based craft brewery located in the west end of the city (Boisvenue, 2013). The foregrounding of the city in these music videos could have a number of explanations, including regional pride, or a filmmaking necessity for directors working in a city that lacks the formal infrastructure for film and television recording (such as sets, actors, etc.) that larger cities 
like Toronto and Vancouver have. Whether the result of pride or necessity, Ottawa-based indie music videos are nonetheless located in the places and people embedded in the scene.

While these videos emphasise Ottawa's places and people, there is also a suggestive tendency to produce formally experimental videos. Bondar's video for Night Danger (Boisvenue, 2013) provides a suggestive visual extension of the band's lo-fi and live sound. As the music video's director Travis Boisvenue describes it:

The song was recorded live off the floor in the Kichesippi brewery and later mixed. The video was shot in one take, with all effects in-camera. Extra cameras were set up around the room to monitor the band, the video was then fed into televisions. The video you see on the televisions was manipulated live in the space via modular synthesizer. Every element needed to make the video (including personnel and equipment) is visible in the video. (Boisvenue, 2013).

The music video's imagery is grainy, featuring warped lines on the screen typical of stretched VHS tapes; at the same time, the modulation of digital video signal through the use of a synthesizer also produces a range of colours that overlay the image of the musicians, ranging from cooler grey colours, to a blend of brighter oranges and purples (Figure 2, below).

While the video is shot in one take, it features numerous cuts between cameras. There are closer shots of individual musicians in the band, medium-shots of the band performing together (though these are often blurred, out of focus, or even shot upside down), and sporadic shots of the personnel involved in the production of the video, such as the individual working the soundboard and the player of the modular synthesizer that is manipulating footage he is shown to be watching on a screen. The video is a highly unstable one; at one point, the video cuts to a shot of a musician that is then shown to 
actually be a cut to a video monitor when the camera pans out to capture the edges of the television screen in the camera's frame.

\section{Figure 2. Video Still from Bondar's "Night Dangers"}

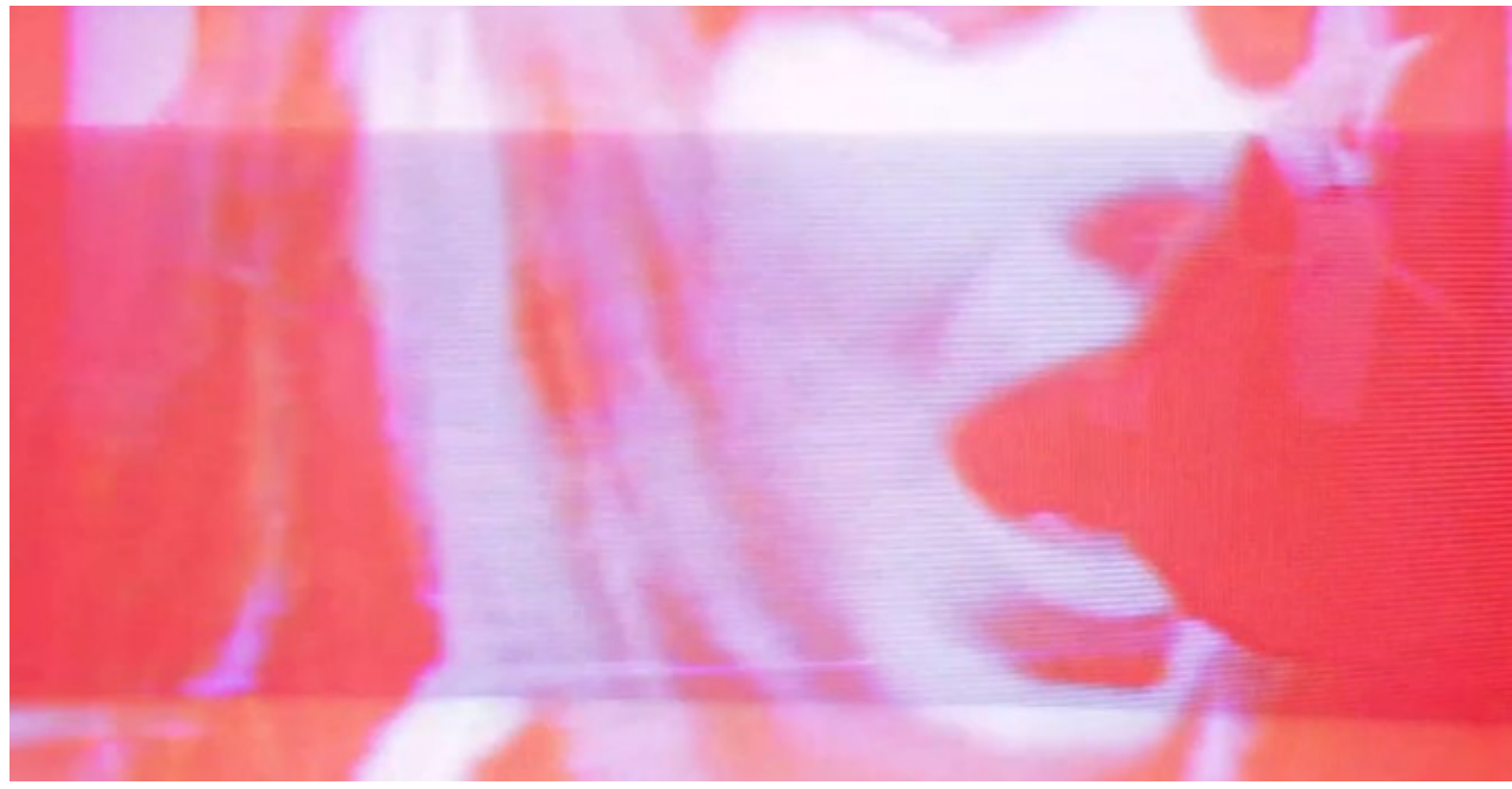

Though these elements fit with the sorts of "postmodern" experimentation associated with music videos since the advent of MTV in the $1980 \mathrm{~s},{ }^{4}$ they also suggest a visual synthesis and stylization of DIY. That is, they foreground and demystify the music production process in the final, recorded sound (Hibbett, 2005, pp. 61-62). Examples of such practices of foregrounding the construction of the song might include: leaving the sound of hitting a four-track recorder's record button to either begin or finish recording a song in the final sound mix; the scraping of fingers and picks against guitar strings; the sound of the tape recording running out before the song ends; and even including the sounds of off-time and off-tune drums or bass notes. These sonic elements are stylized

\footnotetext{
${ }^{4}$ See, especially, Will Straw's (1993) essay on music video for a summary of and challenge to this postmodern thesis.
} 
and work to highlight the production process by including the elements usually left on the cutting floor. This sort of demystification finds its visual parallel in the music video, with its shots of the very production process and use of "real-time" modulation of digital signal through analogue synth (rather than post-production tinkering with the image). One can see in the video both capture and instantiation of the liveness recorded in the moment, encoded in the grain of the digital image, manipulated by (and through) a modular synth.

Another video that features this sort of formal experimentation with the video production process is found in the music video directed by Lesley Marshall (2015) for the Big Dick song Give Up. This video features an unnamed female protagonist, sitting motionless on a couch in an apartment. A number of different people pass through the apartment, attempting to engage her in a variety of activities. Their activeness and her (relative) passivity/indifference is emphasized through Marshall's choice to speed up the image, which provides the image with an accelerated tempo. The female protagonist remains motionless, while those around her move in and out of the frame in an accelerated manner. As well, she is framed by a window behind her, on which random archival footage is projected (which was attained from the website www.archive.org [Marshall, 2015]). This not only underscores the sort of ennui advanced in the song's lyrics, but also reveals this as a highly staged performance of ennui. Both video directors have worked with the Saw Video Media Art Centre (http:/www.sawvideo.com/), which provides training to aspiring filmmakers, rents out equipment to directors, and screens and displays these music videos alongside other video art. This particular filmmaking institution provides an important infrastructure for music video directors, providing 
training and equipment rentals, which reduces the costs of production and levels barriers to expertise. This enables a wider pool of locally-based directors to create smaller-scaled, low-budget, and experimental music videos about local indie musicians.

While this analysis of music videos has highlighted a few recurrent narrative and formal elements, music videos also have important promotional value for musicians. Music videos are typically linked to (and archived on) the video hosting website YouTube (www.youtube.com), though Vimeo (www.vimeo.com) has also emerged as a music video hosting platform for musicians and directors. In contrast to YouTube, the latter platform offers higher resolution, high definition videos, no advertising, and allows riskier content. The music videos for independent musicians largely circulate online and they are useful for prompting coverage of Ottawa-based musicians by a number of different music blogs and websites, as well as providing new content for fans to share through their blogs and social media networks. Though the place of music videos has changed since the 1980s, they continue to fulfill online what Will Straw (1993) has identified as one of their key roles: ". . . the institution of the single-song as the crucial factor in the marketing of an album" (p. 9). For instance, The Acorn's release of the music video Dominion (Marshall, 2015) off of the album Vieux Loup in September 2015 coincided with the announcement of the band's fall tour schedule. Exclaim! writer Sarah Murphy (2015) paired a description of the new album, touring band members, and regions hit on tour with the following description of the music video:

In addition to the tour dates, the Acorn have shared a new video for Vieux Loup cut "Dominion," which features vocals by Boyhood. It contrasts shots of wildflowers and water with more industrial elements of the landscape like buildings and chain-link fences, all brought together with some artistic splitscreen effects. (para. 3) 
Ottawa Showbox too featured a news story about this video's release, which appeared two days prior to the Exclaim! story. In this write-up, mention is made as well of The Acorn's fall tour; unlike Exclaim's story, Muñoz (2015) includes an interview with the video's director Lesley Marshall, who explains what camera she used, where she got it from, and the aesthetic motivations of the video (paras. 3-4).

The promotion of musicians and albums, centring on the single song unit, is particularly amenable for marketing both music and musicians via social media. Musicians either post the song to their social media site of preference, or share a link to their social media profiles via the initial video as well as through subsequent news stories emerging from blogs, websites, etc. The social media account becomes a nexus of sorts, when the (re-)posts of the social media pages of different music blogs and websites redistribute initial postings on these platforms.

Writing about music videos in the 1980s, Will Straw (1993) concludes that this particular media format works, alongside the twelve-inch dance single and licensing songs to movie soundtracks, as "... part of a more general tendency towards the dismantling of the link between song, album, and performer-identity, a link of coherence which has been critical to the meaning of rock/pop music in the 1970s" (p. 9). The sort of "dismantling" identified by Straw is useful in digital media environments, whereby the music video now works as a conjunctive site that draws together disparate media sites (including social media sites, music video pages, and different music blogs). These videos provide both the content and subject of stories posted on music websites, they can work to further extend the promotional cycle of an album after its initial release, they become useful content for fans to share within their social media networks, and they can 
draw together the disparate elements that comprise a musician's expansive digital media personae/profile.

\section{6 "Talking Bullshit with Cool People:" City Slang Radio}

The final scene-bound media site this chapter examines is City Slang, a punkoriented radio show broadcast on the campus/community radio station CHUO 89.1 FM. The show is hosted and produced by Emmanuel Sayer (a local music promoter, cofounder of the Ottawa Explosion Festival, and program director of CHUO) and Travis Boisvenue (a music video director, freelance music writer, and graphic designer), and it specializes in broadcasting a wide range of punk, lo-fi, and garage rock music released on independent record labels. Like independent music, campus/community radio has an "other" to distinguish itself from: corporately owned and operated commercial radio stations. Richard Sutherland (2012) explains "the Canadian radio industry is also relatively concentrated, with the top five broadcast chains accounting for $67 \%$ of the revenue in this sector" (p. 45). It is standard practice, moreover, in the commercial radio industries to align particular musical genres to specific listening demographics (broken down along the lines of age, gender, and economic brackets) as a means to more accurately target advertisements through various formatting and narrowcasting strategies (Kruse, 2003, p. 71; Straw, 1990). Conversely, campus/community radio stations are independent, traceable to the fact that these stations are not only independently owned and operated (i.e. they are not affiliated with the larger, corporately owned and operated radio stations), but they also typically eschew such practices of formatting, instead enabling DJs to broadcast what they pick. This freedom is evident in, and actually emphasized across, the DJ banter on City Slang. For instance, in episode 75 co-host 
Emmanuel Sayer programmed a block of songs based around a number of albums that he purchased while travelling outside of Ottawa (Sayer and Boisvenue, 2015a). In a later episode, Sayer picked a set of lo-fi songs from the 1990s, framing it as emerging from a feeling of nostalgia spurred by the onset of winter (Sayer and Boisvenue, 2015b). These sorts of details provide a greater degree of personalization that both fits with, and emphasizes, the greater level of control over song selection that DJs working in campus/community radio have.

Yet, a number of scholars have questioned the concatenation of independence with free-form programming by highlighting the various restrictions posed to the actual degree of autonomy DJs possess, from commercial pressure from major record labels to program particular groups (Kruse, 2003, pp. 74-75), to the potentially heavy-handed controls that a station's Program Director may place on DJs (Waits, 2008). In Canada, programming on campus/community radio is regulated by the Canadian Radio-television \& Telecommunications Commission's (CRTC) licensing requirements, which demands these stations program local music that is different from commercial radio:

campus and community stations offer programming based on the needs and interests of a community through: maximum use of Canadian-produced programming; the broadcast of local and regional news and information; the broadcast and promotion of local cultural and artistic expression; the promotion of Canadian emerging talent with an emphasis on local musical and spoken word talent; and the broadcast of local and regional content related to social, economic and community issues. (CRTC, 2010)

Rather than inhibiting the programming of City Slang, however, the CRTC's programming requirements are actually conducive to realizing the interests of this show, which broadcasts a genre of music largely absent from commercial rock and alternative rock radio stations and appeals to local listeners interested in this particular genre. 
While the show is the product of both the regulations undergirding the licensing of non-commercial radio stations, as well as the city's music scene, locality is "produced" (Berland, 1990) through the show's airing of local advertisements, its highlighting of particular venues, places, and bands located in Ottawa in both guest interviews and DJ banter, and its broadcast of a narrower cross-section of punk and garage rock music that both emerges from and passes through the city of Ottawa, Ontario. Indeed, episodes typically begin with an interview with a punk-oriented musician that either has or will be performing in the city in the upcoming weeks. The interview is often quite casual in tone and recorded in a range of locations, from music clubs to on the street after shows, when musicians are packing up equipment. As Boisvenue (2014) explains: "City Slang is all about talking bullshit with cool people .... These are people that goofed off, talked shit on their friends, or drank too much while we interviewed them. So, perfect City Slang interviews." This interview segment typically comprises the first half hour of the show and is interspersed with a number of songs by that particular musician. The musicians featured are often (but not always) either from the city or passing through Ottawa on tour. Following the interview, which is often pre-taped and mixed to blend with songs programmed, the second half of the show features a mix of songs selected by the show's hosts. Each host takes a turn selecting these sets, introducing them and outlining the broader theme that connects these songs. These sets are open to change, however, depending on who else is in the studio: sometimes musical guests and interviewees are invited to pick a song or even a set of songs. This programming of both local and international punk locates the city's indie music scene within the broader national and international circulation of independent punk rock music (and its myriad subgenres). 
The show also emerges from the hosts' interests and involvement in the city's

music scene; an involvement emphasised by Sayer in an episode oriented to fundraising:

It is only on radio stations like ours that you'll hear interviews like this because most other radio stations, if during the interviewer's 9 to 5 job at the radio station the interview didn't go through, they would just cancel it and find another guest to book. Whereas, all of the hosts here at the station are involved in the community that their show covers, so we're going to be at that show anyways, we're going to see this band anyways, so we might as well shove a microphone in their face ... and see what happens. (Sayer and Boisvenue, 2015c, 31:30-32:00).

Taken together, the show emerges from the activities and musical tastes of two participants in the city's music scene and locates Ottawa within a wider punk sound by programming Ottawa-based musicians alongside a wider range of music. The show's emphasis on these particular indie music genres that circulate through the region - but are not specific to it - has facilitated the show's rebroadcast through other campus/community radio stations in Canada, including: CFUV 101.9 FM in Victoria BC; CHMA 106.9 FM in Sackville NB; and Radio Laurier in Waterloo, ON (Sayer and Boisvenue, 2015c).

This particular campus/community radio show also has a robust digital media presence, possessing profile pages on the social networks Instagram and Twitter (but not Facebook). The show uses social media to post and promote upcoming episodes, upcoming shows in the city, and other news connected to the station and the show, such as new music videos directed by Boisvenue or bi-annual fundraising drives. Both social media accounts are future-oriented, promoting the show before it has aired. As well, the tweets issued by the show typically incorporate hashtags and user handles that then extend outwards into the featured/guest musicians' social media pages (particularly when that musician in turn retweets these posts). 
City Slang also has a website largely used for archival purposes. Because CHUO's website does not hold a long backlog of previously aired episodes, the show's hosts decided to make back episodes available, either through a podcast available to download from the Apple iTunes store, or as a MixCloud file available to stream through the website (E. Sayer, Personal Communication, January 15, 2015). Each episode of the show that has been recorded is not only uploaded to the website, but also features tags that facilitate the search and retrieval of previous episodes of the show. These archiving features render episodes accessible outside of the geographic and temporal limits of the over-the-air broadcast. It also provides a form of cross-media promotion, whereby the podcast promotes the radio station and the radio station promotes the podcast.

This form of cross-media production and promotion is also evident in the zine that has been produced by the show, which is also entitled City Slang. The zine features a few original interviews with bands that have been featured on City Slang; original artwork and design from local designers, the hosts, and musicians previously featured on the show; and photographs of live shows that have happened in the city. In particular, these photographs capture the urgency of the live show, featuring (in a style that can be rooted back to Charles Pederson's photography of Seattle's underground scene in the 1980s) images of Ottawa's music scene. These images focus on lively interactions between fans and musicians, with musicians framed from the front of the show. As evidenced in Figure 3 (below), the zine provides snapshots of the "orderly disorder" transpiring in the city's music scene..$^{5}$ Specifically, the image positions the band at the centre; the fans also appear

\footnotetext{
${ }^{5}$ A number of scholars have used the tension between order and disorder as a means to characterize rock music, including: Cohen (1991), Frith (1981, 1996), Laing (1985/2015), and Straw (1998a).
} 
in the shot, alongside the musicians. The image's processing in black and white highlights features of the singer and fans, while the darkness of the image also produces shadows that obscure both musicians and audiences. This more level depiction resonates with the narratives of autonomy and egalitarianism advanced in a wider cross-section of indie rock discourse (Arnold, 1993; Azerrad, 2001; Fonarow, 2006), whereby the band and fans are framed nearly equally in the shot. Yet insularity is also suggested, evident in the lack of detail about when and where this particular show happened (a tendency evident in the other live concert photos included in the zine). The implicit assumption seems to be that the reader of this zine was already there and is in the know about when and where this event happened.

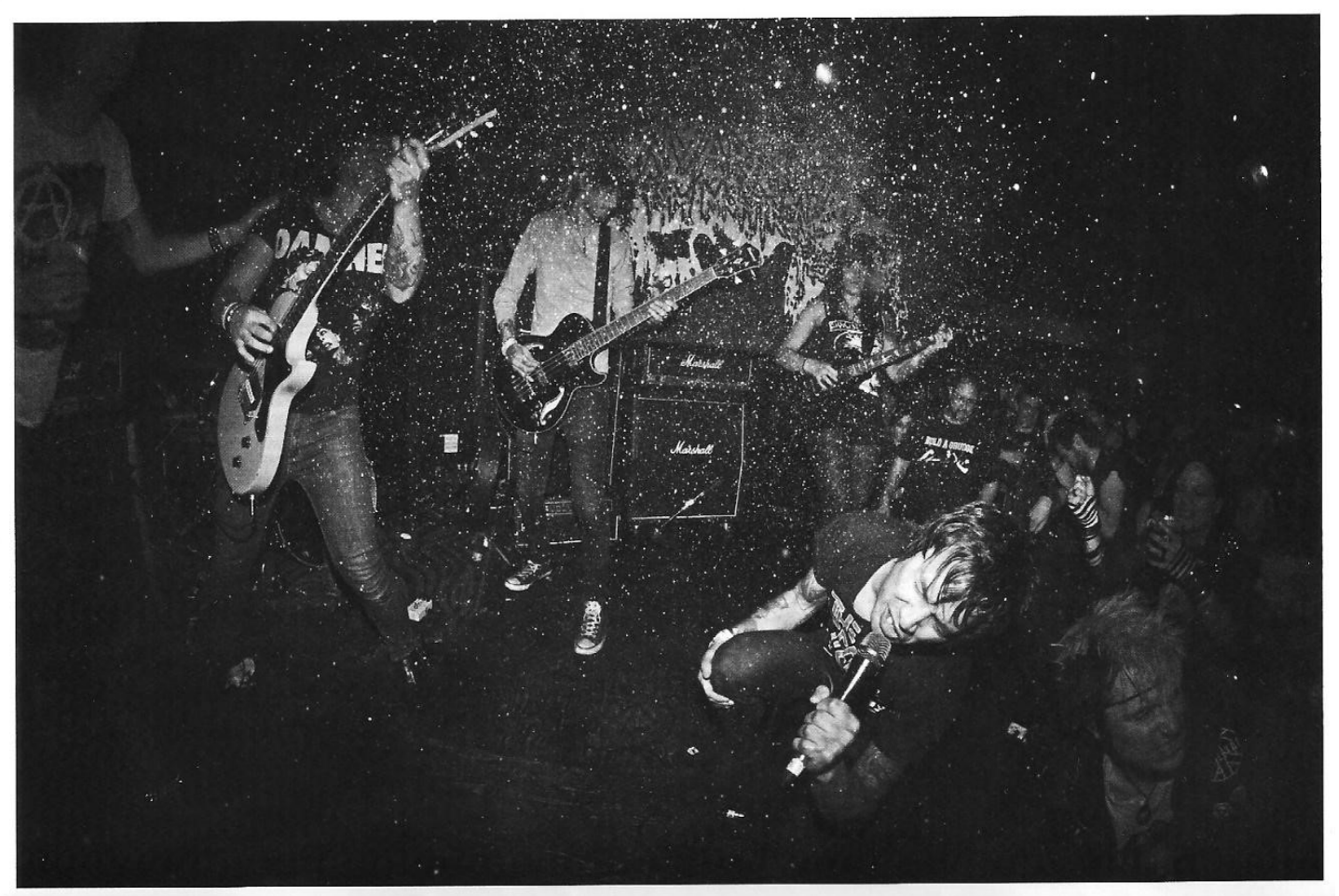

Figure 3. City Slang Zine (Photography by D.A. Reid) 
As with the zines examined above, the City Slang zine is self-distributed and printed in small number. Its ephemerality produces a collectable document of City Slang, these live shows, and more broadly, the scene in which the zine is entangled. During the zine's print run, it was regularly promoted both on the show and online (primarily through the show's Twitter and website). It was available both for purchase in the city (featured in the zine racks at Pressed and Gabba Hey!), as well as available at the cost of a donation to CHUO. The cost of the zine in this iteration - a promised donation - blends together the gifting and sharing economies that characterize zine distribution (Duncombe, 1997/2008; Piepmeier, 2008; Chidgey, 2009). Specifically with its mail distribution-inreturn-for-donation strategy, the zine works as an incentive that produces a collectible and tangible artefact the show. Fundraising is, moreover, one of the primary ways in which campus/community radio attains funds (Arnold, 1993; Barclay, Jack \& Schneider, 2001/2011), so the zine works as incentive to donate and support. Its ephemerality, traces of tactility, niche focus, and gifting (as incentive to donate) resonate, as well, with the forms of "embodied community" that emerge in the milieu of zines outlined above (Piepmeier, 2008).

Sayer suggested that City Slang's goal was to create a radio show that would also provide audiences with a "multimedia experience" (Sayer, Personal Communication, January 15,2015$)$. The show's multimedia design hinges, moreover, on the convergence of old and new media sites. Henry Jenkins (2006) defines convergence as involving “. . . the flow of content across multiple media platforms, the cooperation between multiple media industries, and the migratory behaviours of media audiences who will go almost anywhere in search of the kinds of entertainment experiences they want" (p. 2). While his 
work on convergence focuses on the ways in which amateur media producers are creatively appropriating and transforming intellectual property possessed by larger corporate entities (such as the Star Wars, Harry Potter, and The Matrix franchises), in this instance the independent infrastructure of campus/community radio station provides the means, training, and technology to produce the radio show. The independent infrastructure of the radio station converges, in turn, with a number of different media sites (MixCloud, Twitter, and Instagram). These sites not only rely on user-generated content, but also have varying degrees of corporate affiliations. These affiliations problematize the relationships of resistance set out by both representations of indie as resistant to corporate cultural industries, as well as Jenkins' depiction of convergence through the lens of clashes between corporate entities as IP owners and fans as disruptive remixers. In City Slang, there is a more everyday and promotion-oriented logic evident in the convergence of these different media sites, which produce multiple media pathways for listeners to follow and access the show. This sort of navigation is further encouraged through each media site promoting the other. For instance, the zine contains a link to the show's website on its opening page; the website features high-resolution images of the concert photography and design located in the zine, along with MixCloud files of the radio show; the podcast available through the Apple store features advertisements for CHUO and the zine; and the radio show mentions the zine, website, and podcasts available through the Apple store. This produces a promotional echo-chamber of sorts, whereby the message circulates through this distributed network of media sites that converge at the point of the City Slang radio show. The listener-as-cross media navigator works, in turn, to piece together these elements. For, as Jenkins (2006) further argues, 
"the circulation of media content - across different media systems, competing media economies, and national borders - depends heavily on consumers' active participation" (p. 3). Experiencing City Slang's form of multi-media radio entails cross-media navigation.

Taken together, City Slang emerges from the hosts' involvement in the city's independent music scene and hones in on select aspects of the city's scene, from the punk and garage rock music and musicians that circulate through the city to a narrower crosssection of featured venues (House of Targ and Gabba Hey!) and festivals (Ottawa Explosion Weekend). The show cuts through the wider range of musical activity that shapes the city's scene, thus filtering the overabundance of "noise" generated in the scene by focusing, in particular, on the punk and garage rock genres. At the same time, it also locates both listeners within Ottawa's indie scene, as well as the scene within the broader styles, sounds, and touring networks of international punk rock.

\subsection{Locating Scenes, Scene Locations}

The 2014 edition of the Arboretum Music Festival in Ottawa started with a panel entitled Why I Left Ottawa?, featuring the popular independent musician Kathleen Edwards; CHUO 89.1 FM program director and City Slang co-host Emmanuel Sayer; independent musician Olivier Fairfield; and professional photographer Rémi Thériault. While it was convened to focus on the challenges facing the creation and funding of art, music, and culture in Ottawa, across this wider-ranging conversation, participants began formulating the following characterization of Ottawa: it is a city with a vibrant yet largely underground arts and music culture that emerges through the largely collaborative efforts of a closely knit creative "community." The panel and audience came to agree that, in 
Ottawa, the problem is not so much that nothing ever happens in the city; instead, there is a lot of culture happening in the city, but the only people taking notice are the same group of scene participants. This insularity is both boon and hindrance, providing a close-knit feeling of community for those who are "inside" that scene, at the cost of setting up barriers of entry for those who circulate "outside" of the scene.

The scene-bound media examined in this chapter fit ambiguously in this problematic of insiders and outsiders. On the one hand, these media are produced by "insiders," emerging from the practices and passions of participants already involved in the city's music scene, including: musicians and record label owners (Small Talk); fans and show promoters (Ottawa Showbox); music venues (The House of Targ Zine); and local show promoters and video directors (City Slang). On the other hand, the overarching locative functions of these media, ranging from music videos, to show listings, to interviews, abound across these media, demonstrating the more navigational role these "way-finding" media possess (Straw, 2004, p. 413).

The indie music scene is both background and foreground, context and text; these media sites are embedded in scenic activity and produce representations of that activity. Zines, music video, and campus/community radio, which were central to the formation and circulation of indie music in the 1980s, persists (Arnold, 1993, 2014; Barclay, Jack, and Schneider, 2001/2011; Duncombe, 1997/2008; Kruse, 2003). Blogs are specific to this current moment, but the convergence of old and new across these examples, taken alongside the overarching focus on representing the city's music scene, tease out broader tendencies in these scene-bound media to locate the city's scenic activity. 
Pushing media into the foreground of this chapter's study of the city's indie music scene provides a through-line for the tension in scene studies between participant-hinging sociologies of experience and broader studies of institutional logics. Experience is foregrounded across these media sites, whether in framing song choices in a song set, highlighting directorial intent in music video production, communicating exclusions experienced, or reviewing a live show. Experience is not merely a sociological truth to be revealed, but also a recurrent stylistic and formal feature cutting across these media, which work to stylize the scene in more personal terms.

Yet, in terms of institutional logics that exert and influence processes of musical turnover, sedimentation, and stylization, we can see varying rhythms and effects. Social media and blogs produce a daily rhythm of promotion and coverage, communicating in the very frequency of these mediations a sense of "buzz" about the city's scenic activities. Websites and podcasts produce archives of the city's various pockets of scenic activity, storing such potentially ephemeral practices as live performances (with critical coverage and photography), past issues of zines, and terrestrial radio broadcasts. Yet there is a sense of turnover and ephemerality too, whether in the planned scarcity of zines that get pulled after a month of being in the city, or the terrestrial radio broadcasts that are limited to a certain time and place in the city. Social media tend to be used for futureoriented means, promoting upcoming zine issues, campus/community radio broadcasts, and music videos. Music videos are integrated in promotional cycles and provide a record of the city's musical activities. Thus, these media not only work to create "buzz" but also endow the local scene with subcultural memory: a dispersed, institution-contingent archive of past musical and scenic activity. 
Scenic locality is articulated in these media as proximate, inviting, and navigational. Yet while these media work to invite potential consumers, providing them with means and resources to navigate through the city, these media also work through exclusion. Specifically, these media primarily locate independent rock in the city centre, focusing on the smaller and denser cluster of music venues outlined at the opening of this chapter (4.2). In doing so, lesser attention is paid to music's circulation outside of the city centre, in the suburbs of, for instance, Barrhaven or Kanata. These media also hone in on independent rock music, thereby bracketing other music scenes in the city, such as jazz, experimental, blues, hip hop, and improvisational. This runs against the grain of live music's overlapping circulation through the city's music venues, whereby venues like Pressed, Ritual, and Raw Sugar program a wider range of music than the indie rock prioritized in these scene-bound media sites.

To conclude, keeping up with what is new, finding out where things are happening, and sifting through the archives are concurrently logics embedded in the artefactual nature of these media and participant experiences that undergird the repeating focus on locating the city's scenic activities. Both of these tendencies dovetail in this chapter's study of zines, blogs, music video, and campus/community radio. The next chapter further follows this organizational thread, looking at the ways in which local scenes work as metadata and tags that organize the listening experience articulated within two, indie-oriented digital music services. 


\section{CHAPTER 5. OUR MUSIC SERVICE COULD BE YOUR SCENE: SURVEYING THE "INDEXI-LOCAL"}

\subsection{Local Sound Maps}

In summer 2015, the popular music streaming service Spotify released a "musical map" that listed the most distinctive songs played in different cities across the world. Spotify's Insights blog described the distinctiveness and value of these musical maps, writing:

This is music that people in each city listen to quite a bit, which people in other cities also do not listen to very much. So it is, exactly, the music that makes them different from people everywhere else .... Because this music represents music that over-indexes in these cities, it's a great way to pluck local favorites from around the world and add the ones you like to Your Music in Spotify. (Buskirk, 2015, para. 4)

The musical map surveys the listening habits and practices of listeners situated in different cities, generating playlists for those cities. These musical maps also make two particular promises to the listener. First, to facilitate a sort of musical tourism through the world vis-à-vis the music streaming service. As much is indicated in the opening of this blog post, which contains the following depiction of the musical map's ability to reveal local distinctions amidst global listening habits:

In our connected world, people everywhere tend to enjoy the same top hits . . but when most travelers visit another place, they don't seek out the same food they eat at home, even if they can find it. We travel to experience what makes a place different, and special, by sampling local specialities. Let's try the same approach with music, on a big map of the world. You can click any of nearly a thousand cities to hear a playlist of the music that is most distinctively enjoyed there. (Buskirk, 2015, paras 1-3, my emphasis)

Second, and tied to this touristic application, Spotify also uses these different and localized listening tendencies as a means to generate recommendations for listeners. Though a quotidian feature of many different streaming services (Morris, 2015b; Morris 
and Powers, 2015), recommendations in this instance invite Spotify listeners to further engage with and explore this particular music streaming service. They are asked, perhaps, to step outside their genre interests and try to listen, instead, with geographic locations guiding the way.

A similar interest in guiding listeners through the disparate geographic regions from which music emerges is also evident in Bruce Pavitt's (2015) early 1980s zine Subterranean Pop. In each of the nine issues that comprised this zine, Pavitt guided readers through the Pacific Northwest independent rock scene, profiling such music cities as Vancouver, BC, Seattle, WA, and Portland, OR. In his zine, Pavitt would closely discuss different musical cities by highlighting and reviewing key bands, music venues, and labels. To a certain degree, his zine - which after a run of nine issues, then turned into a monthly column for the free Seattle-based newspaper The Rocket-worked as an important resource for independent music fans, providing interested readers with a resource to navigate through different music-making regions located in the Pacific Northwest.

Both Spotify's musical map and Subterranean Pop's scene-oriented coverage of independent music signpost this chapter's core concern: the place and reconfiguration of local music scenes in digital music services as metadata and tags that organize the listening experience. Closer attention is paid to two streaming services oriented to programming independent music: CBC Radio 3 and Bandcamp. Specifically, I am concerned with examining how local regions enable the navigation of these two services, particularly when they are deployed as metadata and tags that organize the circulation and retrieval of data contained in both services. Through a closer reading of the ways 
these two services integrate local regions into the design of their (respective) interfaces, I argue that these services produce the semblance of locality that both extends into, and resonates with, Canada's diverse network of local music scenes. Both services produce the semblance of locality that I dub the "indexi-local." This chapter considers how local scenes work to not only locate the listening experience articulated in these services, but also organize the search, retrieval, and playback of songs contained within these services.

\subsection{Defining the Indexi-local}

In his work on space's aesthetic and social production, Henri Lefebvre (1974/1991) surmises that there are innumerable spaces entangled within everyday social spaces that can be revealed through semiotic analys is. These include spaces that are unique to the realm of the information sciences; as he explains: "we know enough in this area [of information sciences] to suspect the existence of a space peculiar to information science, but not enough to describe that space, much less to claim close acquaintanceship with it" (86). Lefebvre's work suggestively redefines space, moving from a purview that treats space as an empty container to being socially produced. The indexi-local is argued to be such a space formulated through the re-articulation of local regions to metadata operations.

More precisely, to highlight the re-configuration of local scenes evident in these services, I draw together a range of scholarship with a closer reading of interface design. In particular, Andy Bennett's (2000) definition of locality as "a series of discourses, which involves ways of picturing the local and one's relation to it" (p. 63), provides a more fluid re-definition of the local which enables me to move from scenes to digital music services. Meanwhile, I draw on Jay David Bolter and Richard Grusin's (1999) 
work on remediation, which provides a useful set of analytical tools with which to examine the formal and aesthetic specificity of both services' mobilization of local regions in their design. This examination hinges on such features specific to new media as cross-media distribution, the incorporation and reshaping of old media within this service's design, and the attempt to produce an immediate experience within this new media(-ted) context (Bolter and Grusin 1999, 3-15). Finally, Brian Massumi's (2011) suggestive conceptualization of semblance as a means to map out the aesthetic and political potentiality of performance (or as he dubs it "occurrent") art (pp. 49-57) is drawn on, so as to think of participation in a local music scene as having experiential potential. Drawn together, these services produce both a "picture" and style of "relating" to the local music scene. They draw on and reconfigure - but do not disrupt - existent practices of connection situated in proximity and the cultivation of personal tastes, which have been identified in indie music scenes. In CBC Radio 3 and Bandcamp, the broader allure of interaction and participation is evident, resonating across (and drawing together) local music scenes, user interactions with digital music services (oriented, at times, to broadcast, streaming, and sales), and the database logic of digital media. What is new about the indexi-local is not that it foregrounds the local; rather, it is the reification of the local as means to interact with digital music services that I aim to draw attention to with recourse to this term.

\section{3 “The Home of Independent Canadian Music:" Introducing CBC Radio 3}

CBC Radio 3 emerged in the early 2000s as an experiment in developing an online service, capturing the attention of a younger audience, and facilitating the development and promotional reach of independent Canadian musicians (Belanger and 
Andrecheck 2005, 122-123). After a number of experiments in design and formatting including a stint as an award winning "virtual magazine" - it became, in winter 2006, a stand-alone music news website, digital radio station, and streaming service (with attendant playlist features) devoted to the broadcast and promotion of independent Canadian music. It remained in this format until the year 2012, when CBC Radio 3 became both the model for, and clustered within, CBC's broader digital music service CBC Music. Now CBC Radio 3 is one of two "Community Pages" featured within this service (CBC's terrestrial music station $\mathrm{CBC} 2$ is the other page). These pages stream music alongside a wide ranging number of genre-focused stations (including world, electronic, hip hop, pop, aboriginal, and rock). Key infrastructural features of CBC Music that were uploaded from Radio 3 (and rooted, in turn, within the original design of Radio 3) include: Artist Pages (CBC Music n.d.a) that include information about musicians, mp3s, and links to online retailers (both independent Canadian music retailers and Apple's digital iTunes store); a Concert Calendar (CBC Music, n.d.b) that posts when and where musicians are touring in Canada; user profiles for non-musicians (CBC Music n.d.c); and an embedded music player that appears in and across CBC Music's disparate pages.

CBC Radio 3 circulates as both a radio station web-stream and website that features independent Canadian music. Moving across the programming and content of Radio 3, it is clear that the service defines independence as music produced and distributed on an independent record label (i.e. a record label that stands outside of the recording industry's major label system). This institutional, rather than generic, definition enables the station to program a wider variety of genres, including heavy metal, pop, 
electronic, and hip hop. Its only programming limits are that the music is Canadian and independent. Canadian is defined in terms of where musicians are located and not whether that label is Canadian. Thus, bands like Japandroids and Arcade Fire are broadcast on the service because the groups are Canadian (located in Vancouver and Montreal, respectively), even though their record labels are American (Polyvinyl and Merge, respectively). There are a variety of shows organized within a regular broadcast schedule that is available to stream on CBC Music's embedded music player, as well as CBC's SiriusXM Satellite radio channel and the CBC Music app (for Android and iOS devices). A selection of these shows are cut up and later made available to stream outside of the broadcast schedule as podcasts.

Complementing CBC Radio 3's on-air programming is its website, which largely revolves around a blog (CBC Music, n.d.d) used by various Radio 3 personalities to promote upcoming features on its web stream, post links to stories about indie music (both Canadian and international), and provide additional content (such as trivia, lists, polls, photograph slideshows, etc.). It also provides links to the station's podcasts, broadcasting schedule, and the Artist Pages of musicians played within the service. The mobility of the service is further reinforced through it circulating as a tag ("Radio3") that links other sections of the broader $\mathrm{CBC}$ Music website to the $\mathrm{CBC}$ Radio 3 homepage (and that homepage in turn, to those other webpages). It also has profile pages on a number of social media sites. ${ }^{1}$ Radio 3 weaves media formats and social media services together in its broadcast and promotion of independent Canadian music. The abundance

\footnotetext{
${ }^{1}$ These include Tumblr (http://cbcradio3.tumblr.com/), Facebook (https://www.facebook.com/cbcradio3), and Twitter (https:/twitter.com/CBCRadio3).
} 
of content and access points facilitates listener interactions with the website and music service.

In March 2015, Radio 3 once again shifted formats, when it was announced that there would no longer be DJs featured in the radio stream. Instead, the radio stream would feature sporadic news features from Radio 3 personalities, a constant stream of pre-programmed music vis-à-vis the $\mathrm{CBC}$ Radio 3 station, and the broadcast of interview excerpts with different independent musicians as the between-song "banter." Radio 3 personality Grant Lawrence (2015) explained the decision in a blog post, writing:

It means we want you to hear directly from the musicians we play every day. We want you to hear the stories behind the amazing songs, the latest albums and the epic tours, from the unique perspective of the Canadian artists who are out there living it ... In this new era of CBC Radio 3, one thing you'll hear a lot less of is traditional daily hosting. Our array of new artist features will take the place of our regular host breaks. Familiar long-time CBC Radio 3 personalities will still be valued and trusted assets of what makes CBC Radio 3 what it is, and you'll be hearing from us throughout the day, in our new features and also conversing with you, as always, on our blog and via social media. (paras, 2, 4-5, my emphasis)

The cutbacks to the station's hosting personnel is reframed, in this excerpt, as enabling listeners to articulate a more direct connection to independent Canadian musicians vis-àvis Radio 3. I want to further examine how the service's promise to draw out a more "personal" connection between station and listener, whether through the "direct" communications promised by blogging and social media interactions, or interviews with musicians, emerges through the station's incorporation of local regions as both narrative and metadata.

\section{Local Feel: Locating Canadian Indie Music in CBC Radio 3}

When browsing Radio 3's website, there is a clear and recurrent focus on the musical activities of independent Canadian musicians. Furthermore, the cities and towns 
that musicians come from tend to be the most recurrent piece of information communicated to blog readers. For example, in a blog post promoting an exclusive stream of indie pop band Bend Sinister's album Small Fame a few weeks before its release in the summer of 2012, Radio 3 writer Bartlett (2012) highlighted the band's residence in Vancouver, BC, writing in the opening sentence: "Vancouver progressivepop band Bend Sinister is releasing its first full-length album in four years on July 10." Writing more than one year later for an entirely different exclusive album stream for Tegan and Sara's Polaris Prize short-listed album Heartthrob, Jesse Kinos-Goodin (2013) opened their story by writing: "Tegan and Sara Quin, the twin-sister, singer-songwriter duo from Calgary, Alta., couldn't have asked for a better 2013.” Louise Burns' (2016) short write-up detailing the release of a new Black Mountain music video opens with the following description: "Vancouver psych-rockers Black Mountain recently announced their comeback in the form of a [sic] album entitled $I V$, set to be released on April 1 via Dine Alone" (para 1). These sorts of stories share space with podcasts devoted to the musical histories of cities like Winnipeg (Lawrence 2012a), feature stories on various Canadian music institutions, such as the Vancouver BC-based recording studio The Hive (Burns, 2012), and even maps of the cities in which the "50 greatest Canadian albums of the '90s were recorded" (Warner, 2014). All these stories feature information about the cities and towns through which Canadian indie music circulates. The geographic location of musicians is also evident and foregrounded in Artist Pages, which are provided to musicians that set up a profile and account with $\mathrm{CBC}$ Radio 3 (CBC Music, n.d.a). For instance, a number of Ottawa-based musicians - such as The Acorn, Bondar, Andrew Vincent, and Adam Saikaley - include the city and province from which they come in 
their basic profile information. In fact location is one of the key pieces of required information for musicians that set up an Artist page with the service.

The wider range of geographic locations in this service can be understood as working to locate $\mathrm{CBC}$ Radio 3 in the myriad of local regions through which Canadian indie music circulates, producing the "feel" of locality within Radio 3 (Berland, 1990). Though Berland worked through the ways in which localness is produced in Canadian commercial radio broadcasts in the late 1980 s, the tropes she identifies still help to explain how the local is produced. Steps she identified include: broadcasting advertisements for local businesses; embedding local news stories in news coverage; airing weather reports and updates about the listening area; and highlighting the city in which a radio station is situated in DJ banter (pp. 189-191). The emphasis on location, repeated across these radio broadcasts, aligns a given radio station with the city in which it is located. Berland surmises that this locative function is necessary due to the abundance of non-local and non-Canadian content broadcast within commercial, Canadian radio stations. Or as she further explains:

Clearly what is local is not the music (or much of the news either) but the selection and blending of the various elements of music, information, advertising and other content, in relation to the market conditions of local listeners ... radio's atmosphere of local involvement is designed to attract the highest possible proportion of listening hours for sale to local advertisers, and to maintain and promote the particular local 'feel' that can attract both listeners and advertisers. ( $p$. 189).

While highlighting local regions in a wide cross-section of texts reinforces a station's localness, which needs to be articulated due to the non-Canadian content, this is reversed in Radio 3. The circulation of local regions in Radio 3 through news stories, blog posts, and artist information locates the station's Canadian independent music in the 
abundance of local scenes that produce it. Highlighting Tegan and Sara's location in Calgary or the centrality of the recording studio The Hive for Vancouver-based indie musicians (Burns, 2012) invokes those cities, connecting the listener-reader to these locations. When focusing on content, though, the abundance of local regions represented within Radio 3 does not work as a reaction to (or a gloss on) a surplus of non-Canadian content; instead, it defines the content's Canadianness in terms of the diverse regions that constitute Canada. This is an important clarification to make because both Radio 3's market conditions, as well as its conditions of production, depart from those defining commercial broadcast radio stations. As an online branch of Canada's public broadcaster, the amount of advertising aired is minimal. There are no commercials aired within Radio 3's music stream. The commercials that do air are limited to the time that the web stream loads, as well as to banner ads framing Radio 3's place in the CBC Music service. These commercials tend to promote larger, national and international businesses and brands (such as banks, automobiles, fast food restaurants, and insurance companies). Thus, we can see a twist on the localness of advertisements and text identified by Berland, whereby it is Radio 3's content that is distinctly Canadian and its advertisements that are international.

The service's localness is also a matter of production, for Radio 3's production and broadcast not only emerges through a distributed network of $\mathrm{CBC}$ recording studios spread across Canada, but also features bloggers from a number of Canadian cities, including: Halifax, (e.g. Gordon, n.d.; Reilly, n.d.) Montreal (Rowat, n.d.), Toronto (Martin, n.d.; Kinos-Goodin, n.d.; Maan, n.d.), and Vancouver (Lawrence, n.d.; Warner, n.d.). Thus there is a wide range of local regions both embedded in producing, as well as 
in content covered by, Radio 3's broadcast of independent Canadian music. While location emerges in broadcast radio through the formal features of broadcast infrastructure - i.e. the terrestrial limits of the broadcast as situated in a city or town centre - in CBC Radio 3 this local infrastructure speaks to both inter-local means of production and international means of distribution. Specifically, both the web-stream and website are available to listeners across Canada and the world. Moreover, as of this writing, Radio 3 is neither geoblocked outside of Canada, nor does it follow any particular time zone (Gill 2004). Therefore, rather than a local gloss on international content, the local regions contained in the station work to provide a local orientation to national production and international circulation. Specifically, they serve to both illustrate and reinforce to the everyday listener how exactly $\mathrm{CBC}$ Radio 3 is "The Home of Independent Canadian Music:" that is, in terms of the diverse local regions shaping Canadian indie music. ${ }^{2}$ I will now turn to the integration of local regions within the search functionalities of the Radio 3 website.

\section{Your Scene Could Be our Metadata: Local Regions and/as Metadata}

A striking feature of new media narratives and aesthetics is the question of how the generation and accumulation of new data is managed. Lev Manovich (2001) pinpoints this generative quality in his The Language of New Media when he writes: "they [websites] always grow. New links are continually added to what is already there" (pp. 220-221). The constant addition (and concomitant accumulation) of data within a website increases the demand for information management (Munster, 2013, p. 79). One such

\footnotetext{
2 This was the former tagline of Radio 3 for a number of years; in 2016, its slogan shifted to "Breaking new sound."
} 
technique of information management is the use of metadata, which is the data generated about data that guides, categorizes, and catalogues search and retrieval practices. In Radio 3's website, the data perpetually in the midst of accumulation pertains to Canadian indie music. Because Radio 3 is part and parcel of the broader CBC Music service, I will now turn to the use of local regions as one means to categorize the music and stories featured on the broader CBC Music site. The blurring of Radio 3 with $\mathrm{CBC}$ Music has broader implications further teased out below.

Local regions circulate as one type of metadata that defines and directs the circulation and retrieval of songs and stories in CBC Music. This organizational capacity becomes clearest in two sections of the broader CBC Music website: the service's Search feature and Concert Calendar, which both render transparent this particular technique of information management. If one searches the keyword "Ottawa" (CBC Music, n.d.e) within the CBC Music service's search bar, a wide variety of search results are returned, including: musicians situated in Ottawa; music videos from or about Ottawa; concert recordings and live music sessions recorded in Ottawa; and music-related stories about Ottawa. One can seek out as much information about a given city as they want across the wider CBC Music service. Meanwhile, there is also a Concert Calendar (CBC Music, n.d.b) that can be searched through a number of categories, including by artist, city, genre, and province. Searching Ottawa in this part of the website produces a list of concerts (including venue location) happening in that particular city on any day of the week. This particular application of locality ties the service back to the real musical activities happening in and across a range of cities in Canada. 
This organizational capacity is also evident in the Artist profile page of musicians programmed on CBC Music. For example, on The Acorn's profile page (CBC Music, n.d.f), their geographic location in Ottawa, Ontario appears directly alongside the band's name and music genre. Geographical identifiers are mandatory pieces of information required when a musician sets up a membership, alongside the musician's name and genre. Consequently, these pieces of information appear on each and every single Artist Page for musicians programmed both within and outside of Radio 3, spanning from bands with smaller-scaled regional and national followings (like The Acorn, or Montreal, Quebec's Braids) to larger-scaled Canadian indie bands like the Japandroids or Arcade Fire that have garnered international attention. Though one cannot click through the regions identified in profile pages, local regions can still be used as a search term with which one can retrieve artists and songs included in Radio 3. By searching "Ottawa," one can break down the $\mathrm{CBC}$ music service through the keyword Ottawa.

Treating local regions as metadata makes them important pieces of information that, alongside other pieces of metadata like artist name and album information, work as "paratexts" defining and directing the circulation, retrieval, and representation of digital music (Morris, 2012, p. 851). Boehm (1999) has suggested that the process of designing metadata must necessarily be "influenced by the context in which these objects [data] are based" (p. 181). Radio 3's content, which emphasizes local regions and independent Canadian music, both provides and reflects this context. More precisely, the myriad of texts that stress local regions provide the context to, in turn, deploy local regions as keywords to search with, which produces results that span across the website of the broader CBC Music service. Thus, the locative function specific to Radio 3 (with its roots 
in producing the "feel" of localness) dovetails with the use of local regions as metadata, providing both listeners of Radio 3, as well as visitors to the website with a prompt that they can follow, in turn, to search and navigate through CBC Music's catalogue of music and information, of which Radio 3 is one part. The "feel" of locality produced in the service emerges not only through the emphasis on local regions in texts and profile pages, but also the encoding of local regions as search terms made sensible and orderly through the deployment of metadata. Both tendencies facilitate interactions with the service. It is in this locative functionality, emerging at the intersection of local regions and music service-contingent search terms, that the indexi-local is present.

The shared emphasis on local regions that threads together Radio 3 and $\mathrm{CBC}$ Music fits within CBC's programming mandate to 'be predominantly and distinctively Canadian, reflect Canada and its regions to national and regional audiences, while serving the special needs of those regions" (CBC, n.d.). Pushing the various cities and towns through which Canadian indie music circulates into the foreground of the service effectively visualizes Radio 3's predominant and distinctive Canadianness through its emphasis on the diversity of local regions that constitute Canada. Moreover, it provides the service with analytics of subscription and usage. This allows Radio 3 to distill, from the abundance of regional locations self-identified by musicians and listeners alike, where both listeners and musicians come from. In this sense, the re-articulation of local scenes as metadata actually fits with CBC's obligation to appeal to (and "reflect") specific Canadian regions. This interest guides their digital strategies too, as explained by $\mathrm{CBC}$ President Hubert Lacroix (2013) in a report entitled Strategy 2015: "this year, we continued to implement the three complementary pillars of Strategy 2015-national 
spaces, regional spaces and digital spaces” (CBC/Radio-Canada, 2013, p. 3). Radio 3 shapes its digital musical space with references to local regions that constitute, in turn, Canada's national spaces.

Yet, local regions also persist in this more organizational capacity in another music service aimed at independent musicians: Bandcamp. In Bandcamp, we can see the continued persistence of the indexi-local - that is, an interactive experience of music listening online yoked to the deployment of local regions to organize the listening experience - albeit in a manner more immanent to the practices of musicians subscribing to this particular digital streaming and sales platform. This case study identifies the vernacular deployment of local regions as user-generated tags.

\subsection{Bandcamp: Our Service Could Be Your Scene}

Bandcamp is a private, venture-capital funded digital music retail and streaming service that is based out of Silicon Valley, California. It was initially developed by cofounders Ethan Diamond and Shawn Grunberger as an online retailer providing both unsigned and independent musicians with a platform to sell albums (both physical and digital) and merchandise (Tozzi, Lieber \& Crise, 2011; McIntyre, 2015). While Radio 3 promises listeners access to the "home of independent Canadian music," Bandcamp promises users a platform with which to "discover amazing new music and directly support the artists who make it" (Bandcamp.com). It is primarily aimed at independent musicians and executes its promises of "discovery" and "direct support" through the provision of a customizable and searchable streaming and sales platform. It offers access through both a website and app (available through iOS). As a service primarily oriented to the "discovery" of independent music, Bandcamp is organized around artist and album 
pages. One of the features that helps facilitate discoverability for musicians is, moreover, the service's provision of a "tags" feature, which musicians can use to both describe and categorize the music they upload to the service. The ability to tag genre and geographic location was added to the service in 2010. In a blog post entitled, "Oh No, Not Another Music Community," co-founder Diamond (2010) explains the value of tags in terms of community building, writing:

... we think it [tagging] has the potential to build a community in the best possible sense of the word, where every individual contributes to its strength. It won't, of course, be built overnight. At the time of this writing, there are exactly zero tags in the system, but with your help (and the help of the screaming yellow nag-bar that you'll see next time you log in), it shouldn't be long before the solitary goal of these new features is realized: make every artist on Bandcamp more successful, by making it easier for fans to find you. (para 11)

This excerpt highlights the utility and value of organizing the data contained in the site as a means to find it. It is, moreover, a user-generated form of information management situated in their own interests and know-how. From this, the hope is articulated that users will make connections between albums, songs, and artists that will be valuable to both navigating through the service, as well as locating music to stream and buy.

When examining the tagging activity of Bandcamp accounts that upload albums for streaming and sale, it is clear that two of the most frequent tag types deployed are genre and location. There is no exact template for genre tags, so they range from the more expected (for instance, "indie," "punk," and "folk," which are deployed by Ottawa-based singer-songwriter Andrew Vincent on his Bandcamp page), to more idiosyncratic genre descriptors (such as "Ouija rock" for Ottawa band The Yips). More pressing for the purposes of this chapter is the deployment of location as a tag, with which a range of 
musicians categorize their albums and singles. Ottawa-based independent musicians typically use both "Ottawa" and "ottawa" to categorize their releases.

Tags are a form of metadata that are primarily user-generated. They short-circuit the sort of categorizing work done through the design and deployment of metadata by website designers - exemplified in the above outline of Radio 3's interface and searches - enabling both simultaneous search and retrieval of a particular term. Thus, the deployment of tags in Bandcamp is made possible by those uploading music to the service. They largely serve the purpose of facilitating the search and retrieval of both songs and musicians. For example, when one clicks through tags, two sorts of search results appear: other items that have been tagged with that label by that musician, and other music that has been categorized with that tag. Thus, clicking through the Yips' "Ottawa" tag yields both the albums released by the group that have been identified with that local region, as well as other albums and artists that have used that identifier. The Ottawa tag thus opens up a throughway of sorts, enabling the search, retrieval, and navigation of Bandcamp's music catalogue through that particular term. This listing is then further broken down through two categories: "Bestselling" and "New Releases." These tags are clickable and can open up a wider range of music labelled with that geographic identifier. Like CBC Radio 3, tags work as a user-generated form of metadata that enables the categorization and retrieval of the music uploaded. One can not only click through tags as a means to find Ottawa in Bandcamp, but also use the term Ottawa to search through the website. Thus, one can use Bandcamp as a means to glean the disparate range of independent music produced in, and tagged as coming from, Ottawa. It is through their ability to facilitate connections between musicians, genres, singles, and 
albums that tags are presented as having the potential to produce community within Bandcamp.

In contrast to emerging as metadata produced by $\mathrm{CBC}$ Music to categorize music, Bandcamp tags are user-generated, indicating that local scenes persist as a meaningful part of independent music's digital circulation. Here, local scenes provide a keyword through which to categorize the music and musicians circulating through this service. The wide range of locales incorporated into Bandcamp's representation and provision of independent music visualises the local and inter-local circulation of independent music scenes identified by Will Straw (1991). Specifically, Straw argues that local music scenes are not self-contained; instead, they interlink with other scenes in a disparate number of ways, whether through the movement of touring musicians or the exchange, adoption, and adaptation of sounds and genres in and across scenes. The overall effect of this semiotic and musical exchange between music scenes is that scenes become "overlaid upon each other" (p. 378). In Bandcamp, this layering of local scenes evident as one navigates through the service moves from a subtler idea of how music and people move, to tags that not only enable navigation but also locate the music contained in the service within the local scenes from which indie music emerges. Yet, how does participation emerge in these services?

\subsection{Mapping the Indexi-Local}

In his study of virtual scenes, Andy Bennett $(2002,2004)$ highlights both the sharing of information, as well as performance of informational acumen, as examples of participation. A different style of participation emerges in these services, which I draw out by turning to Jay David Bolter and Richard Grusin's (1999) work on remediation and 
Lev Manovich's (2001) research on database logic. Remediation provides a useful way to situate the service's production of a digital music experience, by foregrounding two logics of digital media: hypermediacy and immediacy (p. 5). Immediacy is most clearly connected to the indexi-local, which I then further highlight with reference to the ways in which local scenes as tags and metadata help organize and guide playback. It is in this section that I draw on Manovich's work.

Hypermediacy involves both the incorporation and reshaping of disparate "old" media and cultural forms within a "new" media object, as well as the spread of user engagements with media across multiple media sites. Both Radio 3 and Bandcamp incorporate and reshape such "older" media formats as broadcast radio (through music stream and podcast) and the music press (through its concert calendar and blog posts). Both services also circulate across disparate social media sites which, taken altogether, suggests hypermed iacy. In both examples, local regions circulate as the content contained in these media in the midst of reformation and spread that works as a through line, drawing together these wider range of texts and media sites. Meanwhile, immediacy pertains to the goal (and ideal) of new media providing a fuller, more immersive experience that effaces the very medium facilitating that experience. In this capacity, immediacy involves ensuring a non-interrupted listening experience by, for instance: minimizing the time it takes for a web stream to load; producing buffer timeframes that ensure the web stream doesn't become choppy; and ensuring that one can click through the website without the music player stopping. These sorts of infrastructural features of a digital music service align with questions about the service's verisimilitude. Though local regions are largely peripheral in these applications, immediacy also emerges in the realm 
of search and navigation. One immerses oneself in the drift of data and songs featured in both services by searching out, clicking through, and playing back songs. The reconfiguration of local scenes as metadata and tags remediates them into searchable terms that enable users to navigate through the service's "database logic" (Manovich, 2001) in a more intuitive and immediate manner.

According to Manovich (2001) a database "is defined as a structured collection of data. The data stored in a database is organized for fast search and retrieval by a computer" (p. 218). He further suggests that the database is a key logic defining new and online media, as evidenced with the browsing and retrieval of data being central to internet navigation (pp. 218-221). Such browsing is an everyday part of Internet usage (Carr, 2011), and is evident in both CBC Radio 3 and Bandcamp, particularly in the reliance of both services on membership profiles, the provision of different customization options, and the demand for interactivity-as-browsing to make these services work. For instance, CBC Music members can create playlists from the music offered on Radio 3; these playlists can, moreover, be made public and shared both within CBC Music and outside of the service through social media services like Facebook. One can also "like" a musician in the service; when one does this, their profile name appears on the musician's profile page, while the musician's name appears under a section of the member's profile entitled "My Likes." The membership, "like" features, and "play" counts produce a quantifiable number of listeners, musicians, and song plays within the broader CBC Music service. Through the creation of a membership and maintenance of that profile, members can create a personal and social listening experience. For users that do not set up a profile, interaction with the service can still take place through users navigating 
across a wide cross-section of texts pertaining to independent Canadian music. Styles of interaction can include: listening to web streams, podcasts, and songs; reading news stories and musician biographies; and searching through live concerts, musicians, and blog indexes.

Bandcamp, too, relies on such practices of navigation and "liking," albeit largely measured with and made public through purchases. When a listener buys an album from the service, their profile picture becomes embedded on the album page offered by the musician, signaling a sort of community of purchasers/fans. One must search and click through blog posts, artist profiles, and album pages (including the range of tags generated) as a means to "discover" and retrieve music. The sort of direct connection and discovery promised by both services hinges on users interacting with, and navigating through, the abundance of information and data contained in these services. These more quotidian facets of social music are guided, in part, by local regions, which circulate as a means to produce a more interactive experience of the music housed within these two music services.

Matthew Fuller (2005) has honed in on the listing facets of databases, arguing that creative potentiality emerges in the interaction between reader and list. As he explains, lists ". . always open up into a matrix of immanent universes. Each of the elements in a list is hypotactically stacked in relation to the immanence of what it is next to, what it abuts to and differs from. Such hypotaxis is virtual, that is, for its actualization it demands power to the imagination" (p. 14). Pierre Levy (1998) stresses this sort of creative and imaginative engagement between a reader and text more broadly, arguing that: "The space of meaning does not exist before the text is read. It is while moving 
through the text ... that we fabricate and actualize meaning" (p. 48). By extension, the abundance of information provided by both music services relies on the reader-listener to follow the links and tags, listen to the songs, and read the stories as a means to both "fabricate" and "actualize" understanding of independent music from what is both provided by the service and known by the user.

Both services' deployment of local regions as tags and metadata provide pathways to interaction. However, this deployment is contingent to the creative inclinations and existent knowledge practices of the listener in the midst of "actualizing" their understanding of independent music in and through their interactions with these digital music services. Both music services hinge on a database logic that demands, in turn, search and navigation. The indexi-local is such a reconfiguration, and more precisely, remediation of the local that provides a means to navigate through this service. Rather than signalling disruption, though, I want to now suggest how these customizations and user interactions resonate with styles of participation connected to indie music.

\section{Our Music Service Could Be Your Scene}

In his influential history of American indie rock, Our Band Could Be Your Life, music critic Michael Azerrad (2001) argues that this style of music and music production provides listeners with a unique connection; as he writes:

The indie movement was a reclamation of what rock was always about. Rock \& roll hinged on a strong, personal connection to favorite bands, but that connection had been stretched to the limit by ... impersonal stadium concerts and the unreality of MTV. Indie bands proved you didn't need those things to make a connection with an audience. In fact, you could make a better connection with your audience without them. (p. 10, emphasis in original) 
The local music scene - with its smaller venues, grassroots promotion, musical networks, and independent record stores - provides the means to realize such "personal connection" outside of the centralized, corporatized, and mass media extended mainstream music. This is largely predicated in realizing a more communal and participatory experience of music by listening to music in more intimate music venues (Shank, 1994; Fonarow, 2006), and producing one's own music in alternative and grassroots musical, entrepreneurial, and media networks (Hesmondhalgh, 1997; Moore, 2007). This crosssection of writing treats the local music scene as a site in which a wide range of creative, musical, and social affiliations shaping indie rock music come into formation.

Will Straw (2004) has identified an "excessive" quality in the social and musical practices that shape a local scene; as he writes: "scenes emerge from the excesses of sociability that surround the pursuit of interests, or which fuel ongoing innovation and experimentation within the cultural life of cities" (p. 412). Straw's claim for experiential excess resonates with Barry Shank's (1994) studies of the affective intensities of the live show, which he describes in the following manner: "within this fluid stream of potential meanings, the audience and the musicians together participate in a nonverbal dialogue about the significance of the music and the construction of their selves" (p. 128). Both authors identify the potentiality of musical experience in the context of the local scene. For Straw, it involves an excess of sociability that makes a scene vibrant; meanwhile, Shank identifies such abundance as central to processes of identity formation. In both instances, the local scene provides the "sites and sounds" in which these opportunities for the creation of social and musical affiliations emerge (Kruse, 2003). 
In later research on local music scenes online, Kruse (2010) suggests that online and social media do not efface local scenes. Rather, they extend these scenes (and their myriad constitutive social and musical affiliations) online, whether in terms of producers and promoters using social media to extend the means of promotion and networking, or consumers using such media to access and engage with the musicians and music emerging from their local scene. This sort of application is evident in both CBC Radio 3 and Bandcamp, which provides listeners and musicians alike with a service to both fabricate and actualize the excess of a scene's "cultural life." To Kruse's suggestion that digital media extends scenes, I would add there is a further process by which local scenes are incorporated as metadata. This incorporation organizes the excesses of scenic activity and data housed in a digital music service. Specifically, clicking through geographic tags enables one to sift through, listen to, and find out about the music that is happening in a city. One can then use genre as a means to further hone in on the data. The excessive data generated by (and contained within) these services, moreover, becomes manageable and organized through the deployment of location and genre tags, which work alongside more traditional pieces of metadata such as artist name, song title, and album name (Morris, 2012).

While the indexi-local has been shown to resonate with and organize both the excess of data and scenes, to what degree do these sorts of services mesh with indie taste practices? In his study of indie rock, Ryan Hibbett (2005) shifts attention away from local music scenes, musicians, and issues of production and distribution in his work on indie rock's online circulation, by focusing instead on issues of taste. He draws out a suggestive analogy between the cultivation of distinct tastes in indie rock subculture and 
the algorithmic logic of recommendation engines mobilized by online retailers like Amazon. For Hibbett, both indie music consumption and algorithmic recommendations work through a logic of differentiation so as to find the new, based on existent taste preferences. This accounting builds off of characterizations of indie rock music as "record collector rock" based in collecting and cultivating good taste (Bannister 2006b; Plagenhoef, 2007; Straw, 1998a). Hibbett (2005) concludes that the sorts of specialized collecting and consumption practices valorized as markers of subcultural distinction are really no different than the sorts of purchasing recommendations that emerge on websites like Amazon (p. 76). Buying based on comparisons between what you like, and on what others who like what you like also like, displays an algorithmic logic. While his contentious reading is more dismissive and critical, largely eradicating consumers of agency, his research also suggests an experience of indie rock music that draws together local music scene and online interactions. That is, his research suggest the creation and cultivation of a listening profile as being central to indie rock. This style of interaction hinges on creating, curating, and sharing playlists and songs, reading about indie music, and either listening to or buying albums offered by both services. This meshes with, and draws on, a sort of personalized listening experience. These sorts of experiences, moreover, resonate with existent and older modes of participation that have been celebrated in the field of indie music, whether by making mix-tapes, reading zines, buying music from trusted taste intermediaries like record stores, or sampling campus/community radio (cf. Azerrad, 2001; Plagenhoef, 2007; Arnold, 2014). The potential to actualize connections often taking place in the local scene - that is, the excess of sociability - is captured and re-stylized through both services' remediation of local 
scenes as embedded participation with a digital music service, guided through the deployment of local regions as metadata and tags that organize playback. The attuned and invested listener, creating a taste profile through texts, sounds, and recommendations located in a local scene overlaps both local scenes and digital music services, suggesting the remediation and reification of indie locality as the indexi-local in these digital music services.

\subsection{The Order of Locality}

Canadian indie music is a marketing hook for Radio 3. It provides the $\mathrm{CBC}$ with precise analytics of usage, and it is contingent to the multiple potentialities of experience and knowing that emerge at the intersection of digital music service and listener. In Bandcamp, meanwhile, the tagging of music and artists by musicians with geographic location yokes the service back into the scene (and the scene, in turn, into the service), with the aim of providing a more immersive and interactive community and listening experience.

It is striking that local regions play such a central role in these two particular digital music services, for the ability to both upload music to the service, as well as access that music from anywhere can signal a sort of placeless, primarily service-oriented listening environment. For example, larger streaming services like Spotify and Apple Music primarily relegate geographic location to biographical information. Their search functionalities focus more narrowly on song names, artist names, genre, and album. To search with location in these services produces results that have location names in the titles of songs, albums, and musicians. Soundcloud, meanwhile, tends to relegate location to a hashtag embedded in the music player. 
These sort of service-oriented listening practices resonate with Paul Théberge's (2004) examination of seemingly placeless networked studios that, by enabling networked collaborations within digital recording environments that span geographical location, work to efface a sense of real location. He pinpoints the aesthetic consequences of this sort of globally networked style of recording in Shania Twain's 2004 album $U p$ (and in particular, its world mix). This album integrated an assortment of musicians from around the world through the sharing of digital files, thereby divorcing Shania Twain's actual involvement in recording in those different global locations (pp. 774-776). There is a politics of placement and location, in other words, connected to seemingly postgeographic potentials of self-contained digital music environments. Though Théberge looks to the globally extended network studio formation, he is leery of claims to the effacement of the local. Instead, and following Manuel Castells' (1996/2010) subtler reading of the local's place in the globalized "network society," Théberge suggests that the local operates as a node in the networks of global musical flows (p. 772). What this chapter demonstrates is a more pronounced focus on local scenes by streaming services that specialize in independent music. Bandcamp is a service with international reach and usage. In this service, local regions provide routes of access to the circulation of music sold and distributed within the website and app. Though CBC Music is not geoblocked and is potentially available to international audiences, its focus and content is distinctively Canadian. Local regions provide a grid of sorts that organizes the distribution of the distinctively Canadian content programmed within the service. Taken together, the continued circulation of local regions within both Radio 3 and Bandcamp suggests the broader allure and persistence of indie music's desire for direct connection, 
spanning from an earlier "unwired" scenic milieu in which "our band could be your life," to the more complexly imbricating digital and scenic milieu, in which "our metadata could be your scene." The local music scene abridges both milieus. 


\section{CHAPTER 6. A NEW WAVE: CULTIVATING INDEPENDENCE ONLINE 6.1 Independence and DIY Labour}

In the opening pages of his memoir Your Band Sucks, musician Jon Fine (2015)

provides the following reflection on his time playing in the indie rock band Bitch Magnet at the tail-end of the 1980 s, writing:

It seems accidental and frankly miraculous that we all ended up in the same rooms at the same time, but we did, and in those rooms a culture was built, by hand and often from the barest of raw materials. On tour, our bands crashed on fans' floors, not in hotels, and rode in rattling vans, not fancy buses. We loaded and unloaded these vans by ourselves each night. We rarely had managers or other middlemen; we often dealt directly with club owners and labels. Or we released our records on our own, selling them to the companies that distributed them to record stores, hand-packing promotional copies into cardboard boxes to mail them to the hundred or so college radio stations that cared and all the fanzines we knew. ( $p$. xiv)

In this excerpt, Fine depicts independent music as a more participatory and immediate mode of music making that: 1) draws band and fans into close physical proximity; 2) operates at a small scale; and 3) eschews the services of professional intermediaries such as a promotional department, or even distributors, in favour of the band doing this work, themselves. This autobiographical tidbit further foregrounds the "do it yourself" (DIY) ethic which has been treated as one of the defining features of independent music (Laing, 1985/2015; Hesdmondhalgh, 1997; Kruse, 2003; Reynolds, 2005; Moore, 2007;

Waksman, 2009). In his study of zines, Stephen Duncombe (1997/2008) distills DIY into the imperative: "make your own culture and stop consuming that which is made for you" (p. 7). A suggestive representation of DIY-as-imperative is featured below in the, "This is a Chord" image, which was first published in 1977 in the punk zine Sideburns (Rogers, 2012). 
Figure 4. "This is a Chord"

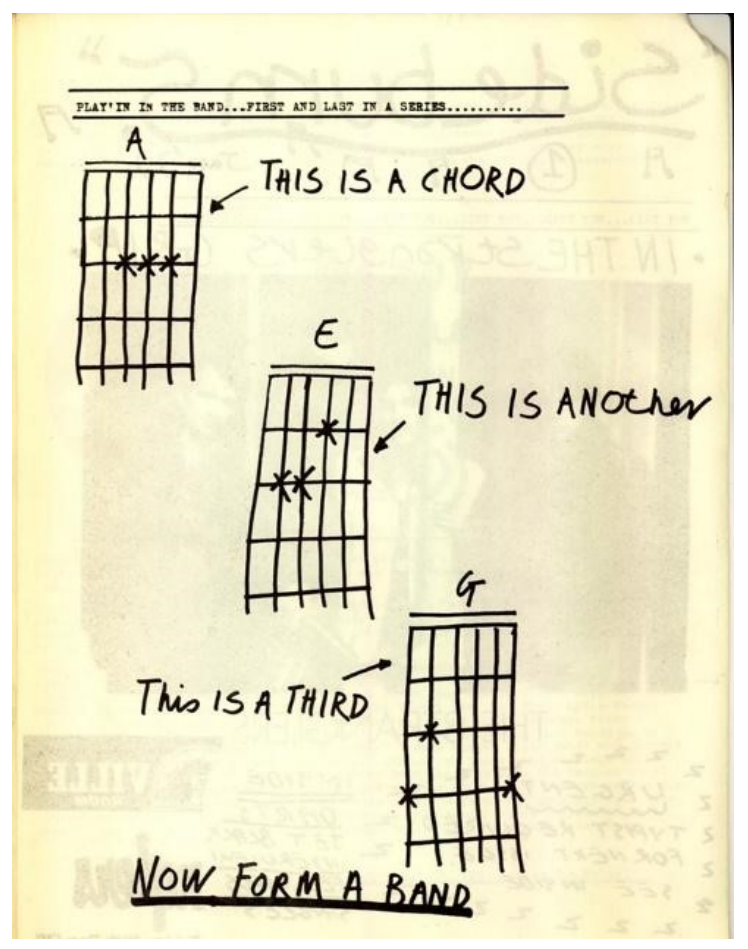

Taking the form of guitar tablature, the image instructs the reader how three guitar chords are formed, including where to place their fingers on the strings, and puts these chords into a sequence that could create a song. The imperative emerges in the closing lines of the image: "now form a band." In a commentary on this image, Jonathan Clover (2009) encapsulates the emotional allure of DIY, writing: "anyone can do it. Don't bow down before the band; be the band. Don't wait. Don't get stuck at home practicing scales. Raw power is enough. Urgency is enough" (p. 76, emphasis removed).

DIY has been celebrated for its potential to democratize both musical and media production. The idea and ideal that "anyone can do it" ranges from starting your own record label, to starting a band, to promoting shows, to writing and distributing a zine. DIY has already threaded through a number of chapters in this dissertation, evident in the 
locally embedded entrepreneurial activities of two Ottawa-based independent record labels and the scene-bound media largely self-produced by scene participants. This chapter examines two digital music services that valorize, incorporate, and monetize these sort of locally embedded DIY activities: Bandcamp and Wyrd Distro. Bandcamp is a digital music service that provides both streaming and retail services to independent musicians and record labels working in a wide variety of genres. While Bandcamp provides a flexible and accessible service to its subscription base that facilitates the ease of distributing and selling independent music, the service also relies on its subscribers to make the service work. While this was provisionally outlined in the previous chapter, through the exploration of music tagging, this chapter highlights the translation of the DIY activities of its subscriber base into forms of labour and user-generated content. The local scene recurs in this service, but when reframed through the vantage of labour, it works as user-generated content for the service and a largely offsite source of warehousing and shipping/receiving for physical album sales. The styles of proximity promised by indie music scenes is translated into click-based transactions of money and attention, thus reinforcing the boundary between fan and musician supposedly troubled in both independent music (Fonarow, 2006; Oakes, 2009) and new media technologies (Jenkins, 2006; Galuzska, 2015).

The second half of this chapter shifts attention to the Canadian independent music distributor and online retailer Wyrd Distro (www.distro.weirdcanada.com). This service also incorporates locally embedded DIY activities, albeit in a different style. Unlike Bandcamp, which provides musicians, record labels, and listeners alike with a service that relies primarily on user-generated content to work, Wyrd Distro works as 
intermediary. The service designs album pages, selects what is sold through the service, generates critical commentary that describes albums for sale, warehouses releases, and ships/receives orders. In these respects, it is a service promoted and framed as being by and for Canadian indie music participants, emerging from and aimed at the scenic activity that generates indie music. Yet, Wyrd Distro integrates Google Forms to manage its informational needs and public communications and rents cloud hosting services from Amazon. Wyrd Distro's integration of Google and Amazon into this realm of "gray media" services (Fuller and Goffey, 2012) adds another layer to the complex interplay of independent and corporate institutions defining the production and circulation of independent music. This suggests a relationship of mutual "integration:" one in which this particular independent organization integrates these corporately aligned computer companies as a means to organize its operations (in particular, by managing its informational needs). These companies, meanwhile, expand their operations and monopolies through the provision of information management services and basic online utilities necessary for this organization to operate online. This process of mutual integration reveals the more infrastructural presence of these corporatized, computational industries in this particular independent music site.

Both examples, moreover, problematize a broader narrative of disintermediation seemingly promised by both DIY and digital means of self-distribution, showing instead the persistence of intermediary organizations in the entrepreneurial and musical practices of indie musicians and record labels. These organizations are shifting, however, towards flexible and accessible models of usage hinging on subscriptions to these services. 


\subsection{Bandcamp}

Bandcamp is a private, venture-capital funded technology company that emerged in 2008. It was initially developed by co-founders Ethan Diamond and Shawn Grunberger as an online retailer providing both unsigned and independent musicians with a platform to sell physical and digital albums and merchandise (Tozzi, Lieber \& Crise, 2011; McIntyre, 2015). Diamond explains the motivation for starting the online retailer as emerging from both his own fandom for independent music, as well as dissatisfaction with services like Myspace that, in providing an advertising-driven platform, effectively subsumed artist pages into the design of the website, thus effacing the distinctive identity of that band and/or musician on that website. As he explains:

In the earliest days, it started because there was a band I really liked. This was 2008, when you have MySpace, Imeem, those sites. Very little choice if you wanted to go on your own. What you ended up with was somebody else's logo, advertisements -- someone else's identity. If you wanted to do it on your own you had to hire a designer, an engineer. It seemed nuts. (quoted in Flanagan, 2015)

The retailer went online in 2008 and offered musicians, in contrast to the abovementioned services, a customizable web page free of advertisements. As of this writing, Bandcamp offers musicians the ability to: upload songs; provide and edit biographical/contact information; generate user-generated tags identifying genre and geographic location; provide album artwork; and determine prices.

In winter 2015, as it approached its seventh year of operations, Bandcamp announced that it had paid out more than $\$ 100$ million to musicians. Co-founder Diamond (2015) explained in a blog post:

Fans give artists $\$ 3.5$ million every month on the site, and buy more than 16,000 records a day, which works out to about one every five second .... Furthermore, sales on Bandcamp are up 30\% in the last 12 months, at a time when the rest of the [music] industry is down $11 \%$. We see this growth as proof that if you give 
fans easy ways to directly support the artists they love, they'll take you up on it every time. (para 1)

This excerpt highlights ease of usage, the evident tendency for consumers of the service to "support" musicians, and demonstrable market growth (with the increase of sales by 30 per cent). Jeremy Wade Morris and Devon Powers (2015) have noted the importance of brand identity in the operations of digital music services, focusing primarily on the experience provided to (or rather, marketed towards) subscribers of streaming music services. As they explain:

... digital music services no longer sell discrete musical objects, nor do they focus exclusively on content offerings. Instead, services sell branded musical experiences, inviting consumers to see themselves and their attitudes, habits and sentiments about music reflected by the service they choose to adopt. (p. 107)

Diamond's description of Bandcamp's particular brand of music sales and promotions draws out a distinction between those previous services that subsume bands into the design of a page and the user-friendly, customizable, and accessible page design offered by Bandcamp. Furthermore, his description highlights the service as one that is easy to use and provides support to independent musicians. For potential investors, this excerpt also highlights sales growth - a narrative that was subsequently picked up by a range of publications, including the music industry publication Billboard (Flanagan, 2015), which identified Bandcamp as evidence that people are still willing to pay for music. The volume of music sales and layout of this particular music service, which will now be shown to focus on single musicians and the discrete album object, also problematizes narratives of complete industry upheaval advanced by Morris and Powers. This signals the continued place of both album and music sales in contemporary, streaming-oriented digital music services. 


\section{Designing Platform Experience}

Following Morris and Powers (2015), what sort of experience does the Bandcamp service promise to users? How is this experience designed through the layout of the service's interface? Bandcamp provides a cheap and accessible service for both music consumers and producers. Listeners (with "Fan" accounts) can sign up free of charge and then consume albums a myriad of ways. They can pay for albums, either physical or digital, through PayPal (bandcamp.com/fans). Consumers can also buy physical copies of albums in retail stores and/or from the musician at their show, and then download a digital copy of that album, free of charge, from a download code. Bandcamp can also be used as a streaming service, depending on the levels of availability that a musician has enabled for their album. Some artists - for instance, Ottawa's Bondar and White Wires have uploaded complete albums, which are available for continuous streaming. Others, like Ottawa-based singer-songwriter Kalle Matson, make only a selection of songs available. However, the number of streams available to non-paying listeners are limited; should a consumer not delete their cookies and playback an album after they have already listened to it, then a message appears that prompts/asks the listener if they want to buy this album. Aside from its prompting of listeners to buy after sampling, Bandcamp also enables its music player to be shared on other websites and social media sites through a mobile and embeddable music player (Diamond, 2013). This provides fans that like a particular musician and/or album with a customizable and mobile platform to share and promote music within their social networks.

Fans are also provided with a user profile, to which they can add personal data such as biographical information and pictures, and list albums they have purchased. If 
one chooses to make their purchases visible rather than hidden, albums appear on the fan's profile page and the fan's profile picture appears on the album's page alongside any comments the consumer may wish to make public. This renders the consumer process public, shifting from a single exchange of money for commodity good, to a more spectacular digital trail, replete with publicly viewable comments and identification of the user's profile on that musician's album page. Though Bandcamp promotes its provision of a service that facilitates easy consumption and support to both musicians and consumers, how exactly does this service work for musicians and labels? Moreover, how does this particular music platform fit with the practices and systems of the music recording industry?

\section{Contracting Labour}

Bandcamp offers Artist accounts for musicians (bandcamp.com/artists) and Record Label accounts for record labels (bandcamp.com/recordlabels). There are two types of artist accounts: one is available to subscribers of the service free of charge (the more general artist account); the other (Bandcamp Pro) is available to artists at the cost \$10/month (US dollars) and offers greater degrees of customizability and audience analytics for musicians (www.bandcamp.com/pro). Meanwhile, record label accounts are priced in two tiers: either $\$ 20 /$ month for labels that will feature fifteen bands, or $\$ 50 /$ month for an unlimited number of bands (bandcamp.com/recordlabels). Both musicians and record labels can sell digital and physical versions of albums at prices they set. As the service sets out in its artist sign-up page (www.bandcomp.com/artists) under the heading "Total Artist Control, Total Flexibility:" 
Charge whatever price for your music you choose, and change it whenever you like. Sell for a fixed price, specify a minimum and let fans pay more if they want (and yes, they do pay more, a whopping $50 \%$ of the time), or give your music away in exchange for an email address. You retain complete control over your customer information, just as you damn well should.

The musician and label are put in charge of pricing, deciding the value of the music commodities they are selling.

On average, digital albums tend to be priced at $\$ 6$, though albums can also be sold at the cost of "set your own price". Using a customizable template provided by Bandcamp, artists and record labels are also responsible for designing and editing the album details contained on their profile pages (with each album opening into its own page clustered within the artist's page). Details include: recording information (studios, producers, engineers, etc.); release information (pressing numbers, formats available, release date, colours of vinyl available, etc.); and contact information (musician emails, websites, social media profiles, etc.). This shows that the service relies on the informational and creative labour of its musicians. That is, through the customizable profile page, musicians are responsible for designing their page and uploading the necessary information to contextualize and describe the content of their recording. Bandcamp takes revenue charges off of sales accredited to PayPal accounts (in both the free and paid tiers). For album sales, Bandcamp charges $15 \%$ in "revenue shares" for album sales, up to $\$ 5000$ worth of sales; after total sales exceed $\$ 5000$, that charge drops down to $10 \%$. Merchandise, meanwhile, is also subject to a $10 \%$ charge (www.bandcomp.com/pricing). Basically, the process of selling and distributing independent music - which has, traditionally, relied on either the services of professional intermediaries (such as a distribution company) or the institutional, social, and touring 
circuits shaping local music scenes - is short-circuited by Bandcamp, which provides a service through which artists can sell, promote, and distribute their music. This not only directly involves the musician in this facet of business, but also provides artists with a more expansive geographic reach for sales and promotion. These areas of business activity suggest that Bandcamp provides distribution services, which has been, historically, the primary area in which the major record labels comprising the recording industry have consolidated their power (Burkart, 2005). To further understand this service's incorporation of select facets of the recording industry's entrepreneurial and commercial practices, it is necessary to examine how it manages relations with Artists that use the service.

Matt Stahl's (2013) study of the creative labour performed by musicians working in the music industry unpacks the myriad ways in which musical work is managed, valorized, and exploited by the music recording industry. As he explains, his focus on creative labour

... starts from the novel assumption that, as creative agents, US recording artists (and many other workers in creative cultural industries) also hold jobs in a capitalist system and therefore have much in common with all other employees. Creative cultural workers, like other employees, are subject to control by their employers and to the appropriation of the products of their labour. (p. 20)

He charts out the logics of control and appropriation through a closer focus on the contracting practices that structure the music industry's relations with musicians. $\mathrm{He}$ surmises that it is in the realm of contracting that the often risky and tumultuous nature of the music industry is controlled for. This line of analysis begs the question: what sorts of contracting terms administer the relationship between Artists and Bandcamp? 
The relationship between Artist and platform is set out in Bandcamp's Terms of Use (www.bandcamp.com/terms_of_use). Bandcamp neither provides royalties to artists that use the service, nor attains "ownership rights" of the musician's release. Instead, it specifies that Artists using the service grant Bandcamp the right to feature, store, and sell both the music and information uploaded to the website (Intellectual Property Rights, para. 1). ${ }^{1}$ Musicians also agree to grant users of the service the right to recirculate and redistribute the music and associated information outside of the music service, depending on subsequent activities taken up by both fans and critics. ${ }^{2}$ In controlling for what other users and Bandcamp can do with the music uploaded, Bandcamp's Terms of Use focus on the final music product and its subsequent circulation through the service, whether within the operations of the service itself or subsequent practices of fans.

This focus on technological uses in the Terms of Use demonstrates Bandcamp's divestment from the labour that goes into creating the music. Bandcamp neither subsidizes the costs of recording, producing, or manufacturing, nor does it intervene in

\footnotetext{
${ }^{1}$ The Terms of Use outlines the service's "right and license to reproduce, distribute, publicly perform (including on a through-to-the-audience basis and by means of a digital audio transmission), publicly display, create derivate works of, communicate to the public, synchronize and otherwise exploit ..." the following:

(1) the Artist's Music and perform the Service on the Artist's behalf (e.g., reproduce, transcode, copy and store the Artist's Music on computer servers owned and/or operated by or on behalf of Company or its authorized sublicensees and distributors, and publicly perform, transmit, synchronize, stream, distribute, and playback the Artist's Music) using any technologies or methodologies now known or hereafter developed, and (2) Exploit all associated copyrightable works or metadata, including, without limitation, song lyrics and musical notations, album cover artwork, photographs, graphics, and descriptive text ("Artworks") in connection with the Service. (Intellectual Property Rights - Artists, para. 1)
}

${ }^{2}$ The Terms of Use further specifies that Artists:

(ii) allow users of the Service to receive public performances and public displays of the Artist's Music and Artworks and to reproduce the Artist's Music and Artworks on any and all devices owned or controlled by the user for non-commercial purposes and receive performances and displays of same; and (iii) reproduce, use, and publish, and to permit others to reproduce, use and publish, the name(s), trademarks, likenesses, and personal and biographical materials of the Artist, in connection with the provision of the Service. (Intellectual Property Rights - Artists, para. 1) 
the creative process. The service also does not seek out artists, instead it relies on them to sign up for the service. In these capacities, it eschews the sort of work - and associated risks - of managers and Artists \& Repertoire (A\&R) personnel in the realm of artist development (Negus, 1999). Instead, Bandcamp provides the services of distribution and promotion though the provision of the music service. One of the key sites of both profit and power that has been identified in the monopolistic tendencies of the recording industry hinges on its control over the means of music distribution: that is, control over the pathways connecting production to consumption of the album (Jones, 2002, pp. 215216; Arditi, 2014, pp. 408-410). Arditi (2014) further specifies the myriad of intermediaries involved in the distribution of physical albums, writing:

It is costly to print and package albums, house them in storage facilities, ship them to stores, and sell them at retail outlets; this is to say nothing of the promotional costs that go into convincing store owners/managers to carry a particular album. Independent musicians/labels cannot compete with the major record labels until they either invest in distribution networks or find ways around the expensive aspects of distributing records to stores. (p. 410)

Bandcamp provides a centralized, cost-effective, and user-friendly platform with which to circumvent these "expensive aspects of distributing records" by selling the albums in and through the platform - whether in app, or through the website - thus eschewing the need of these traditional intermediaries by setting its service up as a central intermediary, through which one sells, distributes, and promotes the release.

\section{Reducing Risks}

David Hesmondhalgh (2013) has noted that one of the greater risks involved in the production of cultural commodities involves the high costs and lack of control associated with producing that cultural object in contrast to the lower costs of its mass 
reproduction (pp. 27-29). The costs of producing an album (including the costs associated with its writing, recording, producing, and mastering) typically exceed the costs of producing the CD or LP on which that recording is, subsequently, circulated.

Hesmondhalgh sets out, moreover, that it is the control over the means of circulation that offsets the riskiness of the investment in cultural production (pp. 27-29). Bandcamp's provision of the technological infrastructure through which albums are sold, promoted, and distributed signals that it has largely divested itself of the risks associated with operating a record label, and in particular, the realm of artist development. Bandcamp does not seek the artists it signs to its service, subsidize production costs or pay out royalties. Instead, it pays artists through "revenue sharing" on sales of albums and merchandise. Musicians provide product to the service, and the service then provides a platform for its (digital) storage and movement.

Its Terms of Use outlines an indefinite period of usage for listeners and musicians alike; a longer-term relationship can be built between user and service, though it pays out in the shorter-term, more immediate cycles of album sales. Contracts too are flexible; Bandcamp neither contracts for project numbers nor years, instead it provides an indefinite service term that hinges largely on when the artist decides to cancel their subscription. The contract relationship can be dissolved by Bandcamp, as well, if the Artist breaks the outlined terms of use. In this respect, the Bandcamp contract is, paradoxically, both long-term and tenuous, for as the Terms of Use further specifies:

[Bandcamp] may terminate your access to all or any part of the Service at any time, with or without cause, with or without notice, effective immediately, which may result in the forfeiture and destruction of all information associated with your membership, including, without limitation, any access to any Music you may have purchased through the Service. (Termination, para. 1, my emphasis) 
The period of coverage for the artist-service contract is quite flexible then, able to be terminated at any time by either party, which indicates the service-oriented and subscription-based operations of this platform. That is, it provides subscribers, whether consumers or producers, with the use of the service, hinging on that user's continued interest in, and proper use of, Bandcamp. Morris and Powers (2015) argue that music streaming services - such as Spotify and Beats Music (now Apple Music) - change the ways in which music consumption works, moving from a model oriented to the purchase of a finite good towards a music service that operates in a manner similar to utility industries such as hydro or gas (p. 109). The seeming dis-articulation of music from a tangible artefact bought and sold, to one that is subscribed to and stored offsite, sets out a consumer relationship with music hinging on subscription. Bandcamp demonstrates this sort of service-oriented functionality in the very provision of a digital music service to which musicians and labels subscribe: one is "signed" to and/or affiliated with Bandcamp by signing up to that service. The terms of usage is indefinite in duration, contingent to termination of subscription by either user or service.

While Bandcamp provides a service that largely augments existent practices of distribution and promotion, it also promises sellers a host of other features, including: analytics (for streams, sales, and searches); search engine optimization (so that Bandcamp pages are top hits in Google searches); access to new audiences through tagging and recommendations features; customizability (in both profile pages and digital/physical combinations); the opportunity to provide "audiophiles" with higher quality music to download (including Apple Lossless and FLAC); and reporting sales to SoundScan (www.bandcamp.com/artists). These services produce the sort of 
demographic and market research for a musician that would traditionally be performed by a record company's marketing department. Moreover, while Bandcamp provides the services of distributor and promoter, bands and labels are responsible for processing and shipping orders of physical albums and merchandise, thus offsetting warehouse and shipping costs to the subscribers. Its provision of a mobile, embeddable, and shareable music playback format also inserts the very promotional facets of the service into playback design. This sets out the very music player as the site of promotion, to be deployed by musicians, label owners, and fans alike. Bandcamp thus re-intermediates processes of distribution. It has attained, moreover, a wide subscriber base, ranging from unsigned musicians to "major" indie labels like Sub Pop and Dischord Records. The service's re-intermediation of distribution, offsetting of informational and manual labour to local scenic activity, centralization of promotion in the very shareability of the music player, and divestment of investing in artist development suggests that it is an independent digital music service. It has not only tweaked many of the practices associated with a traditional record label, but it also provides an opportunity to distribute and promote indie music outside of the recording industry.

\section{Labour, Incorporated}

Taken altogether, these characteristics show that Bandcamp's provision of a music platform hinges on incorporating the labour of its subscription base. This labour is, moreover, creative (releasing the music produced through the creative process of writing and recording music, and designing album pages); manual (packaging and shipping orders); and informational (sifting through demographic research, processing orders, checking payment information, and updating account information). Tziana Terranova 
(2000) argues that "incorporation is not about capital descending on authentic culture but a more immanent process of channelling collective labor (even as cultural labor) into monetary flows and its structuration within capitalist business practices” (pp. 38-39). Bandcamp's service attaches to and incorporates the DIY activities that would already be performed, for the indie labels and musicians it works with are already creating, manufacturing, promoting, and distributing music. As a platform, Bandcamp re-channels, captures, and monetizes this work through flexible contract terms, practices of revenue sharing, and a specialized focus on the more immediate (and traditional) realm of album sales. This fits within a broader turn towards flexible and project-based labour that has been grasped at by writers attending to "immaterial labour" as a dominant and exploitative realm of capitalist praxis.

Maurizio Lazzarato (1996) mobilized the term immaterial labour as a means to demarcate the increasingly precarious and short-term contract-oriented organization of labour in post-Fordist working milieus, focusing specifically on informational labour. He provides the following, quite vivid description of what this sort of labour entails:

Small and sometimes very small "productive units" (often consisting of only one individual) are organized for specific ad hoc projects, and may exist only for the duration of those particular jobs .... Precariousness, hyperexploitation, mobility, and hierarchy are the most obvious characteristics of metropolitan immaterial labor. Behind the label of the independent "self-employed" worker, what we actually find is an intellectual proletarian, but who is recognized as such only by the employers who exploit him or her. It is worth noting that in this kind of working existence it becomes increasingly difficult to distinguish leisure time from work time. In a sense, life becomes inseparable from work. (pp. 136-137)

While Lazzarato's description of immaterial labour would seem to speak to the type of work specific to a contracted or temp worker at an unnamed agency working in precarious and often task-oriented projects, Michael Hardt and Antonio Negri (2000) re- 
articulate the term to grasp at a broader problematic. Namely, they attend to the sorts of ". . labour that produces an immaterial good, such as a service, cultural product, knowledge, or communication" (p. 290). Studies of immaterial labour generally tend to underline the exploitative conditions that face different creative and informational workers (e.g. Brown, 2014; Dyer-Witheford, 1999, 2015). A consideration of Bandcamp as service that translates DIY praxis into a form of immaterial labour speaks to the ways in which musicians and labels (or "Artists") that sign up for the service enter into a flexible, primarily self-employed, and potentially precarious contract with Bandcamp. The contract hinges on two tendencies: the sale of individual albums, and terms of subscription. The service provides analytics and a sales platform, but for the service to work both informational and manual labour needs to be performed, too, including: editing profile pages; gleaning analytics generated by the service; and processing and shipping orders received. Thus, on top of the creative labour already performed to self-record and produce music before musicians even upload music to the e-store, musicians are then required to do the informational labour of designing and editing profile pages and shipping/receiving orders placed on any physical merchandise. While Bandcamp both incorporates and monetizes the sorts of informational, creative, and manual labour performed by its subscriber base, this labour is also valorized as creative and empowering by those participants that are operating within the context of DIY (Duncombe, 1997/2008).

What I want to suggest instead with this notion of DIY labour - which negotiates both narratives of precariousness and exploitation connected to immaterial labour and notions of empowerment through DIY means - is that this service has ambiguous impacts 
on what locally situated independence actually means. On the one hand, the musicians and labels that use the service still operate at a local and independent scale, with the added benefit of potentially reaching a wider audience. This renders the business of music distribution more convenient for the labels and musicians that use this service by providing subscribers with a platform that is both accessible and usable, with flexible terms. Musicians and labels are also reimbursed with a majority of the percentage in revenue shares gleaned from album and merchandise sales. On the other hand, however, this service further reinforces the bifurcation of musicians and fans that both indie music (Reynolds, 2005; Fonarow, 2006; Moore, 2007) and online media (Benkler, 2006; Jenkins, 2006) have been argued to trouble and transgress. Bandcamp sets out two disparate streams of users in its operations, whereby musicians and labels possess distinct Artist profiles that are set up to receive payments, while consumers are set out as "fans" whose accounts are primarily debited for payment. Musical community emerges, in the confines of this platform, through producers selling their wares and fans listening to, sharing, and consuming them. This re-articulation is synthesized in Bandcamp's current (as of fall, 2015) slogan, which is embedded on the website's homepage (www.bandcamp.com): "Bandcamp is a rock-solid platform for artists to sell their music and merchandise to their fans, and a thriving community of enlightened listeners who get that the best way to support the artists they love is by directly giving them money." This translates the myriad potential emotional and affective connections entangled in the production of musical community in a scene (Shank, 1994) into simpler terms: the exchange of money; the garnering of attention; or the re-distribution of music through fan "shares" to different blogs, websites, and social media networks. The local music scenes 
from which indie music emerges provides, moreover, the DIY labour (which is informational, creative, and manual) and warehousing that makes this service's promise of digital community work.

Taken altogether, Bandcamp troubles the current, seemingly post-commodity drift of digital music that has been written about in both popular music reportage and scholarly analyses of pop music. The distinct object available for purchase persists, with both artists and fans aligning in this service around the playback and sale of music, whether single or albums, digital or physical formats. On top of the options to buy physical releases and digital copies, Bandcamp also offers a digital copy to be hosted on the Bandcamp app (available in both Apple and Android's IOS). This makes available a copy of what one has purchased for playback through Bandcamp's cloud. Bandcamp supports the distribution, sale, and promotion of independent music, providing a central platform that enables music to circulate outside of the recording industry's corporate system. It hinges on flexible terms of use, providing both an indefinite subscription duration, as well as immediate payment based solely on individual album and merchandise sales. Both of these tendencies depart from the sorts of totalizing contracting practices that are currently characterizing the recording industry's move towards 360 degree contracts, which work to both monetize and manage areas of non-recording activity, such as publishing, licensing, and live performances, in addition to traditional means of artist development (Stahl and Meier, 2012). Lastly, while it threatens to capture the experiential and social potentiality of independent music into click-based transactions of attention and money, it also provides a platform for both music producers and listeners to 
connect to the myriad sounds and bands constituting the current field of independent music.

It has been recognized that the influx of digital recording and performance technologies since the 1980s has blurred the boundaries between production and consumption (Théberge, 1997). This has spurred greater degrees of labour and participation by music fans (Morris, 2014; Galuzska, 2015) and produced institutional indeterminacy, rooted in cross-industry convergence, and in particular, the increasing presence of the computational industries (Morris, 2015b). The example of Bandcamp indicates a translation of both consumers and producers into service subscribers. Bandcamp provides its subscribers with a range of services; its subscribers provide, in turn, a number of different services and labour (alternately creative, informational, and manual) that makes this platform operate. Fans buy and listen to music; share and promote music through embeddable music players that circulate freely through other websites; and provide the service with commentary, information, and analytics specific to profile activity. Musicians upload albums; design and customize web pages; provide the content that makes this service work; and provide the manual labour of processing and shipping orders. The locally embedded DIY labour undergirding production, distribution, and promotion is incorporated by the service through more flexible and subscriptionbased terms of indefinite duration.

\subsection{Wyrd Distro}

Wyrd Distro was founded and formed by Aaron Levin and Marie LeblancFlanagan in winter, 2014. It is an online retailer and distribution company that branched off of Weird Canada (www.weirdcanada.com), a music blog that features a number of 
different music writers, working on a largely volunteer basis. They cover a wide range of topics concerning independent Canadian music, including: daily reviews of newly released music that includes embedded song clips (Weird Canada, n.d.a); reviews of zines and other alternative press (Weird Canada, n.d.b); and an advice/tips section for both aspiring and practicing independent cultural producers (Weird Canada, n.d.c). Cofounder Levin situates Weird Canada's emergence as being both rooted in the enthusiasm for independent music that he developed during his time as Program Director at the Edmonton-based campus/community radio station CJSR FM 88.1, as well as his dissatisfaction with the lack of coverage of more marginal pockets of experimental and independent Canadian music by Canadian music writers (Hayes, 2013). In its provision of critical coverage of a wider range of independent Canadian music, Weird Canada works as a "subcultural tastemaker" of sorts: that is, it operates as a critical intermediary that provides exposure to the music and culture that it features.

In his study of connoisseurship and canon formation in indie rock, Matthew Bannister (2006b) identifies the centrality of tastemaking and the ways in which various intermediaries - ranging from zine writers to music store workers - sought to "educate" and inform indie music consumers in the 1980s of music's deeper histories, which tended to be elided in more popular critical coverage (pp. 81-82). This educational and informative operation is also evident in Stephen Duncombe's (1997/2008) identification of the ways in which zine writers highlight and reveal disparate "landmarks" central to a music and culture scene's existence (pp. 62-66). The locative functionality of these "landmarks" is commensurate with Chris Atton's (2010) argument that the criticism featured in music zines provides a useful index to the ways in which particular genres and 
canons are formulated. Weird Canada threads together indie's tendency towards canonformation through recovering, identifying and locating marginal music spread across Canada. The "scene" it focuses on emerges in between the local and the national, with a focus on independent Canadian music that expands across Canada, but is sorted through local regions. This sort of tastemaking logic is further intensified by the music blog's tendency to only produce positive reviews. Co-founder Levin roots the decision to celebrate and feature independent Canadian music as emerging from the challenges that face independent musicians to attain national coverage and connection, explaining:

Because of the way Canada is, because it's such a big country and because it's really hard to connect us all together it's not like the States - for a band to tour across Canada, it is almost literally impossible. If you want to get from Toronto to Winnipeg it's over a 20-hour drive and there's nothing between here and there - just places that, even if you're a really popular band, you're not going to have a good show. But if you're a DIY artist you're not even going to make it there. So what Weird Canada began to represent was this entire wave of people who were actively making music, and it was like a beacon where they could all identify and connect with other musicians across the country. And from there it became more than just a blog, it started to become a resource. (quoted in Hayes, 2013)

That is, Weird Canada provides geographically dispersed independent musicians and audiences with a website that facilitates connectivity, whether through advice columns, album reviews, show promotion in local regions, or through the inclusion of the very music-making community it covers in a wide range of volunteer roles.

This goal of fostering connection is further extended through Wyrd Distro, which provides both independent music stores and listeners the opportunity to buy the music featured in Weird Canada. Music journalist David Barry (2014) describes the relationship between these two companies, writing: "if Weird Canada is the lookout from which you can see the mountain of avant-garde and outré Canadian music, then this new project [Wyrd Distro] will be the gondola that helps you scale the peak, a way to get the songs 
off the blog and onto your shelves" (para. 3). And music does go, literally, on to one's shelves, because this particular e-retailer and distributor only sells physical commodities - that is, Compact Discs, CD-Rs, cassette tapes, and vinyl records, with nary a digital download to be found embedded in the website.

Wyrd Distro is based out of Waterloo, Ontario and it is a non-profit company funded with a FACTOR grant - that is largely staffed by volunteers. Because it sells through consignment, Wyrd Distro relies on musicians and labels to both apply to the service and ship the albums accepted for sale to the retailer's headquarters in Waterloo. However, in contrast to the accessible-to-all platform that hinges on user subscriptions provided by Bandcamp, Wyrd Distro extends the sort of critical and subcultural gatekeeping work it does with Weird Canada into the operations of its retail service, only bringing in product to the store that it selects. It requires, as a first step for consideration of inclusion in the e-store, that the musician submit a musical sample to Weird Canada. The release will only be included in the store once it has been featured in Weird Canada because, as they write, "it is easier for us to sell items that we have celebrated" (FAQ, n.d., p. 4). Both Bannister (2006b) and Hesmondhalgh (1999) have noted the central role that the tastes and musical interests of independent record label owners have played in the subsequent aesthetic and economic decisions made by those record labels. Wyrd Distro similarly uses taste as a means to discern what it will and will not include in the e-store, but in this instance, the tastes expressed are those held by its collective of writers connected to Weird Canada. This collapses the traditional pathway of tastemaking specific to both popular and independent music coverage, so that it is only after positive critical reception that a release emerges into the marketplace that is mapped out and 
serviced by Wyrd Distro. As well, against the seeming mechanization and displacement of "real" tastes in the recommendations generated by digital music services through algorithms (Morris, 2015b), we can see the foregrounding of human tastemakers in this particular music blog-cum-e-retailer.

Wyrd Distro also has a number of specifications, or in the service's phrasing, "priorities" guiding the selection process, asking that independent musicians and labels submit music that has only been released in the previous calendar year (rather than whole back catalogues). Other priorities are phrased in the form of the following questions listed in the service's FAQ (n.d.):

Does our community value the art? ${ }^{3}$

Does the art excite our curators?

Does the art meet the standards of our empathy council? ${ }^{4}$

Is the artist(s) from a marginalized group?

Is the art emerging/experimental/underrepresented?

Is the art from a remote or under-represented area of Canada?

Is the art self-published / self-recorded / self-produced?

Is the art being created on a difficult format?

Is this the first time this artist is being featured by us? (pp. 3-4)

Though this list begs the question of transparency - indeed, how does an aspiring

musician know how to gauge a potential rejection in terms of whether their release

spurred "excitement"? - this list nonetheless synthesises what the company seeks to do.

Its objectives include featuring music that has limited commercial appeal, that has been

${ }^{3}$ Weird Canada (n.d.d) lists the following "values" on its website:

We are a space for artistic, literary, and musical enthusiasm; we aim to connect the disparate communities that feed the creative cosmos of Canada; we capture the physical ephemera that contains and surrounds art, literature, and music; we welcome the makers of art, literature, and music who take risks and experiment; we welcome excited minds. (About,n.d.).

4 The "empathy council" is a volunteer-based subsection of Weird Canada and Wyrd Distro that works as a sort of "consultant body" for community/cultural is sues, categorized along the following groups: "Health (physical and mental), race, gender, sexuality, culture, class, age/all ages, rural/remote, and 'other." (Empathy Council, n.d.) 
released either on an independent label or self-released, and that is Canadian, with particular emphasis placed on "under-represented" regions of Canada. These focuses are further reinforced and evident when the layout of the e-store's interface is examined.

\section{Circulation; or the Things Space can Show}

In a number of essays, Will Straw has focused on the ways in which particular retail environments organize and distribute cultural commodities as a means to establish the impact that the embedding and circulation of commodities in particular spaces have on the final forms of cultural expressions. Straw's (2007) "Embedded Memories" essay explores video stores, advancing the suggestive argument that the wealth of product contained in a store - and the ease of moving between genres in the physical space of the video store - fosters the cultivation of deeper knowledge of film. This subsequently helped to shape increasing degrees of intertextuality and pastiche evident in a wider range of "postmodern" cinematic fare (pp. 8-11). His study of music retail at the tail-end of the 1990s highlights the spatial patterning of a broader tension between (and negotiation of) disorder and order in the "music retail sector," which, as he writes, hinges between "... the offering of a potentially chaotic abundance and the marshalling of a variety of means for focusing consumer choice and producing order from amidst this chaos" (Straw, 1998a, p. 63). In terms of the former, he finds that the distribution of commodities in music "superstores" - such as the former Virgin megastore - expresses the (over-) abundance of musical commodities. Their apparent disorder signals the articulation of musical spaces that facilitate the potential for both immersion and discovery in the consumer experience. In terms of the latter, he identifies the uptick of CD reissues, niche 
magazines, and formatted radio stations, treating them as signposts of the effort to curate and organize the overabundance of musical product into specific musical niches.

Though diverging in their research objects, both essays focus on the ways in which particular retail environments both influence and reflect cultural production. It raises the question: how do retail environments shape the meanings contained in particular cultural expressions? Because there is no physical retail environment to step into, to answer this question the interface of the e-store - read as the design of its website and the ways in which consumer/website visitor navigates through the website - becomes an important resource with which to answer this question. In particular, there is evident emphasis on physical commodities, Canadianness gauged through regional composition, and the centralization (ordering) of Canadian indie music's regional disorder.

Wyrd Distro's privileging of physical commodities is evident in the layout of the website. ${ }^{5}$ In particular, the Format category includes four subcategories: cassette tapes, vinyl records (both 12" and 7"), lathe-pressed vinyl, and compact discs (CDs). This category thus provides a means to browse through the store's content, filtering the whole store through one's format of choice. Similar to Bruised Tongue Records' entrepreneurial strategies and commodity productions, there is clear emphasis on older and physical commodities. These commodities are all the product of locally embedded DIY activities. Product photography emphasizes the physical attributes of the music commodities available for sale, with pictures featuring the same style of product photography: a picture

\footnotetext{
${ }^{5}$ Levin frames the decision as both practical and aesthetic, explaining: "I wanted to focus on physically released music, because there's a lot of digital music but the people who were releasing what I wanted to cover were putting it out in a physical form. I think that the commitment to physicality is a really important part of the creative process, because it forces people to encapsulate their ideas in a theme" (quoted in Hayes, 2013).
} 
of the object for sale on a table against a different coloured backdrop. For instance - as featured in Figure 5, below - the webpage featuring Tropical Dripps' 2014 cassette release Cool Dude features a larger picture of the cassette, which is removed from its container and placed at a slight angle in front of it. In the image, one can see both a grey backdrop and table, against which this particular brightly coloured cassette contrasts (Tropical Dripps Cool Dude, n.d.).

Figure 5. Tropical Dripps' (2014) Cool Dude

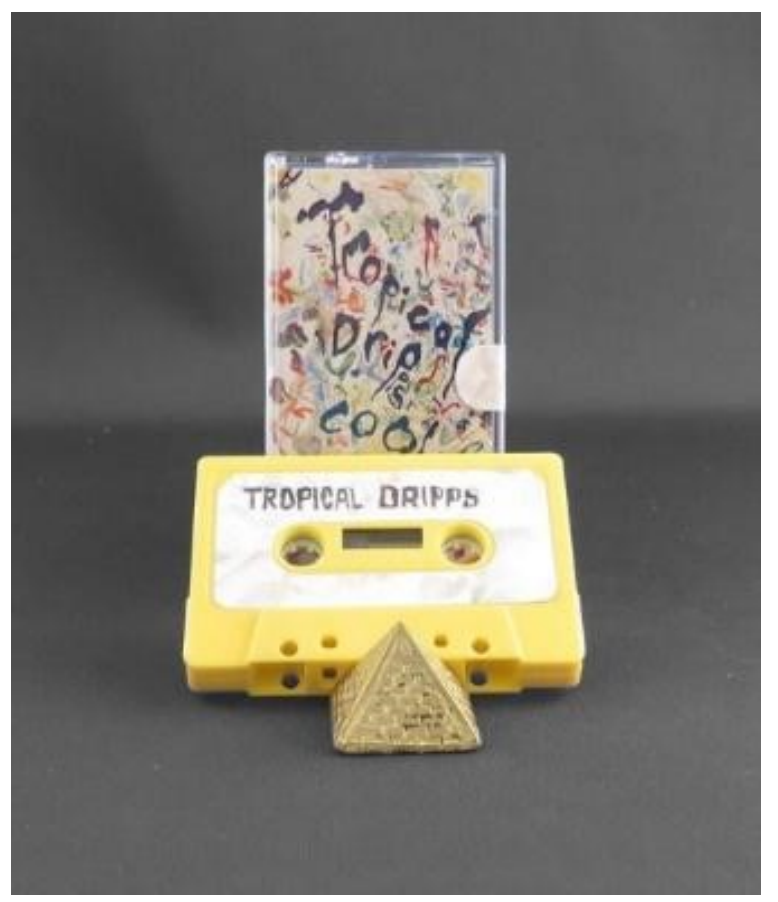

This mode of photographing items for sale spans release formats, including CDs, vinyl albums, and zines. We can see, in the product photography, the e-store's privileging of the album as a "discrete" consumer object. The emphasis placed on the album as "discrete object" is further emphasized in the website's tendency to organize albums through album pages, rather than artist pages (as per Bandcamp). On each album page, further details about that album are incorporated, including: genre details; geographic 
information about where that musical release originates from; embedded song clips; and catalog number and record label (when applicable). It features this information in its details, along with tags about format, geographic location, genre, and musician name, which facilitates the website's navigability.

In studies of remediation and convergence, attention tends to be paid, respectively, to the improvements and tensions contained within the interaction between old and new media. For Bolter and Grusin (1999), to understand the forms and aesthetics of digital media and culture, one must look at the ways in which these newer technological and cultural productions interact with their historical antecedents. Though they seek to introduce a narrative of historical continuities and mutations within networked exchanges, their focus on remediation nonetheless advances a subtler story of absorption and improvement. This is a story in which older media forms (and their correlated cultural expressions) are absorbed into the operations and design of that newer media site. In turn, the newer media site is motivated by the logic/teleology of heightened immediacy and cross-media hypermediacy. ${ }^{6}$ For Jenkins, the interactions between old and new media tend to be subsumed into a broader narrative of increasing consumer participation in pop cultural production, contained within a broader dialectical interplay of grassroots and corporate interactions. What is interesting about Wyrd Distro's incorporation of older media formats, however, is that the very inaccessibility of the album becomes a point of emphasis in the layout of the webpage (and by extension,

\footnotetext{
${ }^{6}$ Refer, in particular, to Michelle Henning's (2007) critical examination of remediation's narratives of progress and technological centrism in relation to digital photography; as well, Lisa Gitelman (2006) provides a suggestive critique of the ways in which Bolter and Grusin present, through their phrasing, media as "intentional agents" in such a way that elides the broader cultural, social, and institutional factors that make media meaningful (pp.9-10).
} 
works to structure the allure of the objects for sale). The cassette tape is not incorporated as means of designing the store, or even the album page; rather, it circulates as a photograph which, taken alongside details about the album, provides a glimpse of the analogue media artefact but not an actual entryway. These details heighten the distinctiveness of that older media format, which remains largely inaccessible, in that format, to the website visitor until it is purchased and delivered. Product photography and description provide, in this instance, the semblance of packaging that one finds in a "brick and mortar" store: that is, the wrap which both invites and defers accessibility. One gets a glimpse of the album cover, but there is no images of the album's insert. Album pages typically feature a song or two available for playback - through Wyrd Distro's embedded song player - but the store does not provide the sort of song streaming that Bandcamp does, which again, draws attention to the album for sale.

While album pages feature geographic tags, the store's focus on Canadian music is also evident in the service's emphasis on regional diversity. Similar to CBC Radio 3, the location of musical acts is embedded as biographical information in album pages; the wide range of volunteers writing for Weird Canada and working for Wyrd Distro are spread across Canada; and the service features local regions as tags and metadata. The service also deploys Region as browsing category (which is then divided into subcategories that reflect each of Canada's provinces and territories). The website also features an embedded map of Canada, which one can click through as a means to glean the different provinces and territories from which music is coming. Because album pages also feature geographic information, one can also use regions in the search bar. If the website visitor is interested in music from Ottawa or Moncton, they can search through 
the site (either through the search bar or embedded map) and begin listening to and buying the music featured.

The e-store's focus on physical commodities and Canadian regions positions Wyrd Distro as a central hub that brings together the decentralized circulation of these labels and musicians. Co-founder Leblanc-Flanagan describes the service provided:

Rather than buying one Aids Wolf cassette from Montreal, a Shearing Pinx cassette from Vancouver and one Alpha Couple cassette from Winnipeg or Toronto, and having to deal with the nuances from ordering direct from each place, you can just go to the Weird Canada store [Wyrd Distro] and do that. (quoted in Jax, 2013)

Chapter 3's examination of Bruised Tongue emphasized the largely localized circulation of the music released by this label. Wyrd Distro provides a central hub from which to access the disparate, regionally located independent music being produced. This service is particularly necessary because of its specialization in releasing physical music commodities through digital means. The service aspires to not only provide an online retail experience that reflects the regional composition of independent Canadian music; additionally, it aims to bring these releases into actual retail environments by providing its distributive services to independent record stores. As co-founder Levin further explains:

The cost of shipping a single item and the interest in buying more than one thing at a time is really what prevents people from supporting and engaging with artists ... So what we want to do with the e-distro [Wyrd Distro] is by having a central repository or store for this music we allow record stores to buy wholesale from us. Traditionally, when a record store buys wholesale, they buy thirty copies of a single album, but when they come to the Weird Canada distro they'll be able to buy thirty individual, separate releases that may be of interest to their store. (quoted in Hayes, 2013)

Wyrd Distro highlights the tension between scarcity and abundance in independent music's geographic and artistic divides, which tie to the relative distances between 
musicians and scenes in Canada. It seeks to distribute to stores too, thus moving releases from its virtual shelves and into actual music scenes.

Wyrd Distro attempts to provide both consumers and stores with a range of products that they can buy (and have shipped) cumulatively, thus expanding the range of product and minimizing the costs of purchases for buyers and stores alike. They aim to sell and promote music from different Canadian regions, coming out from either smallersized indie labels that lack formal means of distribution, or even self-released, DIY artists. They also seek to ingratiate the service into these regions through its outreach to "brick and mortar" retailers. This contrasts from the more isolated and atomized presentation of artist pages on Bandcamp's website, whereby individuals are limited to buying from (and listening to) Bandcamp, and in particular, buying from individual Bandcamp pages and paying shipping costs for all purchases to those individual sellers.

While Bandcamp contracts and incorporates the labour of its artists, Wyrd Distro positions itself as a more traditional distribution service that works through the labour performed by both co-founders, as well as the community of volunteers. Co-founder Marie LeBlanc Flanagan describes the value and service the non-profit provides to labels, musicians, and fans, explaining:

Music fans often want to order physical media ... and they try to order it from Bandcamp, but that requires the musician to package it well, to ship it on time, to be organized, to know where the post office is, and that's not always the case .... It's the same with a lot of small independent record labels: they're doing this after their jobs on evenings and weekends when the post office is closed. There's a real need for someone to help with that. (quoted in Jax, 2013)

Wyrd Distro proffers its services as an intermediary that provides this work, so that labels and musicians can focus on areas of musical praxis other than distribution and retail. Artists are also not asked to design album pages, as these are designed by Wyrd Distro. 
Wyrd Distro merely asks Artists to price releases and provide the service with the relevant information they wish to include on album pages. In screening releases and only accepting select submissions, Wyrd Distro's focus on "curation" actually fits with the sort of business performed by an A\&R department at a record label, charged with finding and signing artists (Frith, 1981). Again, though, as with Bandcamp, the actual support and development of that musical act is largely eschewed, with the exception of support articulated through Wyrd Distro's music criticism adjunct Weird Canada. Finally, rather than contracting through revenue-sharing, Wyrd Distro charges a "handling fee" of $\$ 1.50$ to $\$ 2.00$ which, as the service communicates to Artists:

... will cover the basic handling and hosting costs of Wyrd Distro. Wyrd Distro is a volunteer staffed service, and this fee reflects the lowest-possible, cost-recovery amount we can currently charge. Artists, it is not our desire to make any profit from the sale of your merchandise. We want all profits to be yours. (FAQ, n.d., pp. 6-7)

It too provides a temporary and flexible contract to musicians and labels, enabling them to opt out of their agreement and have their merchandise shipped back, with any potential costs of release being charged to that musician (p. 8).

Taken altogether, both Weird Canada and Wyrd Distro focus on promoting and locating independent Canadian music. Wyrd Distro's provision of a digital retail and distribution service that branches off of its music blog and specializes in physical music commodities highlights a suggestive interplay of digital and analogue media and sites. Wyrd Distro's emphasis on curation (i.e., critical selection of what it includes on its virtual shelves) threads together with its more celebratory focus on innovative and marginal music. This emphasis also limits the store's actual warehousing and staffing practices. It provides musicians with a digital music service with which to sell, distribute, 
and promote music. The service works for these musicians, designing album pages, photographing releases, and providing shipping and processing of orders for those musicians. It provides a centralized hub through which one can browse and buy Canadian music, using the very "residual" media formats and geographic regions comprising Canada as a means of organizing the layout and navigability of the e-store's interface. The e-store not only draws together and reorganizes the dispersed circulation of independent musicians (and their respective music commodities), but also curates and excludes musicians and releases based on the aesthetic and taste it seeks to both produce and reflect. It also emerges from this very DIY milieu, as both the music blog and e-store were created and run through the largely volunteer efforts of a wide cross-section of independent music enthusiasts based in Canada. While Bandcamp incorporates DIY practices, and the sort of creative, informational, and manual labour this entails, Wyrd Distro performs this sort of DIY practice.

What I now want to explore is Wyrd Distro's integration of a cross-section of corporately aligned online media services in its operations, which work to facilitate its DIY operations. David Hesmondhalgh (2013) has noted the tendency towards networking between smaller and larger firms in the operations of today's media and cultural industries. The Canadian Media Concentration Research Project (2014) argues that this is part and parcel of contemporary, primarily networked media environments, surmising:

... digitization magnifies economies of scale and network effects in some areas, while reducing barriers to entry in others, thereby allowing many small players to flourish. A two-tiered digital media system may be emerging, with numerous small niche players revolving around a few enormous 'integrator firms' at the centre. (Contentious debates, para. 11) 
Both Amazon and Google will be shown to operate as "integrator firms" with which Wyrd Distro intertwines. This integration takes place, more specifically, through the infrastructural role that larger digital media companies play in the operations of Wyrd Distro, with the integration of Google Forms for information management purposes and Amazon's Web Services for website cloud hosting.

\section{Google Capital and Amazon Cloud Hosting; or the Networking of DIY}

Wyrd Distro uses Google's Forms (www.google.ca/forms) service for a number of administrative purposes, including: communicating important information to potential sellers and buyers about the distributor's general operations and protocols (FAQ, n.d.); receiving applications and submissions from potential writers, artists, and musicians to consign their releases with Wyrd Distro (Submit to, n.d.); and receiving feedback from both consumers and sellers that use the service (Contact and Feedback, n.d.). Google's Forms service is deployed for the purpose of both collecting and managing the information it requires for its everyday operations. Google Forms provides a free and modifiable platform through which users can procure and manage information. Wyrd Distro integrates Google into its operations as a means to not only communicate with users of this service, but also to procure relevant (and pertinent) information from its artists and customers. ${ }^{7}$ Google's Forms service assists Wyrd Distro in managing its informational needs. This service is, moreover, part and parcel of Google's broader

\footnotetext{
${ }^{7}$ For example, to consign recordings to Wyrd Distro, one needs to fill out a form that includes the following information: applicant/consignee name; email address; city and province; account type (i.e., whether applicant is an artist or label/publisher/collective); account name (for instance, the name of band, label, and/or organization); title of release(s); year of release; whether or not the applicant has been written about by Weird Canada (grouped along five sub-categories:yes, no, coming soon, I don't know, I didn't submit); link to music; and a box entitled "Anything else?" that, while lacking official description, does request that the applicant refrain from submitting a press release (Wyrd Distro Consignment Form, n.d.)
} 
valorization and monetization of both the users of these services, as well as the information these users generate.

In his political economy of Google, Christian Fuchs (2012) describes Google as "one of the most profitable media companies in the world" (p. 43). It generates profits by selling data generated by users to advertisers (pp. 43-44). Or, as Fuchs explains:

"[Google] instrumentalizes all users and all of their data for creating profit" (p. 44). This data is generated, moreover, through the unpaid "surplus-value generating labour" of Google users (and uses), which includes such everyday activities as:

... searching for a keyword on Google, sending an e-mail vis Gmail, uploading or searching for a video on YouTube, searching for a book on Google Print, looking for a location on Google Maps or Google Earth, creating a document on GoogleDocs, maintaining or reading a blog on Blogger/BlogSpot, uploading images to Picasa, translating a sentence with Google Translate, etc. (p. 43)

Generating profits from the myriad services and platforms it provides to users, largely free of charge, hinges, more generally, on the data generated by users and the subsequent sale of that data to advertisers. There is, therefore, a trade-off: on the one hand, Wyrd Distro uses Google Forms to streamline the various paperwork generated in (and necessary to) its practices of contracting consignments and procuring feedback from customers. On the other, Wyrd Distro's use of this particular service contributes another data profile and pocket of information that is of value to (and valorized by) Google.

While Google has monetized the means through which Wyrd Distro manages its informational needs through its easy-to-integrate Google Forms service, Wyrd Distro also relies on Amazon's cloud services to host its website (Levin, 2013, Technical Overview). Kirsten Berg (2011) provides the following definition of cloud computing, explaining:

Cloud computing offers the option to have computer programs and data stored by an outside provider and made accessible via the web rather than having them 
reside on in-house servers. And familiar corporate names including .Amazon, Apple Inc., AT\&T, Google and Microsoft Corp., as well as smaller outfits have already started offering these services. (p. 16)

The difference between cloud hosting, as compared to previous iterations of hosting data online, involves "... the difference from simply getting their programs and data over the Internet versus having to pay for building and maintaining their own data centers and installing suites of software on each computer" (p. 16). Potential costs of software, hardware, and even hydro are minimized with such services. Seth Fineberg (2015) explains that cloud hosting is a particularly valuable service for smaller organizations, writing:

Cloud hosting services have particularly become more popular with smaller firms that do not have dedicated IT departments or no longer want to shoulder the costs of maintaining applications and servers ... a variety of services have emerged over the past several years that can enable applications or entire IT systems to be in the cloud without the firm having to maintain them. (p. 22)

Wyrd Distro pays Amazon a yearly fee for use of its cloud hosting services (Levin, 2013, Sustainability), thus outsourcing the sort of hardware and operational capacities to a third party.

Critical attention has tended to focus on Amazon in terms of its capability to "profile" consumers through its proprietary algorithms and data mining of consumer history (Hibbett, 2005; Humphreys, 2006). As well, attention has also been paid to its pricing practices, which have not only posed a number of challenges to "brick and mortar" book retailers, but also spurred questions about its ability to dominate the marketplace through its predatory pricing practices, which drastically undercut its competition (Taras, 2015, pp. 81-86). Both of these elements speak to the size and power of Amazon as a retailing company. Yet, Amazon's cloud hosting services gesture to 
another iteration of power and profit: that is, Amazon as landlord, renting out parcels of cyberspace. More precisely, Amazon rents out the hardware services with which to occupy cyberspace to smaller companies that may lack the budget, hardware, and knowhow to manage and host these sorts of websites. If, as Nick Dyer-Witheford (2015) has noted, there is an increasing body of "cyber-proletariats" (that is, those individuals that labour for, and are exploited by, digital media industries), this example would suggest, in turn, the power of such industries to circulate as a sort of "cyber-bourgeo isie" that owns and rents out cyberspace.

Moreover, the name recognition of these companies in this particular realm of cyberspace allocation spurs further questions about their monopolistic practices and the rhythms and degrees of concentration in online milieus. Dwayne Winseck (2012) has noted the higher degree of corporate concentration in the realm of online media uses, particularly in the Canadian mediascape (p. 161). Working with statistics and measures procured in 2010, Winseck gleans concentration in online activity through a closer focus on three areas: search, social media services, and web browsing. He finds that Google dominates the field of searching online (surmising, moreover, that "by 2010, Google accounted for 82.4 per cent of searches"); Facebook is the primary social media platform (with an approximate 63.2 per cent of the social media market share); and both Google and Microsoft dominate the realm of web browsers, with Chrome and Internet Explorer accounting for 17.7 per cent and 52.8 per cent, respectively, of web browsing usage (p. 161). Focusing on levels of concentration reveals the narrower assortment of corporate entities that tend to dominate the media and cultural industries. This is a game of smaller numbers, whereby the majority of activity is relegated to a few companies. In Winseck's 
later work with the Canadian Media Concentration Project (2014), the collective of authors argue that increasing degrees concentration matters because it can enable select and dominant online "players" to: define income distribution for creative workers; increase the potential and power of select companies to work as "gatekeepers" that restrict and filter access to both platforms and content; monetize and sell advertisements based off of user generated content; facilitate synergistic promotional practices beneficial to that particular company; and finally, "set defacto corporate policy norms governing the collection, retention and disclosure of personal information to commercial and government third parties" (Why does media, para. 3). In this example, Amazon - along with the other corporate entities expanding into the realm of data hosting - becomes a "gatekeeper." Rather than filtering for content, these gatekeepers filter the very means and methods through which smaller companies, like Wyrd Distro, create an online presence. In terms of locality and location, these examples of how Google and Amazon extend into the realm of DIY activity suggests another way in which the local is valorized by these companies: the provision of apps and web services that are embedded within and work to support local DIY in such matters of "gray media" as administration and web hosting.

\section{Gray Media Power}

Stephen Duncombe $(1997 / 2008)$ has argued that DIY is valuable for the ways in which it creates cultural and media spaces that operate outside of the realm of corporatized mass media industries; as he writes:

In an era marked by the rapid centralization of corporate media, zines are independent and localized, coming out of cities, suburbs and small towns across the USA .... Rejecting the corporate dream of an atomized population broken 
down into discrete and instrumental target markets, zine writers form networks and forge communities around diverse identities and interests. Employed within the grim new economy of service, temporary, and 'flexible' work, they redefine work, setting out their creative labour done on zines as a protest against the drudgery of working for another's profit. (p. 2)

This excerpt valorizes DIY as a different sort of work: one that profits the individual creator, rather than a broader system that could potentially alienate the producer from the power, meaning, and value of their own labour. The examples of integration examined in this study of Wyrd Distro resonate with Duncombe's concern over "centralization." However, these examples also suggest a far more flexible exchange between creative and corporate entities than Duncombe's more rigid modelling of corporate and subcultural differences accounts for. If anything, it is the "drudgery" of information work that is monetized by Google and Amazon. The presence of larger companies like Google and Amazon in the infrastructural realm challenges existent concerns with the homogenization and recuperation of independent subcultural expressions by corporate entities. Their involvement suggests instead a subtler form of monetization and power, in which these entities facilitate the everyday operations of this subcultural milieu through the realm of "gray media" (Fuller and Goffey, 2012).

Matthew Fuller and Andrew Goffey identify gray media in such areas as databases, word documents, spreadsheets, and website design software. On the one hand, these media technologies are gray because their seemingly seamless operations contribute to the myth of "frictionless" communication that is prioritized in digital milieus; as they argue:

The transparency of the facilitation of activity that is produced when devices, practices, protocols and procedures, gadgets and applications, mesh and synchronize simultaneously creates vast black-boxed or obscurely grayed-out 
zones. .. that permit the abstract social relations characteristic of 'frictionless' communication to take root. (p. 4).

On the other, such media are gray, for they closely intertwine with the various administrative and "decision making" practices they are deployed to achieve, thus becoming invisible.

Under the conditions of programmable control that digital mediation creates, the sophisticated infrastructures and practices of communication enter into the calculus of decision making of all sorts, not always as an explicit factor but more typically as an environmental variable with a hoped-for or unnoticed stability that allows the objectives of decision making to proceed untroubled. (p. 4)

Gray media are, in short, administrative media that are largely used as means to achieve particular ends; one doesn't necessarily think of them as distinct media forms unto themselves, until they stop working (as for instance, when a Word Document crashes). For Wyrd Distro, Google Forms provides a platform for its informational needs; Amazon, meanwhile, provides the means to have a "live" website. Both of these services are incorporated into, and instrumental to achieving, Wyrd Distro's broader interest in documenting, supporting, encouraging, and selling independent music.

John Durham Peters (2015) argues that infrastructure is an increasingly important element of media studies that demands closer critical scrutiny, so as to understand how media organize and facilitate the experiences of everyday life (pp. 34-36). The example of Wyrd Distro demonstrates the subtler ways in which both Google and Amazon have monetized the "gray media" used by Wyrd Distro to manage the information and resources necessary for their broader interest in facilitating and supporting independent cultural production. They provide another set of infrastructural tools with which Wyrd Distro can produce, promote, and sell DIY culture. At the same time, they enable Wyrd 
Distro to operate as a DIY organization: one that operates with break-even revenues; is able to have an online presence without purchasing infrastructure; and provides support to the unpaid work done by both the website's co-founders and volunteers. The ambiguity is that such DIY praxis contributes further reinforces the higher degrees of corporate concentration within the networked media industries.

\subsection{Digital DIY; or, Do It Yourself, With Our Service}

Both Wyrd Distro and Bandcamp provide independent musicians and labels with a digital music service through which to sell, distribute, and promote music. While they share this common interest, their strategies overlap and diverge in suggestive ways. Bandcamp incorporates the creative, manual, and informational labour (i.e. DIY labour) of both independent musicians and labels as a means to make its service work; Wyrd Distro performs this sort of labour. Bandcamp is largely indiscriminate in its artist selection process, instead positioning itself as a platform available to any musician, label, or fan that signs up for the service; Wyrd Distro positions itself as a tastemaking hub that draws together music scenes and artists through its "curation" of what ends up on the estore's virtual shelves. Bandcamp is a private, venture capital-funded tech company that provides users with an advertisement-free platform; Wyrd Distro is an independent, nonprofit, volunteer-driven, and FACTOR-funded organization that integrates Amazon and Google for administrative purposes. Both Bandcamp and Wyrd Distro provide the services of distribution, retail, and promotion, and in doing so, divest their businesses of the expenses (and risks) associated with artist development and management. Through these strategies, both services support the production of economic and institutional independence from the recording industry's corporate system. Yet, they imbricate with 
the realm of corporatized computational industries in suggestive ways. Bandcamp is the product of venture capital, operating primarily as a private and profitable computational company re-routing and monetizing the less risky facets of the music business vis-à-vis the provision of a digital sales and streaming platform for independent musicians. Wyrd Distro is a grassroots and independent e-retail and distribution service that, in the midst of drawing together the disparate and highly dispersed musical products of DIY musicians located across Canada, integrates with larger corporations so as to manage its informational and administrative needs. Thus, institutional and economic independence from the recording industry persists online, with digital services both incorporating and performing the sorts of locally embedded DIY practices that have previously structured independent status. These industries have, moreover, captured and monopolized the realms of "gray media" infrastructure, undergirding the accessible platforms and services used by independent musicians, labels, and e-retailers.

Both case studies illustrate the shifts impacting the place of traditional intermediaries in distributing and promoting independent music. Bandcamp positions itself as a distributive and promotional intermediary, a point of contact between musician and consumer. Wyrd Distro, too, positions itself as intermediary by not only providing a technological platform for the sale and distribution of music, but also warehousing, pricing, and distributing the physical commodities it sells. Both companies provide the service of intermediaries in an era of seemingly increasing disintermediation spurred by digitization. Moreover, both platforms provide a range of flexible and subscriptionoriented services that facilitate the ease and ability to "do it yourself," which as this chapter has demonstrated, is not only a subcultural ethic and mode of subcultural 
production, but also a form of locally embedded labour that persists and is incorporated by these particular digital music services. 


\section{CHAPTER 7. LOCALITY, INDEPENDENCE, AND DIGITIZATION}

This dissertation was concerned with the place of local music scenes in contemporary indie rock music. It used Ottawa's indie rock scene as a "finely-grained case study" (Gitelman, 2006, p. 11) with which to establish the articulation and reconfiguration of locality in three scenic institutions: indie record labels, scene-bound media, and digital music services. In the interest of examining how digitization has impacted and reconfigured locality in indie music, I identified each site's tendency to locate indie music in the city's local scene, whether by indie record labels, scene-bound media specializing in covering indie rock music, or digital music services.

Each chapter enacted a closer reading of a selection of case studies. The dissertation moved from locally-embedded record labels and scene-bound media to digital music services. Foregrounding local scenes and scenic institutions in this examination of digitization aimed to trouble a tendency in digital music studies to focus narrowly on either digital platforms or political economy. By asking after the residue and reconfiguration of locality in digital settings, I aimed to foreground a concern with the imbrication of old and new media and cultural forms. We could call this re-placing the local in studies of digital music. In another way, it locates broader disruptions in distribution and consumption connected to digitization in local scenic settings.

The closer focus on specific case studies introduced certain partitions between the local and digital. For instance, the examination of the locally-focused entrepreneurial and musical activities shaping the production of indie was relegated to, on the one hand, digital music services Wyrd Distro and Bandcamp, and on the other hand, two Ottawa- 
based record labels. While this bifurcation made certain organizational sense, with the former two case studies demonstrating the production of independence in primarily digital milieus, and the latter two record labels highlighting the contemporary production of independence at the level of the local scene, these two areas actually blend together. Bandcamp is utilized by both Ottawa-based record labels; both Wyrd Distro and Bruised Tongue Records focus on distributing “cruder" lo-fi, experimental, and punk rock music through older, more tactile media formats (in particular, lathe-cut vinyl records and cassette tapes); and Kelp Records (particularly its Megaphono branch), Bandcamp, and Wyrd Distro offer interested indie musicians services that support their DIY activities. Megaphono facilitates connectivity between local, Ottawa-based musicians and international industry personnel through its provision of both sync-licensing services, as well as its annual music festival. Bandcamp offers independent musicians and labels a platform with which to sell and distribute music in both digital and physical iterations to a potential audience both emerging from and circulating outside of the confines of that musician's local music scene. Wyrd Distro offers, alongside its Weird Canada adjunct, a critical, promotional, and distributive apparatus for Canadian-based independent musicians creating within more non-commercial genres a chance to connect with audiences and musicians outside of their local milieu.

To conclude, I pose three overarching arguments that tie together the disparate case studies structuring this dissertation. These pertain to the three core issues: locality, independence, and digitization. 


\subsection{Locality}

Local music scenes contain the social, professional, and musical activities enfolded into independent record labels, scene-bound media, and digital music services. Through a focus on archival research, articulation, and political economy, I framed locality in indie music as both process and "wish." These were articulated in the confluence of artefactual logics, discourse, and entrepreneurial strategies. Locality is articulated in Kelp Records as support system. Support emerges through artist management services that provide assistance to local musicians in terms of career development, grant writing, and coordinating networking opportunities for local musicians. In Bruised Tongue Records, locality is articulated as a project of proximity through the recovery and reinvigoration of media formats connected to indie histories. The release of zines promoting label activity, in-house manufacturing of cassettes and vinyl records, and distribution and sale of recordings through live performances and two music venues located in the city, evinces a more participatory and locally connected means of releasing music into the dovetailing local and digital indie music market.

The scene-bound media specializing in indie rock, meanwhile, work to locate the city's scene in different capacities. They produce representations of the city's music scene contingent to the interests, passions, and involvement of media producers. They locate the city's scene in broader musical networks and styles. They also work to locate and render accessible particular pockets of the city's scenic activity through their cartographic and navigational practices. Locality in this instance hinges on accessibility and proximity. It depends on creating media that, through these locative capacities, invite and open up the city's scene. But such accessibility is contingent and provisional, 
facilitating both access and insularity that resonates with the distributed network form that Ottawa's indie music scene possesses. Certain venues, places, and neighbourhoods are privileged over others in the distribution of independent rock in the city. The scenebound media and local labels reimagine the city, highlighting experiences of proximity and connectivity in the city's downtown core, even as whole neighbourhoods and genres are excluded from coverage and representation.

The promise of locality as proximity and accessibility threads through the deployment of local regions as metadata and tags organizing the browsing and listening experiences produced in different indie-oriented digital music services. Through my examination of the indexi-local in Chapter 5, it was demonstrated that local regions provide an intuitive, valuable, and vernacular context for the metadata generated in both CBC Radio 3 and Bandcamp, which helps to organize and navigate the (over-)abundance of data contained in both music services. They also produce the semblance of a more involved and interactive experience of the service that ties together online and offline practices of connoisseurship contingent to the field of indie music. This is enacted through the cultivation of a distinct listening profile that emerges through playback, sharing, and playlist functionalities.

Finally, the promises of support and accessibility recur in the articulation of locality evident in both Bandcamp and Wyrd Distro. Both services promise musicians, labels, and consumers more "direct" access to one another. Bandcamp is an international indie music service, featuring indie music from labels and musicians spread throughout the world, working in different genres, and operating on different scales of independence. Wyrd Distro is specifically oriented to independent Canadian music. Both of these 
services, and in particular Wyrd Distro, specialize in selling and distributing the sort of DIY and handmade products described, above, in Bruised Tongue. Thus, the local matters in an artefactual manner as well: that is, as physical artefact, produced in limited numbers, that contains both promise and residue of "embodied community."

For labels, local music scenes anchor the disruptions in the digital music marketplace. Scene-bound media enfold digital media for a range of purposes that, more broadly, reinforce these media's locative functionalities. For digital music services, local music scenes provide the content, products, metadata and tags, warehousing services, shipping/receiving needs, and consumers on which their distribution relies. Across these instances, local scenes continue to locate indie music.

\subsection{Independence}

Independence hinges on, and is formulated through, the DIY labour of media producers, musicians, retailers, and record labels that are attempting to create culture outside of the corporatized realm of the music and cultural industries. Yet distributing, selling, and promoting indie music is a struggle, as evidenced in the disparate ways in which the institutions examined in this dissertation negotiate and integrate entrepreneurial strategies and media platforms reaching across the cultural, media, and computational industries. Both the independent record labels and digital music services examined in this dissertation demonstrate a more critical engagement with the commercial and entrepreneurial logics organizing the operations of the recording industry. Both services integrate and discard practices from this industry within their operational procedures, including: artist development, distribution, manufacturing, sync-licensing, 360 degree contracts, and management. This experimentation does not signal some sort of 
subcultural bricolage, in which these methods are used to resist what these "dominant" practices signify and effect. Instead, there is an evident provision of service to support scenic activity. That is, the provisional experimentations with these broader commercial logics are being used to support locally produced indie music. Moreover, these strategies navigate wider disruptions in the means of distribution and consumption effected by digitization.

In regards to the broader political-economic project of opposing corporate power through institutional and entrepreneurial means, the wider-ranging entanglement of independent organizations with the corporatized structure of the networked and digitized cultural, media, and computational industries is evident. This ranges from the tendency for independent organizations to demarcate online presence through the integration and renting out of "gray media" services provided by Amazon and Google, to the nearubiquitous presence of social media services - and in particular, Facebook and Instagram - in the DIY activities of indie labels, media producers, and musicians. These sites work to translate the creative, informational, and manual labours underpinning DIY from a subcultural ethic to valuable and monetized user-generated content. It also reconfigures DIY as service both provided by and for a range of indie music participants.

This suggests the continued power and place that corporate entities have to control digital infrastructure, illuminating the ways in which the use of gray media by independent organizations can work to reinforce higher levels of corporate concentration within the digital media industries. This is a longer-standing trajectory, though, that can be traced out to the sorts of monopolies that companies like Bell and AT\&T cultivated in the realms of telegraphy and telephony (Winseck, 1997; Hesmondhalgh, 2013). A.J. 
Christian (2012) highlights a more "circuitous" history of the interplay of independent and corporate entities in the operations of the media industries (p. 84). From radio to television, there has been a history of independent media and culture producers and broadcasters being supplemented and overtaken by corporate entities. While Christian highlights the forcefulness of corporate entrenchment into these media sites, he also examines the ways in which different pockets of independent companies have "carved out spaces" in these larger industries (p. 84). This is evident in the production of local and public access television, which emerged against the monopolistic organization of the broadcast television networks (p. 84).

Adopting this longer purview, these contemporary examples index a longerstanding tendency for corporate power to be exerted in the media and cultural industries through control over communications infrastructure. Facebook, Google, and Amazon operate as gatekeepers that facilitate access to the ways that the scenic institutions examined in this dissertation communicate, manage information, and demarcate presence online. While these services enable indie activities, these very activities further reinforce the degrees of power and concentration evident in the computational industries. Taken altogether, independence does not emerge from a "pure" place outside of corporate praxis; instead, it is always already networked and being renegotiated.

\subsection{Digitization}

A core question guiding this project was: how have local music scenes been reconfigured in digital settings? Across these examples, there is no exact teleology evident that would suggest that digital media have either eradicated or truly (and essentially) transformed what exactly local scenes do and mean. Rather than seeing 
dematerialization of music through cloud and streaming services, a wider range of locally embedded residual media artefacts persist as meaningful sites through which independent cultural expressions are created and disseminated in digital settings. These digital music services intensify the allure of these older media artefacts by enumerating production numbers to highlight scarcity, providing potential producers with advice on how to manufacture cassettes and zines, and producing product photography that foregrounds physical attributes of media.

Moreover, in the midst of digitization, select elements of the independent music system persist, such as the distribution company, practices of artist development, and local music scene. Local music scenes anchor the instabilities in music that connect with digitization, providing support services that help musicians connect both within and outside of that scene. Digital music services support local scenes by promising centralization and access. Yet, traditional retail and distribution services have been reorganized. This is evident in the increasing encroachment of disparate digital music and media services into the business of independent music, which has facilitated and centralized the ease of DIY in local music-making milieus. In effect, both "old" and "new" media and practices intertwine in the production and promotion of independence within the DIY activities of indie record labels, musicians, digital platforms, and media producers. The deployment of both old and new media for particular entrepreneurial, experiential, creative, and promotional ends challenges any sort of intrinsic teleology to new media, whether that is the promise of new media improving on the performance of old, or old media providing sites of resistance against the "dominance" of new formats. Instead, these varying uses signal, following Carolyn Marvin (1988), the "anchoring" (p. 
4) and negotiation of a host of extrinsic social, economic, and subcultural interests in and through these media sites, whereby existent sensibilities impact on uses of new media and new media spur the negotiation and reformulation of existent sensibilities.

Though there is neither dematerialization nor improvement evident in the telos of digital media, or indeed, any sort of intrinsic logic of obsolescence that relegates old media to the dustbins of subcultural praxis, I would like to suggest that there is an overarching media logic evident across both old and new media activities: that is, the tendency for media to reorganize local spaces, subcultural experiences, and temporal relations (Innis, 1951; Peters, 2013; Galloway, 2014). Zines (in their paper and PDF iterations), Facebook event pages, tweets, blog posts, geotagged album and artist pages on Bandcamp, and lathe-cut vinyl records all work to break up and reorder the city's music scene. Digital platforms enfold and recode local regions as metadata and tags that work to organize digital music services. Both social media and digital music services translate DIY into user-generated content and click-based transactions of money and attention that facilitate both atomization and connectivity. These sites have also reconfigured DIY as service provided by and for indie musicians.

Local media reorganize the city, producing ground-level representations of what and where music happens in the city. PDFs, podcasts, zines, and blogs work to promote, archive, and centralize the disparate scenic activities that transpire in the city. If overabundance is a characteristic that threads together scenic activities (Shank, 1994; Straw, 2004), subcultural experiences (Hebdige, 1979), and data housed online (Manovich, 2001; Munster, 2013), then both old and new media work to sift through, stimulate, and 
reorganize this semiotic, informational, experiential, affective, and social overabundance.

Despite the evident disruptions that digitization have been shown to effect on the media sites, entrepreneurial strategies, and subcultural practices shaping indie music, older practices and sensibilities persist. Attending to the intersections of technology and culture, and indeed, to indie music's cultural mediations, works to both nuance narratives of complete disruption articulated to digital media, whilst challenging narratives of decline and compromise repeatedly articulated to independent music (Hesmondhalgh, 1999, p. 56; Azerrad, 2001, p. 500; Reynolds, 2005, pp. 390-391). Instead, this dissertation mapped out the continued value, power, and allure of independent music's scene-bound activities, commodities, and media sites to both scene participants and digital music services alike. 


\section{References}

Acland, C.R. (2007a). Introduction: Residual media. In: C. Acland (Ed.) Residual Media. Minneapolis, MN \& London: University of Minnesota Press, pp. xiii- xxvii.

Acland, C.R. (Ed.). (2007b). Residual Media. Minneapolis, MN \& London: University of Minnesota Press

Acland, C.R. (2012). Swift viewing: The popular life of subliminal influence. Durham \& London: Duke University Press.

Acorn, The. (n.d.). About. Retrieved from

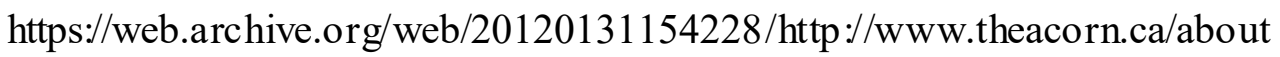

Arboretum. (2014). City Guide. Retrieved from http://www.arboretumfestival.com/cityguide/

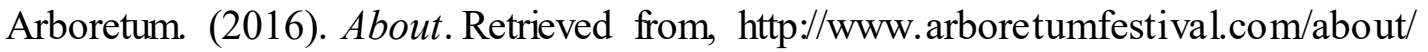
Arditi, D. (2014). iTunes: Breaking barriers and building walls. Popular Music and Society, 37 (4), 408-424. DOI: /10.1080/03007766.2013.810849

Arnold, G. (1993). Route 666: On the road to nirvana. New York: St. Martin's Press. Arnold, G. (2014). Exile in guyville. 33 1/3. New York \& London: Bloomsbury.

Atton, C. (2010). Popular music fanzines: Genre, aesthetics, and the 'democratic conversation.' Popular Music and Society, 33 (4), 517-531. DOI: $10.1080 / 03007761003694316$

Azerrad, M. (2001). Our band could be your life: Scenes from the American indie underground 1981-1991. Boston, MA \& New York, London: First Back Bay Books. 
Bannister, M. (2006a). White boys, white noise: Masculinities and 1980s indie guitar rock. Burlington, VT: Ashgate.

Bannister, M. (2006b). "Loaded:" Indie guitar rock, canonism, white masculinities, Popular Music, 25 (1), 77-95. DOI: 10.1017/S026114300500070X

Barclay, M., Jack, I.A.D., and Schneider, J. (2011). Have not been the same: The Canrock renaissance 1985-1995. Toronto: ECW Press. (Original work published 2001).

Bartlett, M. (2012). Bend Sinister's 'Small Fame' will be your summer anthem. $C B C$ Music. Retrieved from http://music.cbc.ca/\#/blogs/2012/7/Bend-Sinisters-SmallFame-will-be-your-summer-anthem-streaming-album

Baym, N.K. \& Burnett, R. (2009). Amateur experts: International fan labour in Swedish independent music. International Journal of Cultural Studies, 12 (5), 433-439. DOI: $10.1177 / 1367877909337857$

Bélanger, P.C., and Andrecheck, P. (2005). "CBC's Electronic Radio 3: Connecting with the Elusive Youth." Journal of Radio Studies. 12 (1): 120-135. DOI: 10.1207/s15506843jrs1201_10

Bell, J. (2015, March 27). A small blast from the past with The Acorn - watch the video for "Influence" [Premiere]. The Line of Best Fit. Retrieved from http:/www.thelineo fbestfit.com/new-music/discovery/the-acorn-influence

Berg, K. (2011). Federal government enters the era of the 'cloud.' The New Media \& The Law, 35(4), 16-18. Retrieved from http:/proxy. library.carleton.ca/login?ur=http://search. ebscohost.com/login. aspx? direct=true $\& d b=$ fh $\& A N=69935347 \&$ site $=$ ehost- live 
Berland, J. (1990). Radio space and industrial time: Music formats, local narratives, and technological mediation. Popular Music. 9 (2). 179-192. DOI:

$10.1017 / \mathrm{S} 0261143000003895$

Berry, D. (2014, February 14). Wyrd distro looks to make Canada weirder, one DIY album at a time. National Post. Retrieved from http://news.nationalpost.com/arts/music/wyrd-distro-looks-to-make-canadaweirder-one-diy-album-at-a-time

Bennett, A. (2000). Popular music and youth culture: Music, identity and place. Basingstoke, Hampshire and New York: Palgrave.

Bennett, A. (2002). Music, media and urban mythscapes: A study of the 'Canterbury sound.' Media, Culture \& Society, 24 (1), 87-100. DOI:

$10.1177 / 016344370202400105$

Bennett, A. (2004). Consolidating the music scenes perspective. Poetics, 32, 223-234. DOI: $10.1016 /$ j.poetic.2004.05.004

Boehm, C. (1999). The metadata bear. Or: bearing the weight of accessibility. Journal of Educational Media. 24 (3), 177-189. DOI: 10.1080/1358165990240302

Boisvenue, T. (2009, July 29). Rewind to the 1980s: Ottawa's Bruised Tongue is bringing back the plucky cassette. Ottawa Citizen, p. C8.

Boisvenue, T. (Travis Boisvenue). (2013, March 11). Roberta Bondar-Night danger. [Video file]. Retrieved from http://cargocollective.com/travisboisvenue/RobertaBondar-Night-Danger

Boisvenue, T. (2014). Small Talk Mix. Small Talk, 13. Retrieved from http:/www.smalltalk.ca/vol-13/ 
Boisvenue, T. (Travis Boisvenue). (2015, April 8). Influence. [Video file]. Retrieved from https:/vimeo.com/124422518

Bolter, J.D. \& Grusin, R. (1999). Remediation: Understanding new media. Cambridge, MA: MIT Press.

Bondar. (2012). S/T [Cassette tape]. Ottawa: Bruised Tongue Records.

Bondar. (2013). Hiss [Cassette tape]. Ottawa: Bruised Tongue Records.

Bondar. (2014). Caustic Cassette tape]. Ottawa: Bruised Tongue Records.

Brown, B.A. (2014). Will work for free: The biopolitics of unwaged digital labour. tripleC, 12 (2), 694-712. Retrieved from http://www.triplec.at/index.php/tripleC/article/view/538/619

Burkart, P. (2005). Loose integration in the popular music industry. Popular Music and Society, 28 (4), 489-500. DOI: 10.1080/03007760500159013

Burkart, P. (2014). Music in the cloud and the digital sublime. Popular Music and Society, 37 (4), 393-407. DOI: 10.1080/03007766.2013.810853

Burns, L. (2012). Real cool time: The hive. Retrieved from http://music.cbc.ca/\#/blogs/2012/7/Real-Cool-Time-The-Hive

Burns, L. (2016). Watch Black Mountain's strange new video for "Mothers of the Sun." CBC Music - Radio 3. Retrieved from http://music.cbc.ca/\#!/Radio3/blogs/2016/2/Watch-Black-Mountains-strangenew-video-for-Mothers-of-the-Sun

Buskirk, E.V. (2015). Musical map: Cities of the world. Spotify Insights. Retrieved from https:/insights. spotify.com/us/2015/07/13/musical-map-of-the-world/ 
Canadian Independent Music Association (n.d.). How independent is the Canadian music market? Retrieved from http:/cimamusic.ca/how-independent-is-the-canadianmusic-market/

Canadian Media Concentration Research Project (2014, November 26). Media and internet concentration in Canada, 1984-2013. Retrieved from http:/www.cmcrp.org/2014/11/26/media-and-internet-concentration-1984-2013/.

Canadian Radio-television and Communications Commission (2010). Campus and community radio policy. In Broadcasting Regulatory Policy CRTC 2010-499. Ottawa, ON. Retrieved from http $/ /$ www.crtc.gc.ca/eng/archive/2010/2010499.pdf

Carr, N. (2011). The shallows: What the internet is doing to our brains. New York and London: W.W. Norton and Company.

Castells, M. (2010). The rise of the network society (2 ${ }^{\text {nd }}$ ed.). Malden, MA: Blackwell Publishers. (Original work published 1996).

CBC. (n.d.). Mandate. Retrieved from http $/ /$ www.cbc.radiocanada.ca/en/explore/mandate/

CBC Music. (n.d.a). Artist. Retrieved from http $/ /$ music.cbc.ca/\#/artists CBC Music. (n.d.b). Concert calendar. Retrieved from http $/ /$ music.cbc.ca/\#/gigs/ CBC Music (n.d.c). Sign in. Retrieved from http://music.cbc.ca/\#/login.aspx CBC Music (n.d.d). CBC radio 3. Retrieved from http $/ /$ music.cbc.ca/\#/radio3/blogs/ $\mathrm{CBC}$ Music (n.d.e). Search results - Ottawa. Retrieved from http $/ /$ music.cbc.ca/\#/search/?q=Ottawa CBC Music (n.d.f). The acorn. Retrieved from http:/music.cbc.ca/\#/artists/The-Acorn 
CBC/Radio-Canada (2013). Change is the new status quo: Corporate plan summary 2013-2014 to 2017-2018. Retrieved from http://www.cbc.radiocanada.ca/_files/cbcrc/documents/corporate-plan/corporate-plan-summary-201314-2017-18.pdf

Chidgey. R. (2009). Free, trade: Distribution economies in feminist zine networks. Signs, 35 (1). 28-37. DOI: $10.1086 / 599265$

Christian, A.J. (2012). Beyond big video: The instability of independent networks in a new media market. Continuum: Journal of Media \& Cultural Studies, 26 (1), 73 87. DOI: $10.1080 / 10304312.2012 .630137$

Christman, E. (2016). U.S. recording industry 2015: Streams double, Adele dominates. Billboard. Retrieved from http:/www.billboard.com/articles/busines s/6835216/us-recording-industry-2015streams-double-adele-dominates-nielsen-music

Clark, P. (2015, February 10). Review. Small Talk 17. Retrieved from http://www.smalltalk.ca/vol-17/

Clover, J. (2009). 1989: Bob Dylan didn't have this to sing about. Berkley, CA: University of California Press.

Cohen, S. (1991). Rock culture in Liverpool: Popular music in the making. Oxford \& New York: Clarendon Press.

Contact and feedback. (n.d.). In Google Docs, Retrieved from https:/docs.google.com/forms/d/1FPKjOg7PmFL27 to77Lt9A4U0t2f4jfbSAiz7U $5 \mathrm{bzzd} 8 /$ view form 
Crossley, N. (2008). Pretty connected: The social network of the early UK punk movement. Theory, Culture \& Society, 25 (6), 89-116. DOI: $10.1177 / 0263276408095546$

CTD, Ltd. (n.d.). CTD, Ltd. Retrieved from, http://www.ctdltd.com/

Cruickshank, J. (2012). Live music in Westboro: House concerts an undiscovered Ottawa gem. Apartment 613. Retrieved from http:/apt613.ca/live-music-in-westborohouse-concerts-an-undiscovered-ottawa-gem/

Davis, J. (2007). Going analog: Vinylphiles and the consumption of the 'obsolete' vinyl record. In C Acland (Ed.), Residual media (222-236). Minneapolis, MN \& London: University of Minnesota Press

Dean, J. (2010). Blog theory: Feedback and capture in the circuits of drive. Cambridge \& Malden, MA: Polity Press.

Deleuze, G. (1995). Negotiations: 1972-1990 (M. Joughin, Trans.). New York: Columbia University Press. (Original work published 1990).

Diamond, E. (2010). Oh no, not another music community! The Bandcamp Blog. Retrieved from https:/blog.bandcamp.com/2010/02/11/oh-no-not-another-musiccommunity/

Diamond, E. (2013, June 12). All new players up! Twitter too! The Bandcamp Blog. Retrieved from http//blog.bandcamp.com/2013/06/12/all-new-players-up-twittertoo/

Diamond, E. (2015, March 06). Dolla dolla bill y'all. The Bandcamp Blog. Retrieved from http://blog.bandcamp.com/2015/03/06/dolla-dolla-bill-yall/ 
Diamond, E. (2016). Bandcamp, downloads, streaming, and the inescapably bright future. Bandcamp Daily. Retrieved from https:/daily.bandcamp.com/2016/05/19/bandcamp-downloads-streaming-and-theinescapably-bright- future/

Drystek, N.J. (2014). 21 ${ }^{\text {st }}$ century Helen - Achilles after HD \& Beyoncé. Small Talk, 15. Retrieved from http:/www.small-talk.ca/vol-15/

Duncombe, S. (2008) Notes from underground: Zines and the politics of alternative culture. Bloomington, IL: Microcosm Publishing. (Original work published 1997)

Dunn, K, \& Farnsworth, M.S. (2012). "We ARE the revolution:” Riot Grrrl press, girl empowerment, and DIY self-publishing. Women's Studies, 41, (2), 136-157. DOI: $10.1080 / 00497878.2012 .636334$

Dyer-Witheford, N. (1999). Cyber-Marx: Cycles and circuits of struggle in hightechnology capitalism. Urbana: University of Illinois Press.

Dyer-Witheford, N. (2015). Cyber-proletariat: Global labour in the digital vortex. London: Pluto Press.

Dyer-Witheford, N. \& Sharman, Z. (2005). The political economy of Canada's video and computer game industry. Canadian Journal of Communication, 30 (2), 187-210. Retrieved from http://www.cjconline.ca/index.php/journa1/article/view/1575/1728

Empathy Council. (n.d.). In Google Docs Retrieved from https//docs.google.com/forms/d/1 gRhJoBY0pnad gc5qVqIYjrHjinWN0WDAOyBIMzDMoU/viewform 
FAQ. (n.d.). In Wyrd Distro. Retrieved from https:/docs.google.com/document/d/1gRla0bEnAFmCOc9RbSWb6e_C1qBLFbR cnk30eFbDgM8/edit

Feibel, A. (2014). Gabba hey! Ottawa's music hub at City Centre. The Ottawa Citizen. Retrieved from http:/ottawacitizen.com/entertainment/local-arts/gabba-heyottawas-music-hub-at-city-centre

Fine, J. (2015). Your band sucks: What I saw at indie rock's failed revolution (but can no longer hear). New York: Viking.

Fineberg, S. (2015, March). Case studies: Cloud hosting; for firms share their experience with the hosted cloud. Accounting Today, 29(3), 20, 22. Retrieved from https:/proxy.library.carleton.ca/http://go.galegroup.com/ps/i.do?id=GALE\%7CA $403674908 \& \mathrm{v}=2.1 \& \mathrm{u}=\mathrm{ocul}$ carleton $\& \mathrm{it}=\mathrm{r} \& \mathrm{p}=\mathrm{AONE} \& \mathrm{sw}=\mathrm{w} \& \mathrm{asid}=7 \mathrm{c} 926939 \mathrm{e} 0$ f659039753c34d3ffd06fc

Flanagan, A. (2015, March 06). Bandcamp hits $\$ 100$ million payout milestone, plans artist subscriptions. Billboard. Retrieved from http:/www.billboard.com/articles/business/6494556/bandcamp-100-millionpayout-milestone-artist-subscriptions-ethan-diamond

Fonarow, W. (2006). Empire of dirt: The aesthetics and rituals of British indie music. Middletown, CT: Wesleyan Press.

Foucault, M. (1972). The archaeology of knowledge and the discourse on language. New York: Harper Colophon Books. (Original work published 1969).

Frith, S. (1981). Sound effects: Youth, leisure, and the politics of rock ' $n$ ' roll. New York: Pantheon Books. 
Frith, S. (1996). Performing rites: On the value of popular music. Cambridge, MA: Harvard University Press.

Fuchs, C. (2012). Google capitalism. Triple C: Journal for a Global Sustainable Information Society, 10(2), 42-48. Retrieved from http:/www.triplec.at/index.php/tripleC/article/view/304

Fuller, M. (2005). Media ecologies: Materialist energies in art and technoculture. Cambridge, MA: MIT Press.

Fuller, M. \& Goffey, A. (2012). Evil media. Cambridge, MA: MIT Press.

Gabrys, J. (2011). Digital rubbish: A natural history of electronics. Ann Arbor, MI: University of Michigan Press.

Galloway, A.R. (2004). Protocol: How control exists after decentralization. Cambridge, MA: MIT Press.

Galloway, A.R. (2014). Laruelle: Against the digital. Minneapolis, MN: University of Minnesota Press.

Galuzska, P. (2015). New economy of fandom. Popular Music and Society, 38 (1), 25-43. DOI: $10.1080 / 03007766.2014 .974325$

Gill, A. (2004). Indie music and beyond." The Globe and Mail. Retrieved from http://search.proquest.com/docview/1370956820?accountid=9894

Gitelman, L. (2006). Always already new: Media, history, and the data of culture. Cambridge, MA: MIT Press.

Gordon, H. (n.d.). Member. CBC Music. Retrieved from http://music.cbc.ca/\#!/profile/Holly-Gordon 
Green, S. (2015). The growth of the network media economy in Canada, 1984-2014. The Canadian Media Concentration Research Project. Retrieved from http://www.cmcrp.org/the-growth-of-the-network- media-economy- in-canada1984-2014/

Greenberg, Z.O. (2015). Revenge of the record labels: How the majors renewed their grip on music. Forbes. Retrieved from http:/www. forbes.com/sites/zackomalleygreenburg/2015/04/15/revenge-of-therecord-labels-how-the-majors-renewed-their-grip-on-music/\#66517311debe

Grossberg, L. (1986). On postmodernism and articulation: An interview with Stuart Hall. Journal of Communication Inquiry, 10(2), 45-60. DOI:

$10.1177 / 019685998601000204$

Grossberg, L. (1992). We gotta get out of this place: Popular conservatism and postmodern culture. New York \& London: Routledge.

Grossberg, L. (2010). Cultural studies in the future tense. Durham \& London: Duke University Press.

Hansen, M.B.N. (2004). New philosophy for new media. Cambridge, MA: MIT Press. Hardt, M. \& Negri, A. (2000). Empire. Cambridge, MA: Harvard University Press. Harrison AK (2006) 'Cheaper than a CD, plus we really mean it:' Bay Area underground hip hop tapes as subcultural artefacts. Popular Music 25(2): 283-301. DOI: $10.1017 / \mathrm{S} 0261143006000833$

Hayes, B. (2013, July 02). Our true north strong and free: Interview with Weird Canada. Decoder Magazine. Retrieved from 
http:/Www.secretdecoder.net/features/2013/07/02/our-true-north-strong-and- freean-interview-with-weird-canada/

Hebdige, D. (1979). Subculture: The meaning of style. London: Methuen.

Henning, M. (2007). New lamps for old: Photography, obsolescence, and social change. In C. Acland (Ed.). Residual media (pp. 48-68). Minneapolis, MN: University of Minnesota Press.

Hesmondhalgh, D. (1997). Post-punk's attempt to democratise the music industry: The success and failure of Rough Trade. Popular Music 16(3), 255-274. DOI: $10.1017 / \mathrm{S} 0261143000008400$

Hesmondhalgh, D. (1999). Indie: The institutional politics and aesthetics of a popular music genre. Cultural Studies, 13(1), 34-61. DOI: 10.1080/095023899335365

Hesmondhalgh, D. (2005). Subcultures, scenes or tribes? None of the above. Journal of Youth Studies, 8 (1), 21-40. DOI: 10.1080/1367626050006365

Hesmondhalgh, D. (2013). The cultural industries ( $3^{\text {rd }}$ ed). London: SAGE publications. Hibbett, R. (2005). What is indie rock? Popular Music and Society, 28(1), 55-77. DOI: $10.1080 / 0300776042000300972$

Hills, M. (2002). Fan cultures. London \& New York: Routledge.

Hills, M. (2015). Veronica Mars, fandom, and the "affective economics" of crowdfunding poachers. New Media \& Society, 17 (2), 183-197. DOI: 10.1177/1461444814558909

Hracs, B.J. \& Leslie, D. (2014). Aesthetic labour in creative industries: The case of independent musicians in Toronto, Canada. Area, 46 (1), 66-73. DOI: 10.1111/area.12062. 
Humphreys, A. (2006). The consumer as Foucauldian 'object of knowledge.' [Electronic version]. Social Science Computer Review, 24(3), 296-309. Retrieved from http://ssc.sagepub.com/content/24/3/296. full.pdf + html

Ingham, T. (2015). Independent labels trounce UMG, Sony and Warner in US market shares. Music Business Worldwide. Retrieved from http://www.musicbusinessworldwide.com/independent-label-us-market-sharetrounces-universal-sony-warner/

Innis, H. (1951). The bias of communication. Toronto: University of Toronto Press.

Jax, A. (2013, July 24). How Weird Canada will use \$50k to rethink indie music distribution. BlogTo. Retrieved from http://www.blogto.com/music/2013/07/how_weird_canada_will_use_50k_to_reth ink_indie_music_distribution/

Jenkins, H. (2006). Convergence culture: Where old and new media collide. New York: New York University Press.

Jones, S. (2002). Music that moves: Popular music, distribution, and network technologies. Cultural Studies, 16 (2), 213-232. DOI: $10.1080 / 09502380110107562$

Kelp Records. (n.d.a). Contact. Retrieved from, http//kelprecords.com/contact/ Kelp Records. (n.d.b.) Artists. Retrieved from, http//kelprecords.com/artists/ Kelp Records. (2011, April 18). Kelp 17 shows announced. Retrieved from http:/kelprecords.com/blog/2011/04/kelp-17-shows-announced/ 
Kinos-Goodin, J. (2013). Polaris album stream: Tegan and Sara, heartthrob. CBC Music. Retrieved from http://music.cbc.ca/\#/blogs/2013/8/Polaris-album-stream-Teganand-Sara-Heartthrob

Kinos-Goodin, J. (n.d.). Member. CBC Music. Retrieved from http://music.cbc.ca/\#!/profile/Jesse-Kinos-Goodin

Klausener, R. \& Théirault, R. (silkkenlaumann). (2012, June 19). SILKKEN LAUMANNHouse of common problems. [Video file]. Retrieved from https:/www. youtube.com/watch?v=MB7FiyzMkXg

Klinger, B. (2006). Beyond the multiplex: Cinema, new technologies, and the home. Oakland, CA: University of California Press.

Knopper, S. (2009). Appetite for self-destruction: The spectacular crash of the recording industry in the digital age. New York, London, Toronto, \& Sydney: Free Press.

Kruse, H. (2003). Site and sound: Understanding independent music scenes. New York: Peter Lang.

Kruse, H. (2010). Local identity and independent music scenes, online and off. Popular Music and Society, 33(5), 625-639. DOI: 10.1080/03007760903302145

Laing, D. (2015). One chord wonders: Power and meaning in punk rock. Oakland, CA: PM Press. (Original edition published 1985)

Lawrence, G. (2012a). The weakerthans, cannon bros, chic gamine: The birth of Canadian indie - Winnipeg, podcast \#310.” CBC Music. Retrieved from http://music.cbc.ca/\#/CBC-Radio-3-Podcast/blogs/2012/3/The-WeakerthansCannon-Bros-Chic-Gamine-The-Birth-of-Canadian-Indie---Winnipeg-Podcast- 
Lawrence, G. (2015). CBC radio 3: Putting artists and audience first in 2015. CBC Music - Radio 3. Retrieved from http:/music.cbc.ca/\#!/Radio3/blogs/2015/3/CBCRadio-3-putting-artis ts-and-audience- first-in-2015

Lawrence, G. (n.d.). Member. CBC Music. Retrieved from http://music.cbc.ca/\#!/profile/Grant-Lawrence

Lazzarato, M. (1996). Immaterial labour. (P. Colilli \& E. Emery, Trans.). In M. Hardt \& P. Virno (Eds.). Radical thought in Italy: A potentialpolitics (pp. 133-147). Minneapolis \& London: University of Minnesota Press.

Le, A. (2015). Neil fucking DeGrasse Tyson: A chance encounter. Small Talk, 18. Retrieved from http:/www.small-talk.ca/vol-18/

Lee, S. (1995). Re-examining the concept of the 'independent' record company: The case of Wax Trax! Records. Popular Music, 14(1), 13-31. DOI:

$10.1017 / \mathrm{S} 0261143000007613$

Lefebvre, H. (1991). The production of space (D. Nicholson-Smith, Trans.). Oxford \& Cambridge, MA: Blackwell. (Original work published 1974).

Levin, A. (2013, March 30). FACTOR: Collective Initiations - Marketing of Canadian Music on Digital Platforms. Retrieved from https:/github.com/aaronlevin/openbusiness/blob/master/grant-applications/victories/FACTOR-CMDA-2013-0214/Application.md

Lévy, P. (1998). Becoming virtual: Reality in the digital age. (R. Bononno, Trans.). New York: Plenum Trade.

Maan, R. (n.d.). Member. CBC Music. Retrieved from http://music.cbc.ca/\#!/profile/Reuben-Maan 
Manovich, L. (2001). The language of new media. Cambridge, MA: MIT Press.

Manuel, P. (1993). Cassette culture: Popular music and technology in North India. Chicago \& London: University of Chicago Press.

Marcus, G. (1989). Lipstick traces: A secret history of the twentieth century. Cambridge, MA: Harvard University Press.

Marcus, S. (2010). Girls to the front: The true story of the riot grrrl revolution. New York: Harper Perennial.

Marshall, L. (lesMcRAD). (2013, April 22). Colours. [Video file]. Retrieved from https:/www.youtube.com/watch?v=vZ9NHkWTMJ4

Marshall, L. (2014). Babereham Lincoln - "stir." Small Talk, 7.

Marshall, L. (2015, April 2). (fakeboy12331). Big dick-Give up. [Video file]. Retrieved from https://www. youtube.com/watch? $\mathrm{v}=\mathrm{zK} \times 7 \mathrm{OCrgZYc}$

Marshall, L. (2015, September 23). (TheAcorn). The acorn - Dominion. [Video file]. Retrieved from https://www.youtube.com/watch? $\mathrm{v}=\mathrm{XL} \lg \mathrm{GnR} \_$4TE

Martin, K. (n.d.). Member. CBC Music. Retrieved from http://music.cbc.ca/\#!/profile/Kerry-Martin

Marvin, C. (1988). When old technologies were new: Thinking about electric communication in the late nineteenth century. New York: Oxford University Press.

Massumi, B. (2002). Parables for the virtual: Movement, affect, sensation. Durham, NC: Duke University Press.

Massumi, B. (2011). Semblance and event: Activist philosophy and the occurrent arts. Cambridge, MA: The MIT Press. 
McIntyre, H. (2015, March 10). Direct-to-fan platform Bandcamp has now paid artists \$100 million. Forbes. Retrieved from http:/www. forbes.com/sites/hughmcintyre/2015/03/10/direct-to-fan-platformbandcamp-has-now-paid-artists-100-million/

McLeese, D. (2010). Straddling the cultural chasm: The great divide between music criticism and popular consumption. Popular Music and Society, 33 (4), 433-447. DOI: $10.1080 / 03007761003694118$

Miller, P. (2014, August 7). How to press a vinyl record. Retrieved from http://weirdcanada.com/2014/08/how-to-press-a-vinyl-record/

Moore, R. (2007). Friends don't let friends listen to corporate rock: Punk as a field of cultural production. Journal of Contemporary Ethnography, 36 (4), 438-474. DOI: $10.1177 / 0891241607303520$

Morris, J.W. (2012). Making music behave: Metadata and the digital music commodity. New Media \& Society, 14 (5), 850-866. DOI: 10.1177/1461444811430645

Morris, J.W. (2014). Artists as entrepreneurs, fans as workers. Popular Music and Society, 37 (3), 273-290. DOI: 10.1080/03007766.2013.778534

Morris, J.W. (2015a) Selling digital music, formatting culture. Oakland, CA: University of California Press.

Morris, J.W. (2015b). Curation by code: Infomediaries and the data mining of taste. European Journal of Cultural Studies, 18 (4-5), 446-463. DOI:

$10.1177 / 1367549415577387$ 
Morris, J.W. \& Powers, D. (2015). Control, curation, and musical experience in streaming music services. Creative Industries Journal, 8 (2), 106-122. DOI: $10.1080 / 17510694.2015 .1090222$

Muñoz, M. (2014a). Ottawa music guide: Top Ottawa venues for live music. Ottawa Showbox. Retrieved from http:/www.ottawashowbox.com/2014/11/ottawamusic-guide-top-12-ottawa-venues- for-live- music/

Muñoz, M. (2014b). Industry news: Events, funding deadlines, \& artist submission deadlines for festivals. Ottawa Showbox. Retrieved from http:/www.ottawashowbox.com/tag/music-funding/

Muñoz, M. (2015, September 23). New video: The Acorn - dominion + CABAAL remix. Ottawa Showbox, Retrieved from http:/www.ottawashowbox.com/2015/09/newvideo-the-acorn-dominion/

Munster, A. (2013). An aesthesia of networks: Conjunctive experience in art and technology. Cambridge, MA: MIT Press.

Murphy, S. (2015, September 23). The Acorn announce fall tour, premiere 'Dominion' video. Exclaim! Retrieved from http://exclaim.ca/music/article/acorn_announce_fall_tour_premiere_dominion_vi deo

N/A (2014, September 4). Racism / / what my grandmother taught me. Standard Criteria. Retrieved from http://standardcriteria.ca/brain-drain/racism-what-mygrandmother-taught-me/ 
N/A (2015, January 7). The House of Targ Zine, 10. Retrieved from http:/static1.squarespace.com/static/5335e7a1e4b01dab8f088be1/t/54add6d0e4b0 6532c838bfde/1420678864751/Jan-+v6-WEB.pdf

N/A (2016, January 7). The House of Targ Zine, 22. Retrieved from http://static1.squarespace.com/static/5335e 7a1e4b01dab8f088be1/t/568 f0551e032 7c2cb577ddf2/1452213586551/Targ+Jan+web.pdf

Negus, K. (1992). Producing pop: Culture and conflict in the music industry. London: Edward Arnold.

Negus, K. (1999). Music genres and corporate cultures. New York \& London: Routledge.

Newman, M.Z. (2009). Indie culture: In pursuit of the authentic autonomous alternative. Cinema Journal, 48 (3), 16-34. DOI: 10.1353/cj.0.0112

Nordicity. (2013). Sound analysis: An examination of the Canadian independent music industry. Retrieved from http://www.nordicity.com/media/201336fjtnrdeunp.pdf

O'Connor, A. (2002). Local scenes and dangerous crossroads: Punk and theories of cultural hybridity. Popular Music, 21 (2), 225-236. DOI: $10.1017 / \mathrm{S} 0261143002002143$

O'Connor, A. (2008). Punk record labels and the struggle for autonomy: The emergence of DIY. Lanham, MD \& Plymouth: Lexington Books.

O’Donnell, P. \& McClung, S. (2008). Mp3 music blogs: Their efficacy in selling music and marketing bands. Atlantic Journal of Communication, 16, 71-87. DOI: $10.1080 / 15456870701840004$ 
Oakes, K. (2009). Slanted and enchanted: The evolution of indie culture. New York: Holt Paperbacks.

Ottawa Showbox. (2014). Local album releases of 2014. [Web page]. Retrieved from http:/www.ottawashowbox.com/2014-local-album-releases/

Ottawa Showbox. (n.d.a). About/contact us. Retrieved from http:/www.ottawashowbox.com/about-contact-us/

Ottawa Showbox. (n.d.b). Advertising. Retrieved from http:/www.ottawashowbox.com/advertising/

Outside Music. (n.d.). Distribution. Retrieved from, http://outsidemusic.com/distribution/

Pavitt, B. (2015). Sub Pop USA: The Subterranean Pop Anthology, 1980-1988. Brooklyn, NY: Bazillion Points.

Peters, J.D. (2013). Calendar, clock, tower. In J. Stolow (Ed.), Deus in machina: Religion and technology in historical perspective. Malden, MA: Wiley-Blackwell.

Peters, J.D. (2015). The marvelous clouds: Towards a philosophy of elemental media. Chicago, IL \& London: The University of Chicago Press.

Piepmeir, A. (2008). Why zines matter: Materiality and the creation of embodied community. American Periodicals, 18 (2), 213-238. Retrieved from http:/www.jstor.org/stable/41219799

Plagenhoef, S. (2007). If you're feeling sinister. 33 1/3. New York \& London: Continuum.

Proulx, C.\& Richardson, P. (2013a). Small Talk 1. Retrieved from http://www.smalltalk.ca/vol-1/ 
Proulx, C. \& Richardson, P. (2013b). Small Talk 2. Retrieved from http://www.smalltalk.ca/vol-2/

Reid, D.A. (2015, June 4). Punk points are for fascists. Small Talk 21. Retrieved from http://www.small-talk.ca/vol-21/

Reid, I.G. (2015). Dear Hot 89.9 . . Standard Criteria. Retrieved from http://standardcriteria.ca/brain-drain/dear-hot-89-9/

Reilly, J. (n.d.). Member. CBC Music. Retrieved from http://music.cbc.ca/\#!/profile/JeffReilly

Reynolds, S. (2005). Rip it up and start again: Postpunk 1978-1984. Toronto \& New York: Penguin Books.

Reynolds, S. (2011). Retromania: Pop culture's addiction to its own past. New York: Farrar, Straus and Giroux.

Rietveld, H.G. (2007). The residual soul sonic force of the 12-inch dance single. In C. Acland (Ed.), Residual Media (pp. 97-114). Minneapolis, MN \& London: University of Minnesota Press.

Robinson, J. (2015, May 4. The yips: Air loom. Small Talk 20. Retrieved from http://www.small-talk.ca/vol-20/

Rogers, S. (2012, May 24). Anyone can do it. Data journalism is the new punk. The Guardian. Retrieved from http:/www.theguardian.com/news/datablog/2012/may/24/data-journalism-punk

Rowat, R. (n.d.). Member. CBC Music. Retrieved from http://music.cbc.ca/\#!/profile/Robert-Rowat

Runcimen, C. (2012). Boyhood [Cassette tape]. Ottawa: Bruised Tongue Records. 
Runcimen, C. (2015). Boyhood: When I'm hungry [Vinyl]. Ottawa: Bruised Tongue Records,

S, M. (2015, August 15). Black lives matter on tech wall. Small Talk 22. Retrieved from http:/www.small-talk.ca/vol-22/

Sargent, C. (2009). Local musicians building global audiences: Social capital and the distribution of user-created content on- and off-line. Information, Communication \& Society, 12(4): 469-487. DOI: 10.1080/13691180902857660

Saxberg, L. (2003, April 3). Exciting times for music fans. The Ottawa Citizen. Retrieved from http://search.proquest.com/docview/240634556?accountid=9894

Saxberg, L. (2015, February 5). Ottawa's music scene speaks softly because it lacks a big club. The Ottawa Citizen. Retrieved from http://ottawacitizen.com/entertainment/local-arts/ottawas-music-scene-speakssoftly-because-it-lacks-a-big-club

Sayer, E. \& Boisvenue, T. (2013, Jan 28). City Slang - Episode 3. City Slang Podcast. Podcast retrieved from http:/citys langradio.tumblr.com/post/41871916980/episode3

Sayer, E. \& Boisvenue, T. (2015a). City Slang - Episode 75. MixCloud. Sound file retrieved from http:/www.mixcloud.com/CitySlang/city-slang-episode-75/. Sayer, E. \& Boisvenue, T. (2015b). City Slang - Episode 84. MixCloud. Sound file retrieved from http:/www.mixcloud.com/CitySlang/city-slang-ep isode-84/.

Sayer, E. \& Boisvenue, T. (2015c). City Slang - Episode 96. Mix Cloud. Sound file retrieved from http:/www.mixcloud.com/CitySlang/city-slang-ep isode-96/. 
Shank, B. (1994). Dissonant identities: The rock 'n' roll scene in Austin, Texas. Hanover \& London: Wesleyan University Press.

Simpson, P. (2012, September 10). Two smaller festivals roll out in Ottawa this weekend. Ottawa Citizen. Retrieved from http:/www.ottawacitizen.com/entertainment/smaller+festivals + roll+Ottawa + this + weekend/7224306/story.html

Simpson, P. (2014). He gets by with a little Kelp from his friends. The Ottawa Citizen. Retrieved from http://search.proquest.com.proxy.library.carleton.ca/docview/1530277592/fulltext /C2911D759F8446B6PQ/1?accountid=9894

Smedmor, M. (2016, January 07). Wanted: Space to grow. Standard Criteria. Retrieved from http://standardcriteria.ca/brain-drain/wanted-space-to-grow/

Spalding, E. (2008). Twice born: The origins of the foundation assisting Canadian talent on recordings (FACTOR), 1982-86. Journal of Canadian Studies, 42(2), 140-159. DOI: DOI: $10.1353 /$ jcs. 0.0053

Stahl, G. (2003). Crisis? What crisis? Anglophone musicmaking in Montreal (Unpublished doctoral dissertation). Montreal: McGill University.

Stahl, M. (2003). To hell with heteronomy: Liberalism, rule-making, and the pursuit of 'community' in an urban rock scene. Journal of Popular Music Studies, 15 (2), 140-165. DOI: 10.1111/j.1533-1598.2003.00002.x

Stahl, M. (2013). Unfree masters: Recording artists and the politics of work. Durham, NC \& London: Duke University Press. 
Stahl, M. \& Meier, L. (2012). The firm foundation of organizational flexibility: The 360 contract in the digitalizing music industry. Canadian Journal of Communication, 37 (3), 441-458. Retrieved from http://www.cjconline.ca/index.php/journal/article/view/2544/2325

Standard Criteria. (2015, September 17). Listen // 1 girl 5 babes: An interactive panel on gender and racism in local music. Standard Criteria. Retrieved from, http://standardcriteria.ca/audio-video/listen-1-girl-5-babes-an-interactive-panelon-gender-and-racism-in-local-music/

Sterne, J. (2003). The audible past: Cultural origins of sound reproduction. Durham \& London: Duke University Press.

Sterne, J. (2006). The mp3 as cultural artifact. New Media \& Society 8(5), 825-842. DOI: $10.1177 / 1461444806067737$

Strachan, R. (2007). Micro-independent record labels in the UK: Discourse, DIY cultural production and the music industry. European Journal of Cultural Studies, 10 (2), 245-265. DOI: $10.1177 / 1367549407075916$

Straw, W. (1990). Popular music as cultural commodity: The American recorded music industries 1976-1985. (Unpublished PhD dissertation). Montréal, PQ: McGill University.

Straw, W. (1991). Systems of articulation, logics of change: Communities and scenes in popular music. Cultural Studies, 5(3), 368-388. DOI:

$10.1080 / 09502389100490311$ 
Straw, W. (1993). Popular music and postmodernism in the 1980s. In S. Frith, A. Goodwin, \& L. Grossberg (Eds.). Sound and vision: The music video reader (pp. 3-24). Oxford \& New York: Routledge.

Straw, W. (1998a). 'Organized disorder:' The changing space of the record shop. In S. Redhead, D. Wynne \& J. O'Connor (Eds.), The Clubcultures reader: Readings in popular cultural studies (pp. 39-47). Oxford \& Malden, MA: Blackwell Publishing

Straw, W. (1998b). Sizing Up Record Collections: Gender and Connoisseurship in Rock Music Culture. In S. Whitely (Ed.), Sexing the groove: Popular music and gender (pp. 3-16). London: Routledge.

Straw, W. (1999-2000). Music as commodity and material culture. Repercussions 7-8, 147-172. Retrieved from https $/ /$ www.ocf.berkeley.edu/ repercus/wpcontent/uploads/2011/07/repercussions-Vol--7-8-Straw-Will-Music-asCommodity-and-Material-Culture.pdf

Straw, W. (2001). Scenes and sensibilities. Public, 22-23, 245-257. Retrieved from http:/public.journals.yorku.ca/index.php/public/article/view/30335/27864

Straw, W. (2004). Cultural scenes. Society and Leisure, 27 (2), 411-422. Retrieved from http:/dx.doi.org/10.1080/07053436.2004.10707657

Straw, W. (2007). Embedded memories. In C. Acland (Ed.), Residual media (pp. 3-15). Minneapolis, MN: University of Minnesota Press.

Stuart, A. (2014, August 15). Musical city guide: Ottawa with the Arboretum festival's Rolf Klausener. CBC Music-Radio 3. Retrieved from 
http://music.cbc.ca/\#!/City-Guides/blogs/2014/8/Musical-C ity-Guide-Ottawawith-The-Arboretum-Festivals-Rolf-K lausener

Submit To. (n.d.). In Google Docs, Retrieved from https://docs.google.com/forms/d/18AwDtzkFyWr9xhXDIsbb9GpusabKbsiWcWx 7PzEpr8A/viewform

Sutherland, R. (2012). Sound recording and radio: Intersections and overlaps. In I. Wagman \& P. Urquhart (Eds.), Cultural industries.ca: Making sense of Canadian media in the digital age (pp. 33-52). Toronto: James Lorimer \& Company, Ltd.

Sutherland, R. (2015). Inside out: The internationalization of the Canadian recording sector. Canadian Journal of Communication, 40 (2), 297-314. Retrieved from http://www.cjc-online.ca/index.php/journa/article/view/2834/2562

Taras, D. (2015). Digital mosaic: Media, power, and identity in Canada. North York, ON: University of Toronto Press.

Taylor, A.G. \& Joudrey, D.N. (2009). The organization of information ( $3^{\text {rd }}$ ed.). Westport, CN: Libraries Unlimited.

Terranova, T. (2000). Free labour: Producing culture for the digital economy. [Electronic version]. Social Text, 18(2), 33-58. Retrieved from http://muse.jhu. edu/journals/soc/summary/v018/18.2terranova.html

Théberge, P. (1997). Any sound you can imagine: Making music/consuming technology. Middletown, CT: Wesleyan University Press.

Théberge, P. (2004). The network studio: Historical and technological paths to a new ideal in music making. Social Studies of Science, 34 (5), 759-781. DOI: $10.1177 / 0306312704047173$ 
Théberge, P. (2005). Everyday fandom: Fan clubs, blogging, and the quotidian rhythms of the internet. Canadian Journal of Communication, 30 (4). 485-502. Retrieved from http://www.cjc-online.ca/index.php/journal/article/view/1673/1811

Thornton, S.(1996). Club cultures: Music, media, and subcultural capital. Hanover, University Press of New England.

Tozzi, J., Leiber, N. \& Crise, S. (2011, November 17). Helping indie musicians market their tunes. Bloomberg Business. Retrieved from http:/www.bloomberg.com/bw/magazine/helping-ind ie-musicians- market-theirtunes-11172011.html

Tropical Dripps Cool Dude. (n.d.). In Wyrd Distro. Retrieved from http://distro.weirdcanada.com/products/tropical-dripps-cool-dude

Vance, J.A. (2014). Strange attractor/wtchs/scattered clouds@ @abba Hey! Small Talk 7 , n.p.

Vicente, S. (2014). Yogi's house of targ. Herd 07. Retrieved from http:/www.herdmag.ca/wp-content/uploads/2014/11/Herd-07-Web.pdf

Vincent, A. \& Swain, I. (2015). Connecting Ottawa music: A profile of Ottawa's music industries. Retrieved from http://kelprecords.com/files/2015/03/ConnectingOttawaMusic_March24_2015.pd $\mathrm{f}$

Volume, A. (2014, November 14). "Is someone there? Nope, just a wheelchair?" Standard Criteria. Retrieved from http://standardcriteria.ca/brain-drain/someonenope-just-wheelchair/ 
Waits J.C. (2008). Does 'indie' mean independence? Freedom and restraint in a late 1990s US college radio community. The Radio Journal: International Studies in Broadcast and Audio Media, 5 (2\&3), 83-96. DOI: 10.1386/rajo.5.2-3.83_1

Waksman, S. (2004). California noise: Tinkering with hardcore and heavy metal in southern California. Social Studies of Science 34(5): 675-702. DOI: $10.1177 / 0306312704047614$

Waksman, S. (2009). This ain't the summer of love: Conflict and crossover in heavy metal and punk. Oakland, CA: University of California Press.

Warner, A. (2014). Graphic of the day: Mapping the 50 greatest Canadian albums of the '90s. Retrieved from http://music.cbc.ca/\#/Radio3/blogs/2014/2/Graphic-of-theday-mapping-the-50-greatest-Canadian-albums-of-the-90s

Warner, A. (n.d.). Member. CBC Music. Retrieved from http://music.cbc.ca/\#!/profile/Andrea-Warner

Waterman, B. (2011). Marquee moon. 33 1/3. New York \& London: Continuum.

Weird Canada. (n.d.a). New Canadiana. Retrieved from https:/weirdcanada.com/category/content/newcanadiana/

Weird Canada. (n.d.b). Ex Libris. (n.d.). Retrieved from https:/weirdcanada.com/category/content/ex-libris/

Weird Canada. (n.d.c). How to. Retrieved from https $/ /$ weirdcanada.com/category/content/how-to-content/).

Weird Canada. (n.d.d). About. Retrieved from https://weirdcanada.com/about/ Whibbs, C. (2006, February 28). Kelp records. Exclaim. Retrieved from http://exclaim.ca/music/article/kelp_records 
Why, A. (2014a). Mac DeMarco fan fiction \& erotica. Small Talk, 8. Retrieved from http://www.small-talk.ca/vol-8//

Why, A. (2014b). XXXMAS. Small Talk 4. Retrieved from http:/www.small-talk.ca/vol4/

Why, A. (2014c). Ottawa explosion 2014: Highlights reel. Small Talk, 10. Retrieved from http://www.small-talk.ca/vol-10/

Willis, P. (1978). Profane Culture. London, Henley \& Boston: Routledge \& Kegan Paul.

Winseck, D. (1997). Canadian telecommunications: A history and political economy of media reconvergence. Canadian Journal of Communication, 22 (2). Retrieved from http:/www.cjc-online.ca/index.php/journal/article/view/995/901

Winseck, D. (2011). The political economies of media and the transformation of the global media industries. In D. Winseck \& D.Y. Jin (Eds.), Political economies of the media: The transformation of the global media industries (pp. 3-48). London: Bloomsbury.

Winseck, D. (2012). Critical media research methods: Media ownership and concentration. In I. Wagman \& P. Urquhart (Eds.), Cultural industries.ca: Making sense of Canadian media in the digital age (pp. 147-165). Toronto: James Lorimer \& Company, Ltd.

Witt, S. (2015). How music got free: The end of an industry, the turn of the century, and the patient zero of piracy. New York: Viking.

Woolwine, D., Ferguson, M., Joly, E., Pickup, D. \& Udma, C.M. (2011). Folksonomies, social tagging and scholarly articles. Canadian Journal of Information and Library Science, 35 (1), 77-92. DOI: 10.1353/ils.2011.0002 
Wyrd Distro Consignment Form (n.d.). In Weird Canada, Retrieved from https $/ /$ weirdcanada.com/wyrd-d is tro-consignment- form/

Yarm, M. (2012). Everybody loves our town: An oral history of grunge. New York: Three Rivers Press. 